\title{
EVALUATION OF STAIN BLOCKING PRIMER COATINGS WITH LOW VOLATILE ORGANIC COMPOUND (VOC) CONTENT and EFFECTS OF DRYING CONDITIONS ON THE PROPERTIES OF WATER REDUCIBLE COATINGS FOR POLYPROPYLENE
}

\author{
A Project Report presented to the Faculty of \\ California Polytechnic State University, San Luis Obispo
}

In Partial Fulfillment of

The Requirements for the Degree of Master of Science in Polymers and Coatings Science

By

Megan Alexandra Hart

March 2011 
(C) 2011

Megan Alexandra Hart ALL RIGHTS RESERVED 


\title{
COMMITTEE MEMBERSHIP
}

TITLE:

EVALUATION OF STAIN BLOCKING PRIMER COATINGS WITH LOW VOLATILE ORGANIC COMPOUND (VOC) CONTENT and EFFECTS OF DRYING CONDITIONS ON THE PROPERTIES OF WATER REDUCIBLE COATINGS FOR POLYPROPYLENE

AUTHOR:

DATE SUBMITTED:
MEGAN ALEXANDRA HART

MARCH 22, 2011

\author{
COMMITTEE CHAIR: Raymond H. Fernando, Professor \\ COMMITTEE MEMBER: Dane R. Jones, Professor \\ COMMITTEE MEMBER: Phillip J. Costanzo, Professor
}




\begin{abstract}
Evaluation of Stain Blocking Primer Coatings with Low Volatile Organic Compound (VOC) Content and Effects of Drying Conditions on the Properties of Water Reducible Coatings for Polypropylene
\end{abstract}

Megan Alexandra Hart

The California Air Resources Board (CARB) plans to reduce the volatile organic compound (VOC) limit of specialty primers, sealers, and undercoaters (SPSU), also referred to as stain blocking primers, from $350 \mathrm{~g} / \mathrm{L}$ to $100 \mathrm{~g} / \mathrm{L}$ in January of 2012 . These coatings are primarily used as stain blocking primers over a variety of substrates, such as wood and drywall. Currently the stain blocking primers that are considered most effective are solvent based primers that contain VOC levels much higher than $100 \mathrm{~g} / \mathrm{L}$. The goal of this study is to determine if primers on the market today with a VOC content of $100 \mathrm{~g} / \mathrm{L}$ or less can provide acceptable performance in comparison to primers with a VOC content greater than $100 \mathrm{~g} / \mathrm{L}$. This project had four milestones: 1) survey currently available SPSU coatings and related literature, 2) substrate and stain characterization, 3) benchmark testing of existing formulated commercial products, and 4) prepare a final report.

This report: 1) describes the preliminary work performed in preparation of a more systematic and comprehensive study to evaluate the performance of paints sold for the SPSU market, 2) describes the final results of selected test methods for all primers, and 3) discusses the future steps required for the completion of this project.

In preliminary testing, six primers, both waterborne and solvent based, were selected for testing and comparison. Basic primer characterization was completed, including sag, leveling, contrast ratio, and density, as was preliminary stain blocking testing, including stains by various common markers and tannin staining from dark wood. From the tests conducted during this portion of the project, and through input from an industrial advisory panel, a total of 15 commercially available primers, 7 solvent based and 8 water based, were tested. Acceptable test 
methods representing both the physical properties and the stain blocking capabilities of the SPSU primers were also selected from the preliminary testing and industry counsel.

As a result of the data obtained from stain blocking testing, conclusions were drawn regarding the stain blocking capabilities of both categories of primer and also about each primer individually. Although it cannot be said that all stain blocking primers, both waterborne and solvent based, perform equally, it can be said that there are waterborne primers that perform as well or nearly as well as solvent based primers in several of the stain blocking tests.

Part B of this report addresses the characterization of a water reducible coating for polypropylene. The solvent retention of the paint with varying drying times and film thicknesses is analyzed using thermogravimetric analysis (TGA). Solvent retention affects the production and shipment of coated polypropylene siding. When solvent is retained within the coating, adhesion can be reduced, and stacking or movement of the product may result in adhesion failure.

Corona treatment of polypropylene was used to increase the surface tension of the substrate and improve adhesion. It was hoped that the surface tension would rise to 60 dynes $/ \mathrm{cm}$, however this could not be accomplished. An increase in surface tension to 38 dynes $/ \mathrm{cm}$ was achieved and proved to be effective at significantly increasing the adhesion of the coating to the substrate. 


\section{TABLE OF CONTENTS}

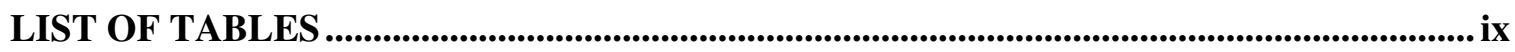

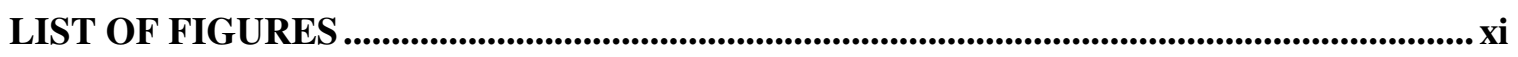

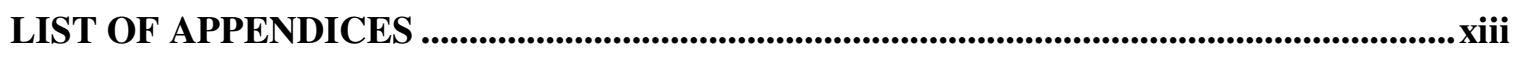

\section{PART A}

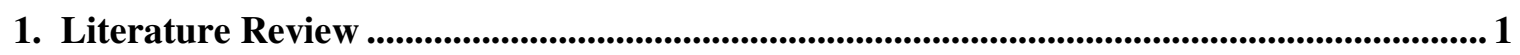

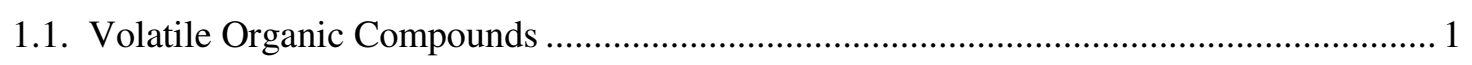

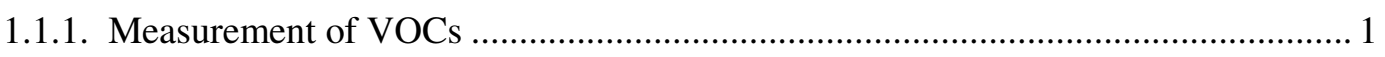

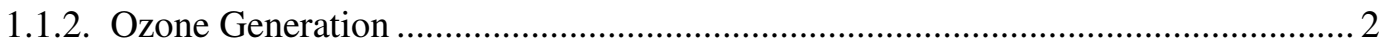

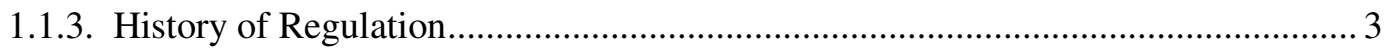

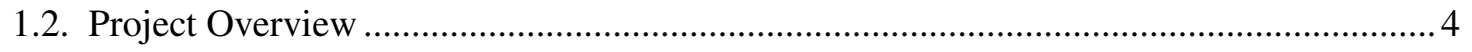

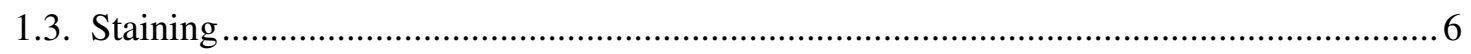

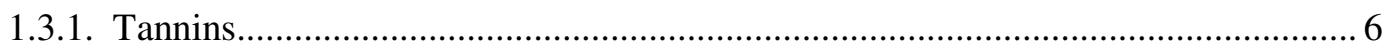

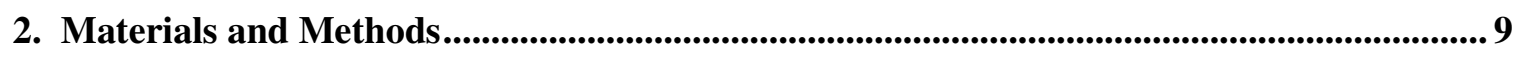

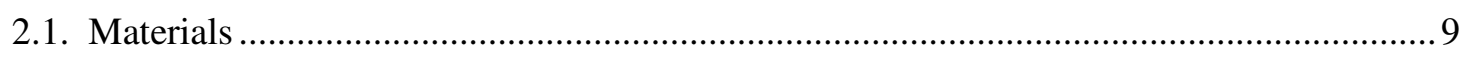

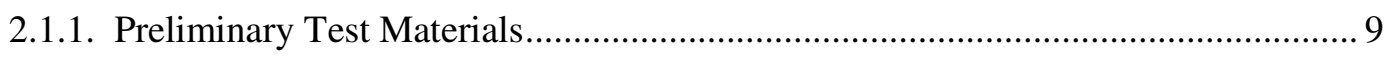

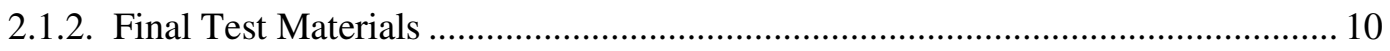

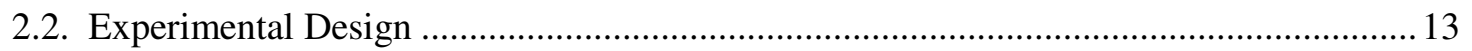

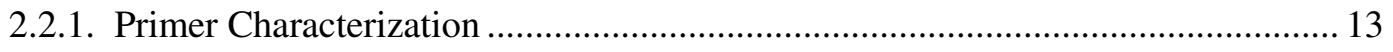

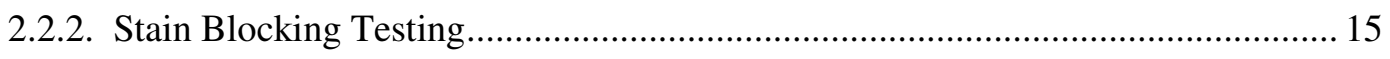

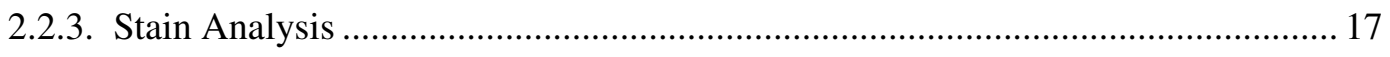

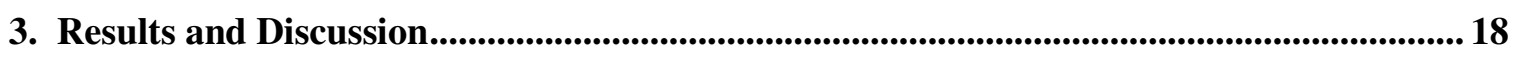

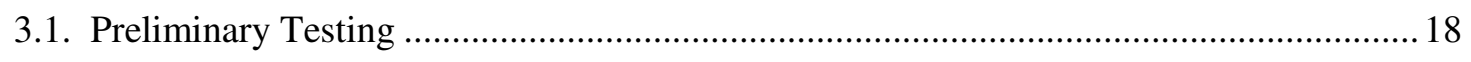

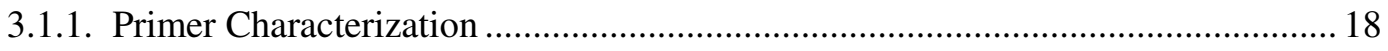

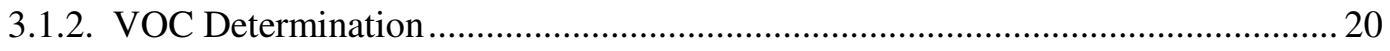

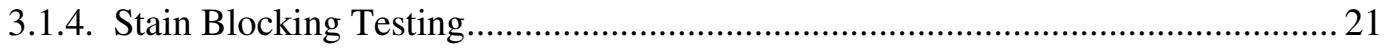

3.2. Comprehensive Testing of Stain Blocking Primers.................................................. 23

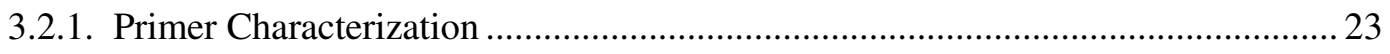

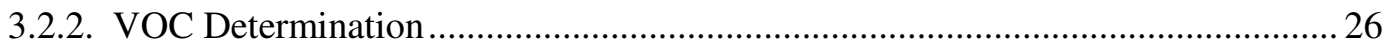

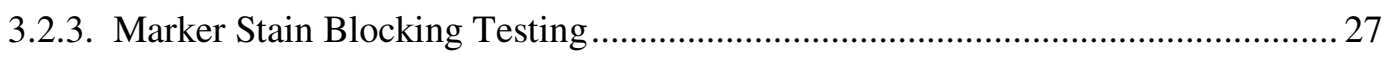

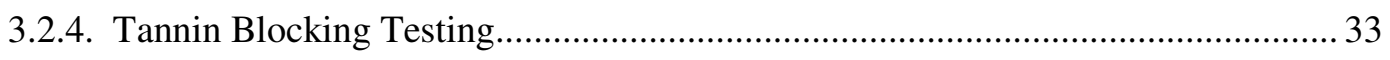

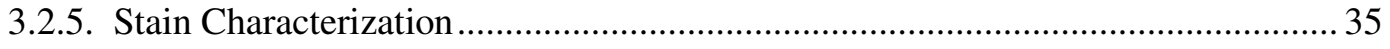




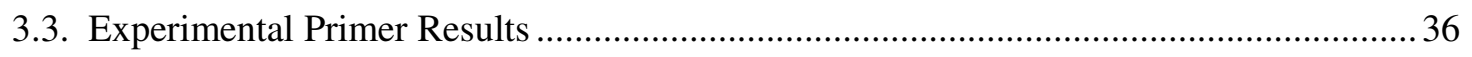

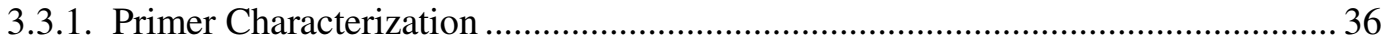

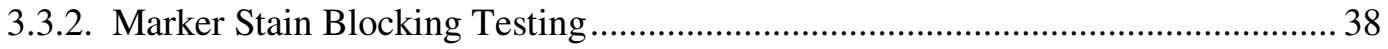

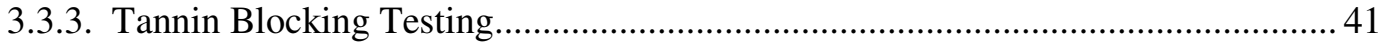

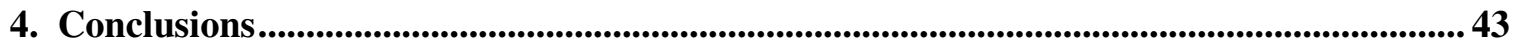

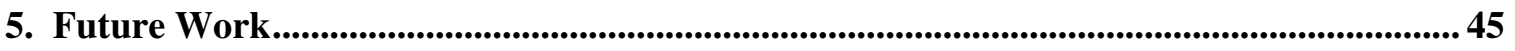

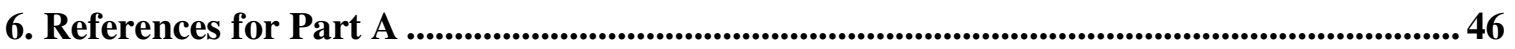

\section{PART B}

7. Introduction..................................................................................................................................................... 48

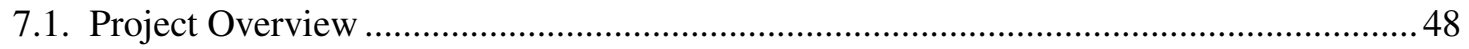

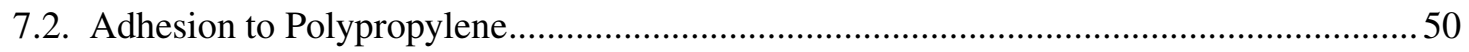

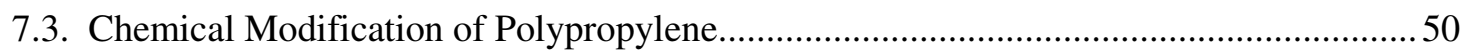

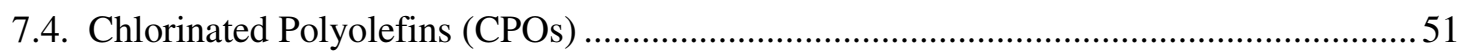

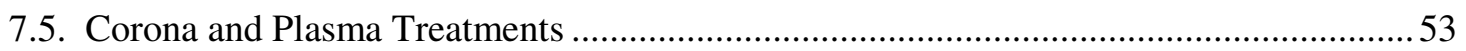

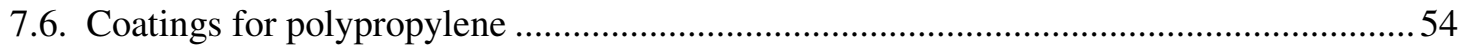

8. Materials and Methods................................................................................................................................5 56

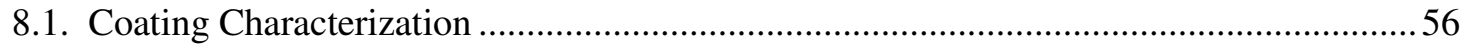

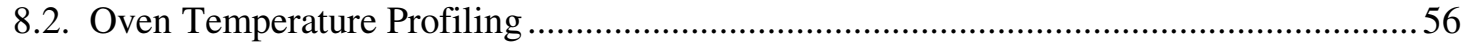

8.3. Determination of Solvent Retention with Thermogravimetric Analysis .........................57

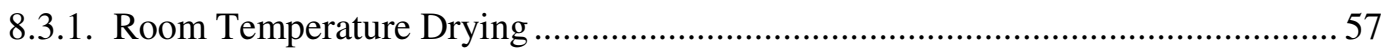

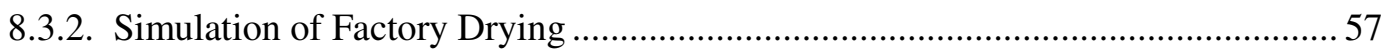

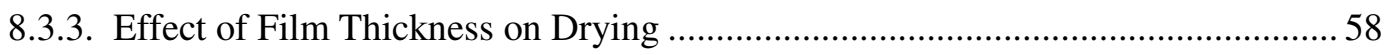

8.3.4. Extended Room Temperature Drying of Samples Dried Under Factory

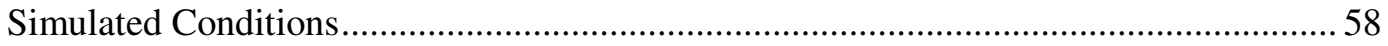

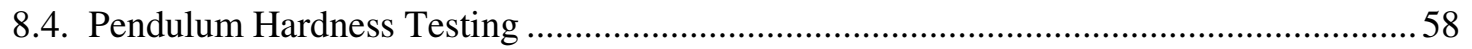

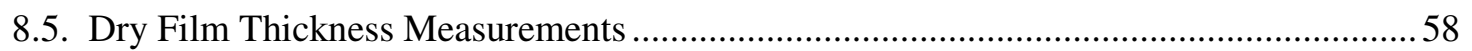

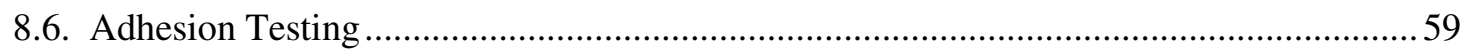

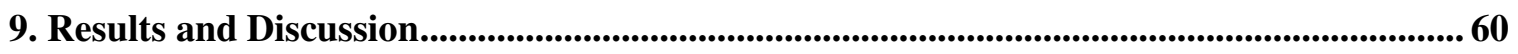

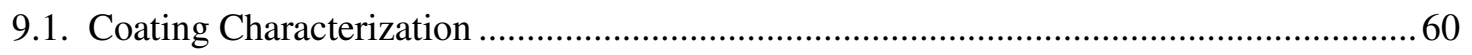

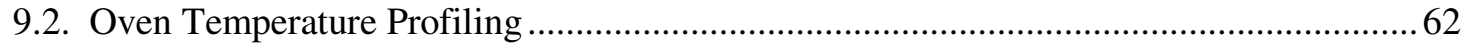

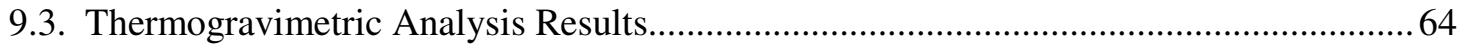

9.3.1. Room Temperature Drying and Simulation of Factory Drying ............................. 64 
9.3.2. Effect of Film Thickness on Drying

9.3.3. Extended Room Temperature Drying of Samples Dried Under Factory

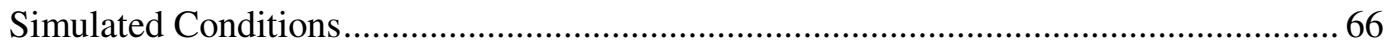

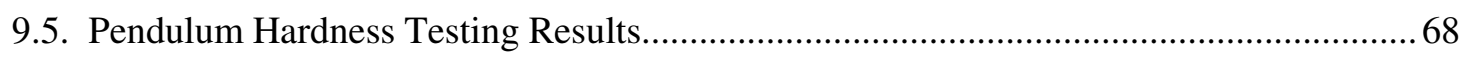

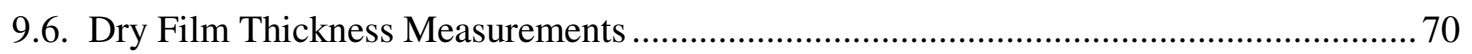

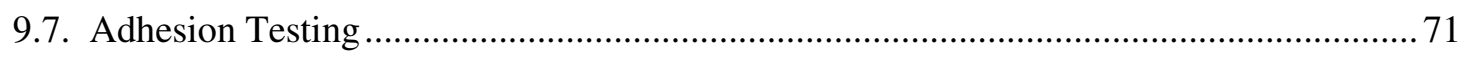

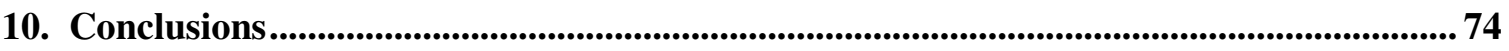

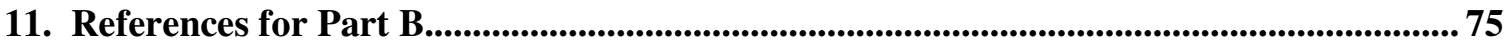




\section{LIST OF TABLES}

Table Page

1.1 VOC Limits in Grams per Liter for Select Categories of Coatings $\quad 4$

1.2 Companies and Organizations of Industry Panel 6

2.1 Stain Blocking Primers Selected for Preliminary Testing 9

2.2 Stain Blocking Primers Selected for Comprehensive Testing 10

2.3 Water Based Primer Formulation Prepared with Experimental Stain-Blocking 12 Resin

3.1 Primer Characterization Results for Preliminary Test Primers 18

3.2 VOC Content in Preliminary Test Paints 20

3.3 Wet Film Thickness (Micrometers) of Primer Applied to Cedar and Redwood 22

3.4 Primer Characterization Results for Solvent Based Paints Used in 25 Comprehensive Testing

3.5 Primer Characterization Results for Water Based Paints Used in Comprehensive 25 Testing

3.6 Characterization Results for Dunn-Edwards Paints and Primers Used as 25 Standards

3.7 VOC Content of All Paints Used in Comprehensive Testing 27

3.8 Average Marker Stain Blocking Rankings for All Stains and Primers (Best: 10) 28

3.9 Average Marker Stain Rankings for All Primers and Select Stains (Best: 10) 30

3.10 Average Marker Stain Rankings for Two Coats of Water Based Primer Test 33 (Best: 10)

3.11 Tannin Stain Rankings for All Primers (Best: 10) 34

3.12 Primer Characterization Values for the Experimental Primer as Provided by 37 Manufacturer

4.1 Summary of Stain Rankings for All Primers (Best : 10) 44

9.1 Characterization Results for CertainTeed Water Reducible Coating 61 
9.2 Minimum, Maximum, and Average Temperature Values from Oven

Temperature Profiling Experiments

9.3 Sample Weight Loss Percent at Select Temperatures, Based on Results in Figure 9.10

9.4 Pendulum Hardness Testing Results for A. 30 Minutes After Drying, and B. 24 Hours After Drying of CertainTeed Water Reducible Coating

9.5 Dry Film Thickness Determination Using Optical Microscope

9.6 Effect of Corona Treatment Time on Surface Tension

9.7 Adhesion Test Results (ASTM D3359) of CertainTeed Water Reducible Coating to Polypropylene 


\section{LIST OF FIGURES}

Figure $\quad$ Page

1.1 Ground Level Ozone Formation from NOx and VOCs (Wicks, 2007) 3

$\begin{array}{lll}1.2 & \text { Typical Structure of Tannins } & 7\end{array}$

3.1 Rheology Results for Solvent Based Primers 19

3.2 Rheology Results for Water Based Primers 20

3.3 Average Marker Stain Test Rankings for all Primers and Stains (Best: 10) 29

3.4 Marker Stain Test Rankings for all Primers and Stains, Excluding Green 31 Highlighter (Best: 10)

3.5 Marker Stain Test Rankings for all Primers and Stains, Excluding Red Sharpie 31 (Best: 10)

3.6 Marker Stain Test Rankings for all Primers and Stains, Excluding Green 32 Highlighter and Red Sharpie (Best: 10)

3.7 Tannin Blocking Test Rankings for all Primers on Cedar (Best: 10) 34

3.8 Tannin Blocking Test Rankings for all Primers on Redwood (Best: 10) 35

3.9 GC-FID Results for the Green Highlighter in Water 37

3.10 Rheology Results for the Experimental Primer 38

3.11 Continuous Ramp Rheology Results for the Experimental Primer 39

3.12 Marker Stain Test Rankings for the Experimental Primer and Top Performing $\quad 40$ Primers (Best: 10)

3.13 Marker Stain Test Rankings for the Experimental Primer and Top Performing 40 Primers, Excluding Green Highlighter (Best: 10)

3.14 Marker Stain Test Rankings for the Experimental Primer and Top Performing 41 Primers, Excluding Red Sharpie (Best: 10)

3.15 Marker Stain Test Rankings for the Experimental Primer and Top Performing 41 Primers, Excluding Green Highlighter and Red Sharpie (Best: 10)

3.16 Cedar Tannin Blocking Results for the Experimental Primer and Top 42 Performing Primers (Best: 10) 
3.17 Redwood Tannin Blocking Results for the Experimental Primer and Top Performing Primers (Best: 10)

$\begin{array}{lll}7.1 & \text { Structure of Polypropylene } & 49\end{array}$

9.1 Rheology Results for Water-Reducible Coating Supplied by CertainTeed 62

9.2 Continuous Ramp Rheology Results for Water-Reducible Coating Supplied by 62 CertainTeed

$9.3 \quad$ Oven Temperature Profiling Results at $60^{\circ} \mathrm{C} \quad 64$

9.4 Oven Temperature Profiling Results at $70{ }^{\circ} \mathrm{C} \quad 64$

9.5 TGA Results for 3 mil Film at Different Room Temperature Drying Times 66

9.6 TGA Results for 3 mil Film at Different Room Temperature Drying Times 66

Following Oven Drying at $60{ }^{\circ} \mathrm{C}$ for 3 or 5 Minutes

9.7 TGA Results for 3 mil Film at Different Room Temperature Drying Times 67

Following Oven Drying at $70{ }^{\circ} \mathrm{C}$ for 3 or 5 Minutes

9.8 TGA Results for Films Having Varying Thickness, 30 Minutes After Oven 68 Drying at $70{ }^{\circ} \mathrm{C}$ for 3 or 5 Minutes

9.9 TGA Results for Films Having Varying Thickness, 24 Hours After Oven 68 Drying at $70{ }^{\circ} \mathrm{C}$ for 3 or 5 Minutes

9.10 TGA Results for 3 mil Film at Different Room Temperature Drying Times 


\section{LIST OF APPENDICES}

Page

A

CIELAB Values for Preliminary Marker Stain Testing

B

Rheology Results for All Primers in Final Testing

80 


\section{PART A}

\section{Literature Review}

\subsection{Volatile Organic Compounds}

In the United States, emissions of volatile organic compounds (VOCs) are regulated by the Environmental Protection Agency (EPA) to limit the formation of ground-level ozone, a constituent of photochemical smog (EPA, 2010). A VOC is defined as any organic compound that participates in atmospheric photochemical reactions, except those designated by the EPA as having negligible photochemical reactivity (EPA, 2010).

\subsubsection{Measurement of VOCs}

Characterization and quantification of VOCs have been the focus of significant research in recent years. EPA Method 24 is the most commonly used method of determining the VOC content in architectural coatings in the United States today (Jones, 2007). In this method, the VOC content is determined indirectly by the subtraction of water content and exempt compound content from the total volatile content of the coating (Jones, 2007), according to the equation:

$$
\mathrm{VOC}=\frac{\left(f_{v}-f_{w}-f_{e x}\right) D_{p}}{1-\left[f_{w}\left(D_{p} / D_{w}\right)\right]}
$$

where,

$$
\begin{aligned}
& f_{v}-f_{w}-f_{e x}=f_{V O C} \\
& f_{V O C}=\text { weight fraction of VOC } \\
& f_{v}=\text { weight fraction of total volatile content } \\
& f_{w}=\text { weight fraction of water content } \\
& f_{e x}=\text { weight fraction of exempt solvents } \\
& D_{p}=\text { density of paint } \\
& D_{w}=\text { density of water }
\end{aligned}
$$

The total volatile content is determined by heating a sample of the coating at $110^{\circ} \mathrm{C}$ for one hour and measuring the weight loss, according to ASTM D2369 (Jones, 2007). This method provides 
poor precision for coatings with a low VOC content, particularly water based coatings (Jones, 2007).

The Cal Poly Polymers and Coatings program has played a key role in developing new ASTM methods to replace EPA Method 24 that is unreliable in quantifying VOC levels in low VOC water based coatings (Jones, 1997; Jones, 2003). Newer methods, including ASTM D6886, provide a way of directly measuring the VOC content using gas chromatography (Jones, 2003). VOC can be calculated based on direct analysis of the fraction of VOC content according to the equation:

$$
\mathrm{VOC}=\frac{\left.f_{\text {VOC }} D_{p}\right)}{1-\left[\left(f_{v}-{ }_{v O C}-e_{e x} \times D_{p} / D_{w}\right)\right]}
$$

where,

$$
\begin{aligned}
& f_{v}=\text { weight fraction of total volatile content } \\
& f_{V O C}=\text { weight fraction of VOC content } \\
& f_{e x}=\text { weight fraction exempt solvents } \\
& D_{p}=\text { density of paint } \\
& D_{w}=\text { density of water }
\end{aligned}
$$

This method is used for the calculation of VOC content in low VOC water based coatings due to the direct nature of calculation.

VOC content is typically reported in one of two ways: coating VOC or material VOC. Coating VOC refers to the amount of volatile content in the coating, excluding water and exempt solvents, while material VOC includes water and exempt solvents. Coating VOC is sometimes known as the regulatory VOC, and is used by air quality districts to determine whether or not a coating is in compliance with the VOC limit rule. Material VOC is also known as the actual VOC.

\subsubsection{Ozone Generation}


VOCs react with an oxygen species, such as nitrogen oxides $\left(\mathrm{NO}_{\mathrm{x}}\right)$, in the atmosphere in the presence of UV radiation from sunlight, as seen in Figure 1.1 (EPA, 2010). This process almost always begins with the reaction of the $\mathrm{VOC}(\mathrm{RH})$ with the $\mathrm{OH}$ radical. It is followed by the conversion of $\mathrm{NO}$ into $\mathrm{NO}_{2}$ through the reaction with the radical $\mathrm{ROO}$ species. $\mathrm{NO}_{2}$ is photolyzed to generate atomic oxygen which then combines with $\mathrm{O}_{2}$ to create $\mathrm{O}_{3}$ (Wicks, 2007).

$$
\begin{gathered}
\mathrm{RH}+\cdot \mathrm{OH} \rightarrow \mathrm{H}_{2} \mathrm{O}+\mathrm{R} \cdot \\
\mathrm{R} \cdot+\mathrm{O}_{2} \rightarrow \mathrm{ROO} . \\
\mathrm{ROO}+\mathrm{NO} \rightarrow \mathrm{RO}+\mathrm{NO}_{2} \\
\mathrm{NO}_{2}+h v \rightarrow \mathrm{NO}+\mathrm{O} \\
\mathrm{O}_{2}+\mathrm{O} \rightarrow \mathrm{O}_{3}
\end{gathered}
$$

Figure 1.1: Ground Level Ozone Formation from $\mathrm{NO}_{x}$ and VOCs (Wicks, 2007).

The result of these reactions is the production of ground-level ozone, an ingredient of photochemical smog, a type of air pollution associated with sunlight-driven chemical reactions (Wicks, 2007). Ozone is a pollutant of concern due to the adverse health effects caused by exposure, including coughing, chest tightness, aggravated asthma, and reduced lung capacity, and the effect that it has on both forests and agricultural crops (CARB, 2011). The highest levels of ozone production are typically found when there are sunshine and temperatures above $30{ }^{\circ} \mathrm{C}$ $\left(86^{\circ} \mathrm{F}\right)$ (Wicks, 2007).

1.1.3. History of Regulation

Regulation of VOCs in paints and coatings began when it was recognized that the solvents in these products accelerate the production of ozone (Challener, 2005). The first regulation concerning architectural coatings was adopted in California in 1977 (Challener, 2005). Generally California has lead the way for the rest of the country for VOC regulations, and often regulations similar to those set by the California Air Resources Board (CARB) and the South Coast Air Quality Management District (SCAQMD) are adopted by the rest of the country. 
In the U.S., VOC limits are regulated on federal, state, and local levels. The allowable amount of VOCs depends on the type of paint (i.e., high gloss, semi-gloss, satin, flat, solvent based, water based, etc.). Because of this, it is necessary for manufacturers to produce coatings that meet the VOC regulations in all regions of sale. One of the main challenges in producing paints and coatings to meet the VOC limits is the issue of performance. Often times problems are seen with the viscosity of low VOC water based coatings (Challener, 2005). Water based paints generally have a higher viscosity than solvent based paints, which affects properties such as the application rate, drying time, and gloss (Challener, 2005). Gloss is affected by poor film formation in low VOC coatings due to the change in coalescing solvents to lower the VOC content. Another issue is the performance of the coating for a specific function, such as stain blocking.

Current regulations for select coating categories can be seen below in Table 1.1. The values found in this table were adopted from the regulations as listed on the California Air Resources Board website (CARB, 2011). All values are coating VOC values and are reported in grams per liter.

Table 1.1: VOC Limits in Grams per Liter for Select Categories of Coatings.

\begin{tabular}{|l|ccc|}
\hline Coating Category & EPA & CARB & SCAQMD \\
\hline Faux Finishing/Glazing & 700 & 350 & 350 \\
Flat & 250 & 50 & 50 \\
Floor & 400 & 100 & 50 \\
Industrial Maintenance & 450 & 250 & 100 \\
Metallic Pigmented & 500 & 500 & 500 \\
Nonflat Coatings & 380 & 100 & 50 \\
Primers, Sealers, and Undercoaters & 350 & 100 & 100 \\
Rust Preventative & 400 & $400[2501 / 1 / 12]$ & 100 \\
Shellacs, Opaque & 550 & 550 & 550 \\
Specialty Primers, Sealers, and Undercoaters & $\mathbf{3 5 0}$ & $\mathbf{3 5 0}[\mathbf{1 0 0} \mathbf{1 / 1 / 1 2}]$ & $\mathbf{1 0 0}$ \\
Traffic Marking & 150 & 100 & 100 \\
Varnishes & 450 & 450 & 275 \\
Wood Preservatives & 550 & 350 & 350 \\
\hline
\end{tabular}

\subsection{Project Overview}

Current regulations in California allow Specialty Primers, Sealers, and Undercoaters (SPSU), also referred to as stain blocking primers, to have a VOC content of up to $350 \mathrm{~g} / \mathrm{L}$. By 
January 2012, it is anticipated that the VOC limit will be lowered to $100 \mathrm{~g} / \mathrm{L}$. This anticipated limit was originally set for an earlier date by CARB, but was set back to January 2012 as a result of the response from the coatings industry. This study is in response to the objections from the coatings industry with the goal of determining whether or not there are stain blocking primers commercially available today that meet the proposed VOC limit of $100 \mathrm{~g} / \mathrm{L}$.

The best performing stain blocking primers currently on the market, as accepted within the industry, are shellac-based primers, with a VOC limit of $550 \mathrm{~g} / \mathrm{L}$, and several oil based primers with a VOC limit of $350 \mathrm{~g} / \mathrm{L}$. In order to lower the VOC limit, products with acceptable performance that meet the new limit or other alternatives must be available.

A survey of the literature did not uncover any study comparing stain blocking performance of less than $100 \mathrm{~g} / \mathrm{L}$ VOC coatings with those containing higher VOC levels. Our discussions with industry experts led to the conclusion that there is currently no industry standard for what classifies a stain blocking primer as having "acceptable" performance. For this project, it is necessary to create a set of guidelines to determine if a stain blocking primer shows “acceptable performance". To define "acceptable performance" and to select candidate primers for comprehensive testing, an industrial panel was gathered by CARB. This panel is made up of the companies and organizations seen in Table 1.2.

Table 1.2: Companies and Organizations of Industry Panel.

\begin{tabular}{|c|c|}
\hline American Coatings Association & Dunn-Edwards Company \\
Akzo Nobel Company & Eliokem Company \\
\hline
\end{tabular}




\begin{tabular}{|c|c|}
\hline Behr Process Company & Kelly Moore Company \\
Benjamin Moore Company & Rustoleum Company \\
Byk USA Company & Sherwin Williams Company \\
California Air Resources Board & \\
\hline
\end{tabular}

This group was consulted through several conference calls on the choice of stain blocking primers, stains to be tested, and substrates to be used.

After input from the industry panel, six primers were chosen for a preliminary stage of testing, and fifteen primers were chosen for the final stage of testing. A series of standard characterization tests, such as sag, leveling, and density determination, were completed. Stain blocking tests, such as marker and tannin blocking, were performed on all primers selected.

\subsection{Staining}

Primers are usually applied to the substrate to provide a foundation for a durable topcoat (Sullivan, 2010). If the substrate is stained, it is important that the primer has effective stain blocking capabilities. Based on a literature survey it was decided that common stains include inks, pens, markers, crayons, tannins, and stains resulting from water, fire, or smoke damage (Deng, 2002). The composition of these stains varies widely between occurrences and little is known about the composition, with the exception of tannin stains. Water, smoke, and fire stains are largely dependent on the substrate and surrounding conditions. Markers and pens are made containing different inks and solvents that are generally not revealed to the public.

\subsubsection{Tannins}

Tannins were researched extensively due to the persistent problem that they present when painting certain wood. Tannins are naturally occurring, plant-based polyphenolic compounds found in wood, including wood used in constructing homes and commercial buildings (Tsang, 2009). They provide durability, stability, and aesthetic appeal to the wood (True, 2007). Over time, it is possible for tannins to migrate, or bleed, from the wood into coatings, causing 
significant yellow to brown discoloration in the case of tannin-rich woods, such as redwood and cedar (Prestemon, 1994).

The main component of tannins is penta-metadigalloyl-glucoside, a derivative of gallic acid (3,4,5 - trihydroxybenzoic acid) (Betremieux, 2002). The typical tannin structures are represented in Figure 1.2 (Betremieux, 2002).

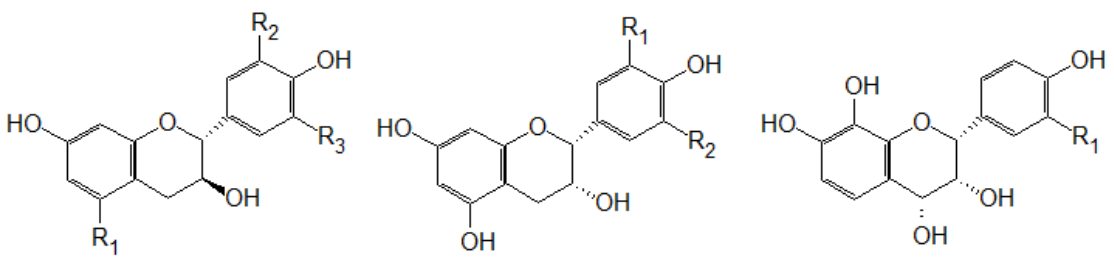

Figure 1.2: Typical Structure of Tannins.

Tannins form a water soluble compound when exposed to the basic conditions typically associated with paints (Twene, 2003). It is generally believed that using a solvent based primer usually is more effective than a water based primer at preventing migration of tannins into the topcoat because solvent based primers are hydrophobic and acts as a barrier to water soluble molecules (Kimerling, 2004). However, there are ways of preventing migration and staining using a waterborne primer, including: 1) the use of active pigments or blocking agents, such as compounds of zinc, aluminum, or titanium, 2) the introduction of definite functionalities, such as urethane or alkyd-urea groups, and 3) the use of amphiphilic block copolymers (Sullivan, 2010). The use of a pre-treatment is also an option, but is undesirable because it adds another costly step in coating wood and could have negative effects on the physical properties of the wood.

Other questions regarding tannins should be considered. For example, waterborne primers will most likely be more effective at preventing tannin bleed if they are formulated for fast drying, with a maximum amount of solids and a minimum amount of co-solvents (Hodges, 2003). Primers with a near-neutral $\mathrm{pH}$ will also have a better chance of preventing tannin bleed, due to the need for a basic environment for the tannins to form water soluble compounds (Hodges, 2003). Other properties of primers, including the flexibility, sandability, scrub resistance, and adhesion, are important for successful tannin blocking (Twene, 2003). 
The migration of water through the wood and coating should also be considered. A staining problem develops during the drying and film forming stage when tannins migrate outward, due to the water present in the painted wood (Hodges, 2003). The driving force for this is the interfacial humidity exchange, where water acts as an eluent, in a similar manner to the mechanism involved in thin layer chromatography (Betremieux, 2002). It is still not known for sure if the migration of tannins stops when hydric equilibrium is reached (Betremieux, 2002). 


\section{Materials and Methods}

\subsection{Materials}

Paints and primers were obtained from local stores or directly from the manufacturer. Stain blocking primers were chosen based on industry recommendations from three VOC categories: shellacs $(<550 \mathrm{~g} / \mathrm{L})$, oil based $(<350 \mathrm{~g} / \mathrm{L})$, and water based $(<100 \mathrm{~g} / \mathrm{L})$.

\subsubsection{Preliminary Test Materials}

\subsubsection{Primer Selection}

Initial testing using a small selection of primers was undertaken to begin the experimental work. This step was completed to develop a set of test methods to be used in the comprehensive study. The six primers chosen for testing are listed below in Table 2.1.

Table 2.1: Stain Blocking Primers Selected for Preliminary Testing.

\begin{tabular}{|c|c|}
\hline Solvent Based & Water Based \\
\hline Zinsser Shellac-Based B-I-N & Zinsser Waterborne Cover Stain \\
Zinsser High-Hide Cover Stain & Behr Premium Plus Waterborne Primer and Sealer \\
KILZ Original Primer & KILZ 2 Latex \\
\hline
\end{tabular}

This list contains one primer in the shellac category, two oil based primers, and three water based primers. The topcoat chosen was a common interior latex paint: Behr Premium Plus Interior Latex Flat Paint.

\subsubsection{Substrates and Staining Agents}

Substrates were selected based on industry recommendation. The substrates used in preliminary testing were cedar boards, redwood boards, and sealed black and white BYK BykoCharts. The marker staining agents selected were red and black Sharpies, red and black Expos, green and yellow highlighters, and red and blue BIC pens. 


\subsubsection{Final Test Materials}

\subsubsection{Primer Selection}

Stain blocking primers for comprehensive testing were chosen based on industry panel recommendations and preliminary testing from three VOC categories: shellacs $(<550 \mathrm{~g} / \mathrm{L})$, oil based $(<350 \mathrm{~g} / \mathrm{L})$, and water based $(<100 \mathrm{~g} / \mathrm{L})$. The fifteen stain blocking primers selected for testing are listed below in Table 2.2.

Table 2.2: Stain Blocking Primers Selected for Comprehensive Testing.

\begin{tabular}{|c|c|}
\hline Solvent Based Primers & Water Based Primers \\
\hline Zinsser Shellac-Based B-I-N & Zinsser Smart Prime \\
Zinsser High-Hide Cover Stain & Zinsser Bulls Eye Zero \\
Zinsser Odorless & Zinsser Waterborne Cover Stain \\
KILZ Complete & KILZ Premium \\
Behr Premium Plus Interior/Exterior Primer \\
and Sealer \\
Benjamin Moore Fresh Start Alkyd Primer \\
Kelly Moore Weather Shield Exterior Alkyd \\
Primer for Stain Blocking
\end{tabular}

This list contains one primer in the shellac category, six oil based primers, and eight water based primers with VOC content of $100 \mathrm{~g} / \mathrm{L}$ or less. It should also be noted that, when possible, both water based and solvent based stain blocking primers were chosen from the same manufacturer.

\subsubsection{Experimental Low VOC Stain Blocking Primer}

An additional experimental water based primer was included in stain blocking testing. This primer is formulated with an experimental water based cationic epoxy resin ester developed by Cytec Company.

Cationic resins based on epoxy chemistry are known to provide excellent barrier properties without the use of usually expensive reactive pigments, such as zinc oxide (Tsang, 
2009; Brandt-Rothermel, 2010). These systems are polycationic systems created by protonation of functional amine groups within the polymer chain (Brandt-Rothermel, 2010). The system is then neutralized with volatile acids, such as formic, acetic, or lactic acid, and the polymer particles swell considerably.

Stain blocking can be achieved in two ways using cationic resins (Brandt-Rothermel, 2010):

(i) cationic groups can form ionic interactions with anionic staining molecules.

(ii) alkaline staining molecules can be neutralized and fixed by the acid groups. Another important factor is the low $\mathrm{pH}$ of the primer, which prevents the diffusion of stains through the primer and into the topcoat (Brandt-Rothermel, 2010). As previously mentioned, adhesion is also important for improved stain blocking. The amine groups within the cationic polymer are able to hydrogen bond with the cellulose in wood, resulting in especially good adhesion to wood and a variety of other substrates (Brandt-Rothermel, 2010).

The cationic resin in the experimental primer is still in the testing stages and is not yet available in any paint formulations available for general purchase. It was included in this study because of manufacturer claims about outstanding tannin blocking capabilities and also to assess the potential of water based stain blocking technology. The experimental stain blocking primer was formulated by Cytec company according to Experimental Lab Formula \# KS 101-4. This formulation was provided by Cytec, and can be seen below in Table 2.3. This primer will be referred to as the experimental primer for the remainder of this report.

Table 2.3: Water Based Primer Formulated with Cytec Company’s Experimental Stain-Blocking Resin.

Pigment Paste

Lbs.

Gals. 
Water

ADDITOL ${ }^{\circledR}$ VXW 6208 (Pigment Dispersant)

ADDITOL $^{\circledR}$ V5.49XW 6393 (Defoamer)

Kronos 2310

Blanc Fixe Micro

Kadox-915 Zinc Oxide

ASP 600

Total Pigment Paste
159.43

48.14

3.46

115.56

138.65

2.31

145.80

613. 35

442.73

613.35

1.15

20.78

8.66

43.29

19.28
19.14

5.49

0.49

3.47

3.80

0.05

6.78

39.22

Slowly add pigment paste to resin while slowly stirring

Experimental Stain-Blocking Resin

49.52

ADDITOL $^{\circledR}$ VXW 6503 (Substrate Wetting)

Water

39.22

0.14

2.49

Premix ADDITOL ${ }^{\circledR}$ VXW 6360 and water (1:5) before

adding slowly while stirring

ADDITOL $^{\circledR}$ VXW 6360 (Thickener)

Water

5.20

Dipropylene Glycol Monomethyl Ether (DPM)

$\underline{\text { Total }}$

100.00

As mentioned earlier in this report, a near neutral $\mathrm{pH}$ and a fast drying time are important factors in preventing tannin staining of the topcoat. The experimental primer formulated using the Cytec resin claims a pH of 5.0-6.5 and a set-to-touch time of 15 minutes. Both of these qualities suggest that this primer may have excellent stain blocking capabilities against tannins.

The experimental primer was not used in all testing. The results are reported separately from those of the commercially available primers, and can be found in section 3.3.

\subsubsection{Standard Coatings Selection}

Dunn-Edwards company's topcoats and primers were chosen as standard paints when topcoat or substrate preparation was required. All of the paints chosen are water based. Vinylastic Premium Wall Sealer was chosen as the primer to be used for sealing drywall substrates to be used in stain testing; ENSO Interior Primer Low Odor Zero VOC was chosen as the standard interior primer; ENSO Interior Eggshell paint was chosen as the standard interior topcoat; 
UltraGrip Premium Interior/Exterior Multi-Purpose Primer was chosen as the standard exterior primer; and, Evershield Exterior Eggshell paint was chosen as the standard exterior topcoat.

\subsubsection{Substrates and Staining Agents}

The substrates used were the same as those in preliminary testing: cedar boards, redwood boards, and sealed black and white BYK Byko-Charts. For this set of testing, the wood boards were lightly sanded to ensure the surfaces were as uniform as possible. Boards containing a significant amount of knots or other irregularities were avoided. The marker staining agents selected were again red and black Sharpies, red and black Expos, green and yellow highlighters, and red and blue BIC pens.

\subsection{Experimental Design}

Test methods selected for preliminary testing proved to be acceptable for characterizing both the primers' basic properties and stain blocking capabilities. Minor adjustments were made to certain tests, and are noted throughout the experimental design section.

\subsubsection{Primer Characterization}

Several basic tests were completed to characterize the stain blocking primers. The sections below provide specific details for of each test as it was completed as well as the relevant ASTM method. These tests are important for future work requiring new samples of primer to ensure consistency between samples for stain blocking testing results.

\subsubsection{Sag and Leveling}

Three sag and leveling draw-downs were made for each primer. Sag draw-downs were made using the Leneta Anti-Sag Meter ASM-1 Standard Range. The sag draw-downs were allowed to dry vertically at room temperature. Visual sag ratings were recorded from $0-10$, with 10 being the best (i.e., none of the paint stripes ran together) in accordance with ASTM D440099.

Leveling draw-downs were made using the NYPC Level Test Blade. The leveling drawdowns were allowed to dry on a flat countertop surface at room temperature. Visual ratings for 
leveling were recorded from $0-5$, with 5 being the best, where all double stripes merged together. ASTM D4062-99 was followed for leveling measurements.

\subsubsection{Contrast Ratio and Gloss}

Three draw-downs with a wet film thickness of 3 mil were made for each primer on black and white BYK Byko-Charts. Contrast ratio data were obtained using a DataColor Mercury Spectrophotometer by measuring the $\mathrm{Y}$ tristimulus values from both the black and white portions

of the chart and calculating the $\mathrm{Y}_{\text {black }} / \mathrm{Y}_{\text {white }}$ ratio. ASTM D6441-05 was followed for contrast ratio measurements.

Gloss measurements were taken as an average of ten data points over the white portion of the draw-down chart using a BYK Gardener Micro-TRI-Gloss gloss meter at a $60^{\circ}$ angle. ASTM D523-08 was followed for gloss measurements.

\subsubsection{Density and Percent Solids}

A stainless steel pycnometer was used to determine the density of each primer in pounds per gallon, according to the procedure outlined in ASTM D1475-98. The percent of solids by weight in each primer was determined according to ASTM D2369-07. To determine the percent solids by weight, an aluminum pan was weighed and approximately $0.5 \mathrm{~g}$ of paint was added and weighed. Latex paint samples had $3 \mathrm{~mL}$ of water added to each pan. All samples were then placed in an oven at $110^{\circ} \mathrm{C}$ for exactly 1 hour. The weight of the paint and the pan was recorded after heating and the percent solids by weight was determined from this information.

\subsubsection{Rheology}

The KU viscosity was obtained for each primer using a BYK Gardner KU-1 viscometer. Viscosity versus shear rate data was obtained for all primers at shear rates from $0.02 \mathrm{~s}^{-1}$ to $200 \mathrm{~s}^{-1}$ with 10 points per decade at $25^{\circ} \mathrm{C}$. All measurements were made with a TA Instruments AR 2000 Rheometer using a cone-and-plate geometry. Each primer was tested at least twice to determine consistency of results.

\subsubsection{VOC Determination}


The volatile organic compound (VOC) level in each paint was determined according to ASTM D6886-03. HPLC grade methanol or acetone was used as the solvent for sample preparation for water based paints and HPLC grade tetrahydrofuran (THF) was used as the solvent for solvent based paints. An Agilent GC/MS/FID was used for all runs.

\subsubsection{Stain Blocking Testing}

Stain blocking testing was completed for all primers, including the previously mentioned experimental primer.

\subsubsection{Marker Stains}

Marker, pen, and highlighter were used to test the stain blocking abilities of each primer in accordance with ASTM D7514-09. For each staining agent, two colors were used. In accordance with this test method, several straight lines, each of a different staining agent, were drawn at least $3 \mathrm{~mm}$ apart on the white portion of BYK Byko-Charts. The stains were allowed to dry for 24 hours and primer was applied perpendicular to the stains at a 3 mil wet film thickness. The primer was then allowed to dry for 24 hours and the standard interior waterborne topcoat was applied parallel to the staining agents (perpendicular to the primer) at a 3 mil wet film thickness. Three charts were made for each primer. Visual rankings of the amount of staining seen through the topcoat were done in a Byko light booth using the standard interior lighting setting using a scale of 1 to 10 , with 10 representing 100\% hiding of the stain, and 1 representing $10 \%$ or less hiding of the stain.

This test was then repeated, for waterborne primers only, using two coats of primer. Using two coats of a waterborne primer with a VOC content of $100 \mathrm{~g} / \mathrm{L}$ or less will have lower VOC emissions than one coat of a solvent based primer. The same test procedure and ranking system were used.

A separate test was designed and conducted in order to determine the degree of error involved in the visual stain blocking rankings. Additional researchers ranked ten randomly 
chosen samples five times each in random order and the standard deviation was calculated from these rankings.

Another test method conducted used select staining agents from the test above. Squares $4 \mathrm{~cm} \times 4 \mathrm{~cm}$ were drawn with ink on sealed BYK Byko-Charts and filled in. The staining agents selected were red and black Sharpies, red and black Expos, and red and blue BIC pens. Preliminary test results showed that the highlighters did not dry on the sealed black and white BYK Byko-Charts and were tested on the unsealed backside of the charts for water based primers. This method was used only in preliminary testing. The staining agents were applied to the white portion of the charts and allowed to dry for 24 hours to maintain consistency with the previously used ASTM D7514-09. Color data (CIELAB values) was then collected as an average of three readings using the DataColor Mercury Spectrophotometer. Primer was then applied at a 3 mil wet film thickness, allowed to dry for 24 hours, and color data was again collected as an average of three readings. The topcoat was then applied with a 3 mil wet film thickness, allowed to dry for 24 hours, and color data was collected as an average of three readings. Three samples were made for each primer.

\subsubsection{Tannin Stains}

Preliminary wood testing was done using cedar and redwood board cut into approximately 12 in $x 8$ in size. Each board was weighed and a coat of one primer was applied using a paint brush. The board was weighed again after priming, the area primed was measured, and the film thickness was calculated. Because of the inconsistency in film thickness due to variation in board smoothness and the varying methods of application between samples, a modified procedure was used for the final testing.

Cedar and redwood boards were purchased for final tanning blocking testing and cut into approximately 12 in x 36 in size. Each board was lightly sanded to ensure uniformity between each sample. The test primer was applied using a 7 mil wet film thickness in two areas on the board. The standard primer, Dunn-Edwards Exterior Waterborne Primer, was applied in a third 
section of the board with the same wet film thickness. The primers were dried for at least 16 hours at room temperature and the standard exterior topcoat, Dunn-Edwards Exterior Water Based Eggshell Paint, was then applied to approximately half of the primed area using a wet film thickness of 7 mil. After 4 hours, wet sponges, approximately 1 inch by 1 inch, were placed on top of the primed areas and the areas with both primer and topcoat. The sponges were covered with plastic cups to prevent evaporation and contamination. After 24 hours the cups and sponges were removed, the test area was gently dried, and both stain magnitude and blistering were ranked on a scale of 1 to 10 , with 10 being no visible tannin bleed through or no blistering.

\subsubsection{Stain Analysis}

Gas chromatography using both mass spectrometry and flame ionization detection (GCMS and GC-FID) were used to analyze two problematic stains: green highlighter and red Sharpie. The less problematic counterparts to these stains, the yellow highlighter and the black Sharpie, were tested for any differences in composition. An Agilent GC/MS/FID was used for all runs. Deionized water was used as the solvent for the highlighters and HPLC grade acetone was used as the solvent for the Sharpies. 


\section{Results and Discussion}

\subsection{Preliminary Testing}

A small but representative number of stain blocking primers were selected in this phase of the project. The purpose of preliminary testing was to practice and refine test methods to be employed during the comprehensive testing phase of a larger number of primers (section 3.2). This is an important step because the results of final comprehensive testing (section 3.2) will be used to make regulatory decisions by the CARB.

\subsubsection{Primer Characterization}

All results for sag, leveling, contrast ratio, gloss, density, and weight fraction of solids can be found in Table 3.1. From this table it can be seen that the sag and leveling values are in close agreement, meaning that generally the paints with the best sag resistance have poor leveling capabilities. Contrast ratio and gloss values at $60^{\circ}$ were included in this study as another method of comparing the primers. Higher contrast ratios do not always lead to a higher stain blocking capacity. Several stain blocking primers block stains by preventing the staining agent from migrating into the topcoat applied on top of the primer. The solid weight fraction was determined for all paints, to be used in VOC calculation. The numbers presented are an average of two or more trials. Density was determined and compared to the information provided on the technical data sheet (TDS) supplied by the manufacturer. All measured densities were reasonably close to the published values (where available).

Table 3.1: Primer Characterization Results for Preliminary Test Primers.

\begin{tabular}{|l|cccccc|}
\hline & Sag & Leveling & Contrast Ratio & Gloss $\left(60^{\circ}\right)$ & Solids (wt. fraction) & $\begin{array}{c}\text { Density } \\
\text { (lbs/gal) }\end{array}$ \\
\hline SB-A & 10 & 0 & 0.89 & 2.5 & 0.780 & 12.4 \\
SB-B & 5 & 3 & 0.91 & 5.6 & 0.529 & 10.0 \\
SB-C & 10 & 0 & 0.94 & 2.9 & 0.775 & 12.5 \\
WB-A & 9 & 2 & 0.92 & 5.3 & 0.477 & 10.6 \\
WB-B & 9 & 3 & 0.94 & 6.9 & 0.548 & 10.6 \\
WB-C & 9 & 2 & 0.94 & 2.4 & 0.617 & 12.4 \\
Flat TC & NA & NA & 0.96 & 2.7 & 0.550 & 12.0 \\
\hline
\end{tabular}


Viscosity versus shear rate was measured for each primer in duplicate. Representative plots for each primer are shown in Figures 3.1 and 3.2. In this plot it can be seen that there is not perfect agreement between the viscosity at a low shear rate and the values obtained for sag and leveling. SB-B gave especially surprising results. Rheology testing for this paint showed a very high viscosity at low shear rates. Low shear rate viscosity normally correlates to the sag and leveling properties of the paint. By this reasoning, SB-B should have showed a high value for sag and a low value for leveling. However, as seen in Table 3.1, the primer showed low sag and high leveling values. Visually, the paint appears as though it has a low viscosity at low shear rates, in agreement with the sag and leveling data. For this reason, further testing was done using both cone-and-plate and parallel plate geometries with the same rheometer as well as with a Brookfield Model DV-II+ Viscometer with an LV3 spindle. This is further addressed in section 3.2.2.

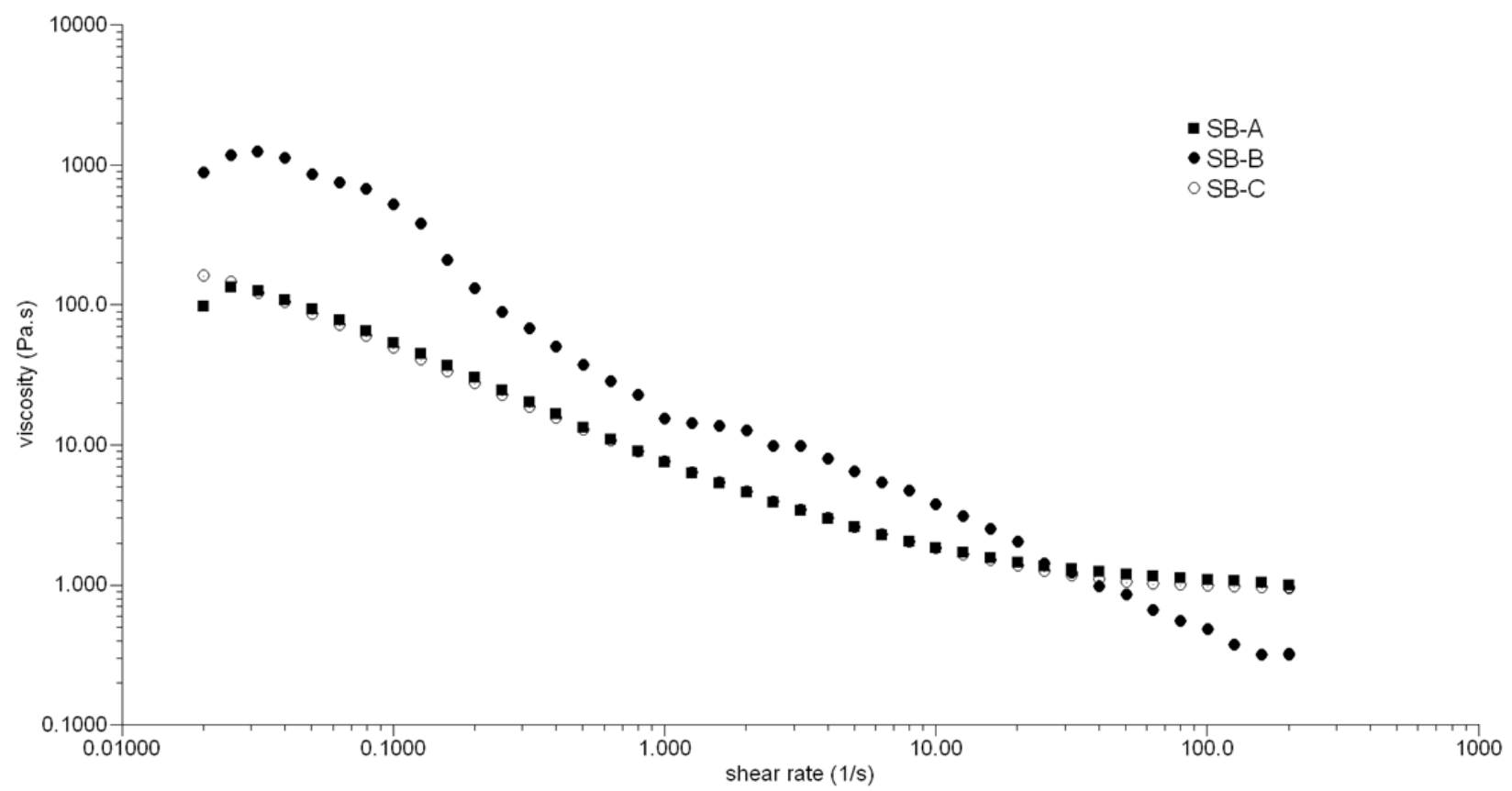

Figure 3.1: Rheology Results for Solvent Based Primers. 


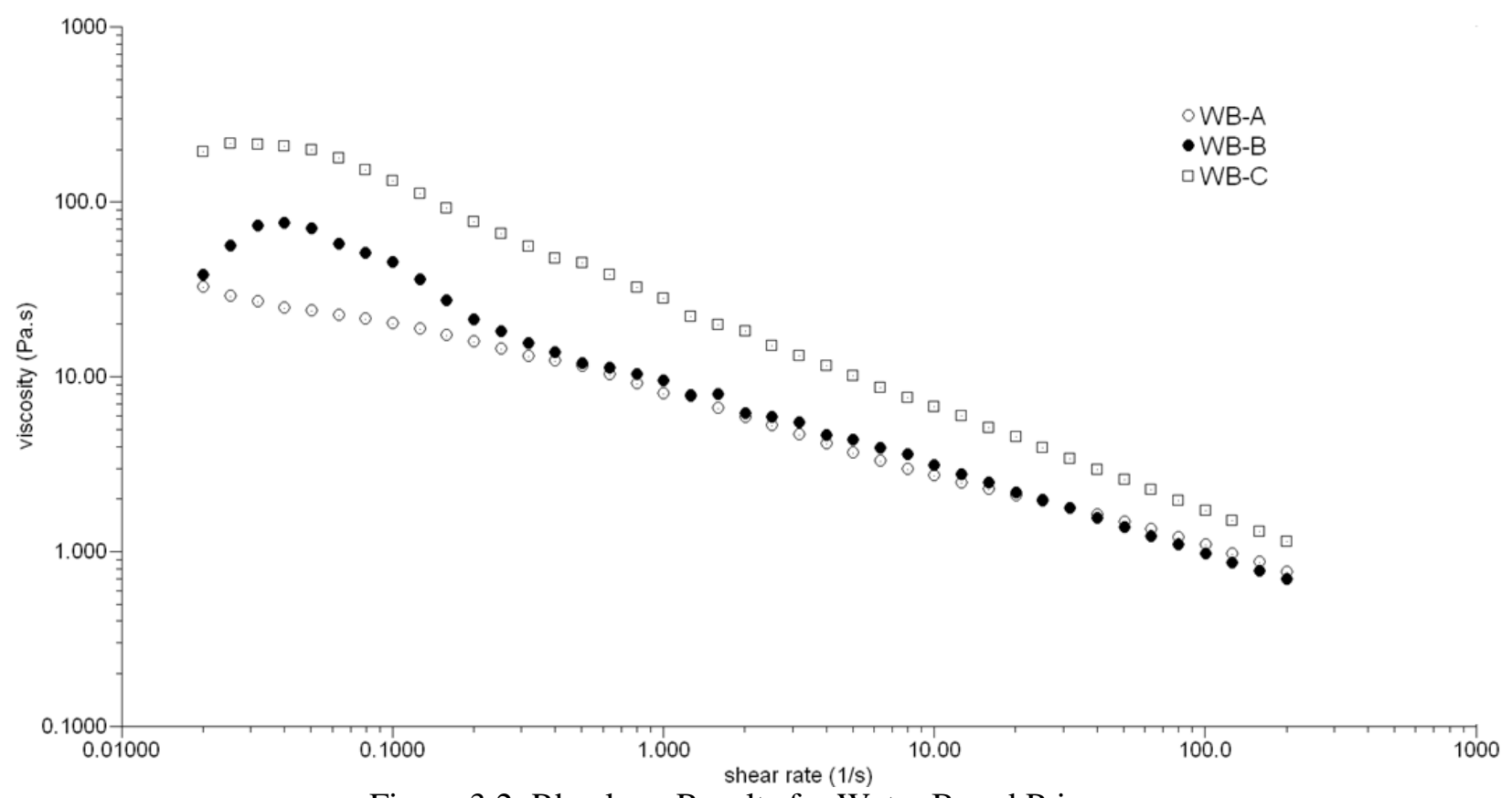

Figure 3.2: Rheology Results for Water Based Primers.

Table 3.2: VOC Content in Preliminary Test Paints.

\begin{tabular}{|l|cccc|}
\hline & $\begin{array}{c}\text { Material VOC (g/L) } \\
\text { ASTM D6886 }\end{array}$ & $\begin{array}{c}\text { Coating VOC (g/L) } \\
\text { ASTM D6886 }\end{array}$ & $\begin{array}{c}\text { Coating VOC }(\mathrm{g} / \mathrm{L}) \\
\text { EPA 24 }\end{array}$ & TDS VOC (g/L) \\
\hline SB-A & 270 & 280 & 220 & $<350$ \\
SB-B & 370 & 460 & 470 & $<550$ \\
SB-C & 250 & 280 & 230 & $<350$ \\
WB-A & 20 & 57 & - & 90 \\
WB-B & 45 & 97 & - & 99 \\
WB-C & 32 & 69 & - & 960 \\
Flat TC & 28 & 74 & - & \\
\hline
\end{tabular}

\subsubsection{VOC Determination}

Table 3.2 shows the VOC values that have been obtained for select primers as well as the expected coating VOC content as provided in the technical data sheet (TDS) from the manufacturer. As shown in Table 3.2, several of these values are consistent with the TDS values. Determining the VOC content of all primers was an important step because the provided TDS coating VOC content can be a calculated value rather than a measured value. VOC values 
determined using Karl Fischer titration are not reported due to the high potential for experimental error when using this test method on low VOC water based paints.

\subsubsection{Stain Blocking Testing}

A method for categorizing the stain blocking abilities had not yet been agreed upon at this point in testing; however, the following provides some insight from basic visual observations from initial testing.

\subsubsection{Marker Stains}

Marker stain testing showed that, in general, water based primers have difficulty blocking water based stains, such as highlighters, while solvent based primers have difficulty blocking solvent based stains, such as permanent marker. For each stain type, there is a noticeable difference in visibility between two colors of the same type of marker stain, which suggests that there is a difference in the composition of staining agent.

For the water based primers it was observed that WB-B did the best job of blocking the stain visibility through the topcoat, followed by WB-A and WB-C, respectively. Yellow highlighter was visible through the topcoat in all water based samples, although the green highlighter showed only through the WB-C samples. Bleeding, or thickening, of the stain line was seen with the yellow highlighter on these samples.

The solvent based primer testing with marker stains provided interesting results. As previously mentioned, it was determined through industry recommendation that SB-B is seen as the most effective stain blocker available on the market. In fact, the testing that was conducted showed that SB-C was the most effective stain blocker, followed by SB-A, and finally SB-B. The permanent markers, both red and black, were visible to some degree through the topcoat of all samples.

Collecting color data from the marker stain square testing was thought to allow for a quantitative measurement of the stain blocking ability of the primer and topcoat. It was difficult to determine if these values agree with the rankings provided from the marker line test because of 
the very small changes in the CIELAB values, seen in Appendix A. Data for the yellow and green highlighters was only reported for latex paints. This was done because the highlighter stain was completely blocked by solvent based primers during previous testing. Because of the inconclusive nature of the CIELAB values, this test was not repeated for comprehensive testing.

\subsubsection{Tannin Stains}

Tannin bleed into the topcoat was not seen for many of the primers. Generally it was seen that the water based primers provided results that were very similar to the oil or shellac based primers. Ranking the samples is difficult due to variation between wood samples and variation in film thickness. Certain wood samples contain different amounts of tannins or knots, which contain a higher concentration and often times a different type of tannin. From this information it was decided that it may be necessary in future testing to base tannin blocking capabilities on a stain made from a concentrated tannin solution applied to a substrate or through more vigorous testing.

For better comparison, film thickness was determined using the area of the section painted, the weight of paint applied, and the density of the paint. Wet film thickness in micrometers for the painted boards can be found in Table 3.3. These values did not provide insight into the results due to the variation in wood samples and the acceptable stain blocking provided by the primers and topcoat.

Table 3.3: Wet Film Thickness (Micrometers) of Primer Applied to Cedar and Redwood.

\begin{tabular}{|l|rr|rc|}
\hline & \multicolumn{1}{|l|}{ Trial 1 } & \multicolumn{1}{l|}{ Trial 2 } & \\
\hline & Cedar & Redwood & \multicolumn{1}{l|}{ Cedar } & Redwood \\
\hline SB-A & 44 & 57 & 56 & 53 \\
SB-B & 33 & 62 & 58 & 47 \\
SB-C & NA & NA & 64 & 39 \\
WB-A & 38 & 30 & 72 & 44 \\
WB-B & NA & NA & 62 & 42 \\
WB-C & NA & NA & 51 & 46 \\
\hline
\end{tabular}




\subsection{Comprehensive Testing of Stain Blocking Primers}

Based on the preliminary results, final primers and test methods were chosen after consultation with the industry advisory group. The results presented below will be considered by the CARB for determining "acceptable" performance of a stain blocking primer and potentially lowering the SPSU category's VOC limit.

\subsubsection{Primer Characterization}

All results for sag, leveling, contrast ratio, gloss, density, and weight fraction of solids can be found in Tables 3.4 - 3.6. From these tables it can be seen that the sag and leveling values are in close agreement - generally the paints with the best sag resistance have poor leveling capabilities. As a group, waterborne paints perform better in sag test and worse in leveling test when compared to the solvent based group of paints. This is consistent with the expected trend between the two groups of paints.

Appearance properties of the coatings are shown in terms of contrast ratio and gloss values at $60^{\circ}$. There is no clear trend between the gloss values of the two groups of coatings (i.e. solvent based and water based). The gloss values are all low, and consistent with what is expected of primers formulated near or above the critical pigment volume concentration. Contrast ratios, however, show a clear trend - the waterborne group has higher contrast ratios than does the solvent based group. It should be noted that higher contrast ratios, while indicating better hiding, are not necessarily indicative of better stain blocking performance. Typically, stain blocking primers are formulated to block stains by preventing the staining agent from migrating into the topcoat applied over the primer. Another clear trend is observed in solids weight fraction results between solvent based and water based groups. The solvent based group, with the exception of SB4, has significantly higher solids (by weight) compared to the water based group of primers. Also, the solvent based group, with the exception of SB4, has higher densities than the densities of primers in the water based group. The combined trends of solids (by weight) and density data indicate that the solvent based group is more highly filled with inorganic fillers. Although the 
primers in the water based group appears to be less filled, the higher contrast ratio of that group indicate presence of more $\mathrm{TiO}_{2}$ in those formulations. The solid weight fraction data was useful in calculation the VOCs discussed later in this report. The numbers presented are based on averages of three trials per paint. 
Table 3.4: Primer Characterization Results for Solvent Based Paints Used in Comprehensive Testing.

\begin{tabular}{|l|ccccccc|}
\hline & Sag & Leveling & Contrast Ratio & Gloss $\left(60^{\circ}\right)$ & Solids (wt fraction) & KU Viscosity & Density (lbs/gal) \\
\hline SB1 & 8 & 1 & 0.91 & 4.8 & 0.768 & 95 & 11.8 \\
SB2 & 10 & 0 & 0.90 & 3.3 & 0.754 & 89 & 11.4 \\
SB3 & 10 & 0 & 0.89 & 2.5 & 0.791 & 89 & 13.3 \\
SB4 & 6 & 3 & 0.93 & 5.8 & 0.516 & 68 & 9.80 \\
SB5 & 10 & 0 & 0.91 & 2.5 & 0.774 & 91 & 12.5 \\
SB6 & 5 & 3 & 0.91 & 5.1 & 0.742 & 91 & 11.3 \\
SB7 & 9 & 0 & 0.94 & 7.0 & 0.770 & 93 & 11.9 \\
\hline
\end{tabular}

Table 3.5: Primer Characterization Results for Water Based Paints Used in Comprehensive Testing.

\begin{tabular}{|l|ccccccc|}
\hline & Sag & Leveling & Contrast Ratio & Gloss $\left(60^{\circ}\right)$ & Solids (wt fraction) & KU Viscosity & Density (lbs/gal) \\
\hline WB1 & 10 & 0 & 0.96 & 3.4 & 0.444 & 99 & 10.1 \\
WB2 & 10 & 0 & 0.98 & 14 & 0.488 & 110 & 10.5 \\
WB3 & 10 & 0 & 0.95 & 6.5 & 0.533 & 120 & 10.8 \\
WB4 & 10 & 0 & 0.97 & 3.5 & 0.517 & 100 & 11.0 \\
WB5 & 10 & 2 & 0.96 & 3.5 & 0.470 & 100 & 10.8 \\
WB6 & 7 & 3 & 0.97 & 11 & 0.495 & 96 & 10.9 \\
WB7 & 10 & 0 & 0.95 & 5.1 & 0.505 & 110 & 10.9 \\
WB8 & 9 & 0 & 0.95 & 5.7 & 0.554 & 110 & 11.1 \\
\hline
\end{tabular}

Table 3.6: Characterization Results for Dunn-Edwards Paints and Primers Used as Standards.

\begin{tabular}{|l|ccccccc|}
\hline & Sag & Leveling & $\begin{array}{c}\text { Contrast } \\
\text { Ratio }\end{array}$ & Gloss $\left(60^{\circ}\right)$ & $\begin{array}{c}\text { Solids (wt } \\
\text { fraction) }\end{array}$ & KU Viscosity & Density (lbs/gal) \\
\hline Drywall Sealer & 6 & 3 & 0.97 & 3.5 & 0.473 & 88 & 10.7 \\
Int WB Primer & 10 & 2 & 0.95 & 8.3 & 0.504 & 110 & 10.8 \\
Ext WB Primer & 10 & 1 & 0.95 & 18 & 0.529 & 110 & 10.8 \\
Int Topcoat & 10 & 0 & 0.97 & 14 & 0.540 & 110 & 10.9 \\
Ext Topcoat & 10 & 0 & 0.98 & 14 & 0.531 & 91 & 10.5 \\
\hline
\end{tabular}


Viscosity as a function of shear rate was determined for each primer at least in duplicate. A representative plot of one run for each primer can be found in Appendix B. As expected, all paints exhibit shear thinning behavior. Viscosities at low shear rate region should correlates with the sag and leveling properties of the paint, with low viscosity resulting in poor sag and good leveling. There is good agreement between the sag and leveling data reported in Tables 3.4-3.6 and the rheology plots in Appendix B. However, as seen in Table 3.4, SB4 primer showed poor sag and good leveling values, but it appears to have the highest viscosity at low shear rate region. Careful examination showed that this primer dries fast within the cone-and-plate fixture of the rheometer, leading to high viscosity responses. The erratic nature of the data points supports this observation. Visually, the paint appears as though it has a low viscosity at low shear rates, in agreement with the sag and leveling data. In the water based primer group (Table 3.5), WB6 performed worst in sag test and it has the lowest viscosity at low shear rate region.

\subsubsection{VOC Determination}

Table 3.7 shows the VOC values that have been obtained for select primers as well as the expected VOC content as provided in the technical data sheet (TDS) from the manufacturer. As shown in the table, several of these values are consistent with the expected values, as provided by the TDS from the manufacturer. As previously mentioned, determining the VOC content of all primers was an important step because the provided TDS coating VOC content can be a calculated value rather than a measured value. 
Table 3.7: VOC Content of All Paints Used in Comprehensive Testing.

\begin{tabular}{|c|c|c|c|c|}
\hline & \multirow{2}{*}{$\begin{array}{l}\text { Material VOC }(\mathrm{g} / \mathrm{L}) \\
\text { ASTM D6886 }\end{array}$} & \multicolumn{2}{|c|}{ Coating VOC (g/L) } & \multirow{2}{*}{ TDS VOC $(\mathrm{g} / \mathrm{L})$} \\
\hline & & ASTM D6886 & EPA 24 & \\
\hline SB1 & 340 & 340 & 230 & 340 \\
\hline SB2 & 280 & 300 & 250 & 350 \\
\hline SB3 & 320 & 320 & 200 & $<350$ \\
\hline SB4 & 460 & 510 & 480 & 550 \\
\hline SB5 & 250 & 280 & 230 & $<350$ \\
\hline SB6 & 260 & 290 & 210 & 340 \\
\hline SB7 & 320 & 320 & 230 & 350 \\
\hline WB1 & 16 & 47 & - & 100 \\
\hline WB2 & 3.6 & 10 & - & "zero" \\
\hline WB3 & 34 & 79 & - & 95 \\
\hline WB4 & 32 & 81 & - & 96 \\
\hline WB5 & 20 & 59 & - & 81 \\
\hline WB6 & 8.0 & 23 & - & "zero" \\
\hline WB7 & 9.7 & 27 & - & $<100$ \\
\hline WB8 & 24 & 56 & - & 92 \\
\hline Drywall Sealer & 17 & 48 & - & 50 \\
\hline Int WB Primer & 4.4 & 12 & - & 2 \\
\hline Ext WB Primer & 38 & 87 & - & 55 \\
\hline Int Topcoat & 4.4 & 11 & - & 2 \\
\hline Ext Topcoat & 33 & 74 & - & 50 \\
\hline
\end{tabular}

\subsubsection{Marker Stain Blocking Testing}

Table 3.8 contains the data for the stain blocking ranking of each stain for each primer.

The score presented is an average of 3 trials with a maximum score of 10 . The values presented in Table 3.8 are highly reproducible, as was determined by quantitative evaluation. A systematic statistical analysis was conducted on a sampling of results to quantify the error in stain blocking rating, as discussed in the experimental design section. From this it was determined that all values are expected to be within \pm 1 ranking value. 


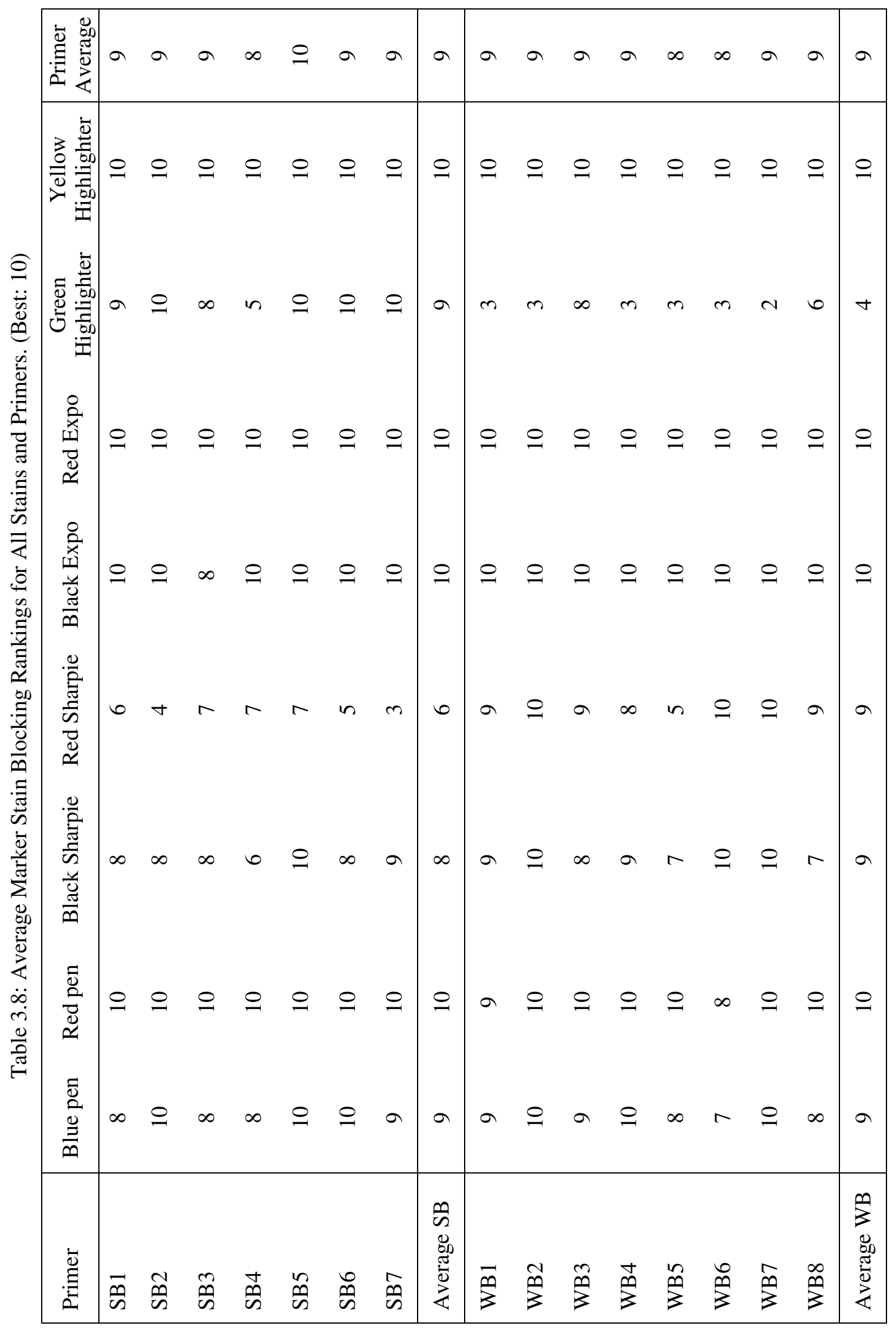


The average marker stain blocking values in Table 3.8 are represented in a bar chart in

Figure 3.3.

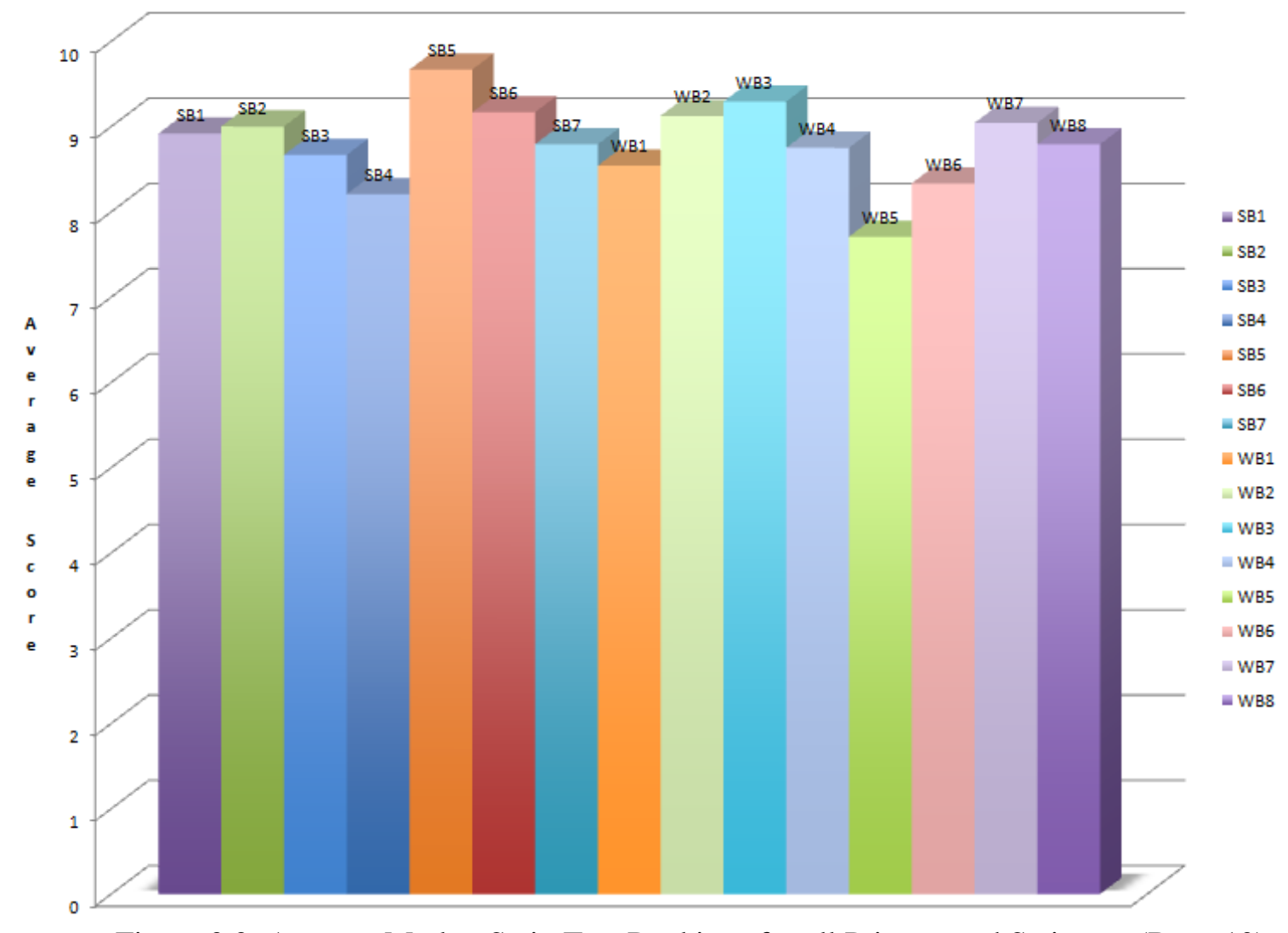

Figure 3.3: Average Marker Stain Test Rankings for all Primers and Stains ～(Best: 10).

As seen in Figure 3.3 and Table 3.8, the solvent based primer SB5 had the best overall performance of all primers, while the waterborne primer WB3 had the best overall performance for waterborne primers. The overall performance of waterborne and solvent based primers is comparable. During testing it was noted that several primers had a very difficult time blocking the red Sharpie and green highlighter stains. These stains were interesting because the black Sharpie and the yellow highlighter did not present a problem for most primers. The average scores for all primers were recalculated omitting the red Sharpie and green highlighter scores. The results are significantly different, as seen below in Figures 3.4 and 3.5. A final plot was made excluding both red Sharpie and green highlighter as seen in Figure 3.6. All recalculated values can also be seen in Table 3.9. 
Table 3.9: Average Marker Stain Rankings for All Primers and Select Stains. (Best: 10)

\begin{tabular}{|c|cccc|}
\hline Primer & Average Score & $\begin{array}{c}\text { Without Red } \\
\text { Sharpie }\end{array}$ & $\begin{array}{c}\text { Without Green } \\
\text { Highlighter }\end{array}$ & Without Both \\
\hline SB1 & 9 & 9 & 9 & 9 \\
SB2 & 9 & 10 & 9 & 10 \\
SB3 & 9 & 9 & 9 & 9 \\
SB4 & 8 & 8 & 9 & 9 \\
SB5 & 10 & 10 & 10 & 10 \\
SB6 & 9 & 10 & 9 & 10 \\
SB7 & 9 & 10 & 9 & 10 \\
WB1 & 9 & 9 & 9 & 9 \\
WB2 & 9 & 9 & 10 & 10 \\
WB3 & 9 & 9 & 9 & 10 \\
WB4 & 9 & 9 & 10 & 10 \\
WB5 & 8 & 8 & 8 & 9 \\
WB6 & 8 & 8 & 9 & 9 \\
WB7 & 9 & 9 & 10 & 10 \\
WB8 & 9 & 9 & 9 & 9 \\
\hline
\end{tabular}

When the score for the red Sharpie is omitted, there is a significant change in the results

(Figure 3.4, Table 3.9). The most noticeable change is the increase in average score for the solvent based primers, creating a visible performance difference between most solvent based and waterborne primers. It appears that there is some component in the red Sharpie that interacts with the primers, especially the solvent based primers. Primers SB5 and WB3continue to display the best performance in their respective categories.

When the green highlighter is omitted from the total score, there is also a significant change in the results (Figure 3.5, Table 3.9). The most noticeable change is the increase in the average scores of the water based primers. From the bar chart it can be seen that it appears as though the water based primers are generally performing better than the solvent based primers, suggesting that the water based primers generally perform better than the solvent based primers at blocking the stains, excluding the green highlighter. 


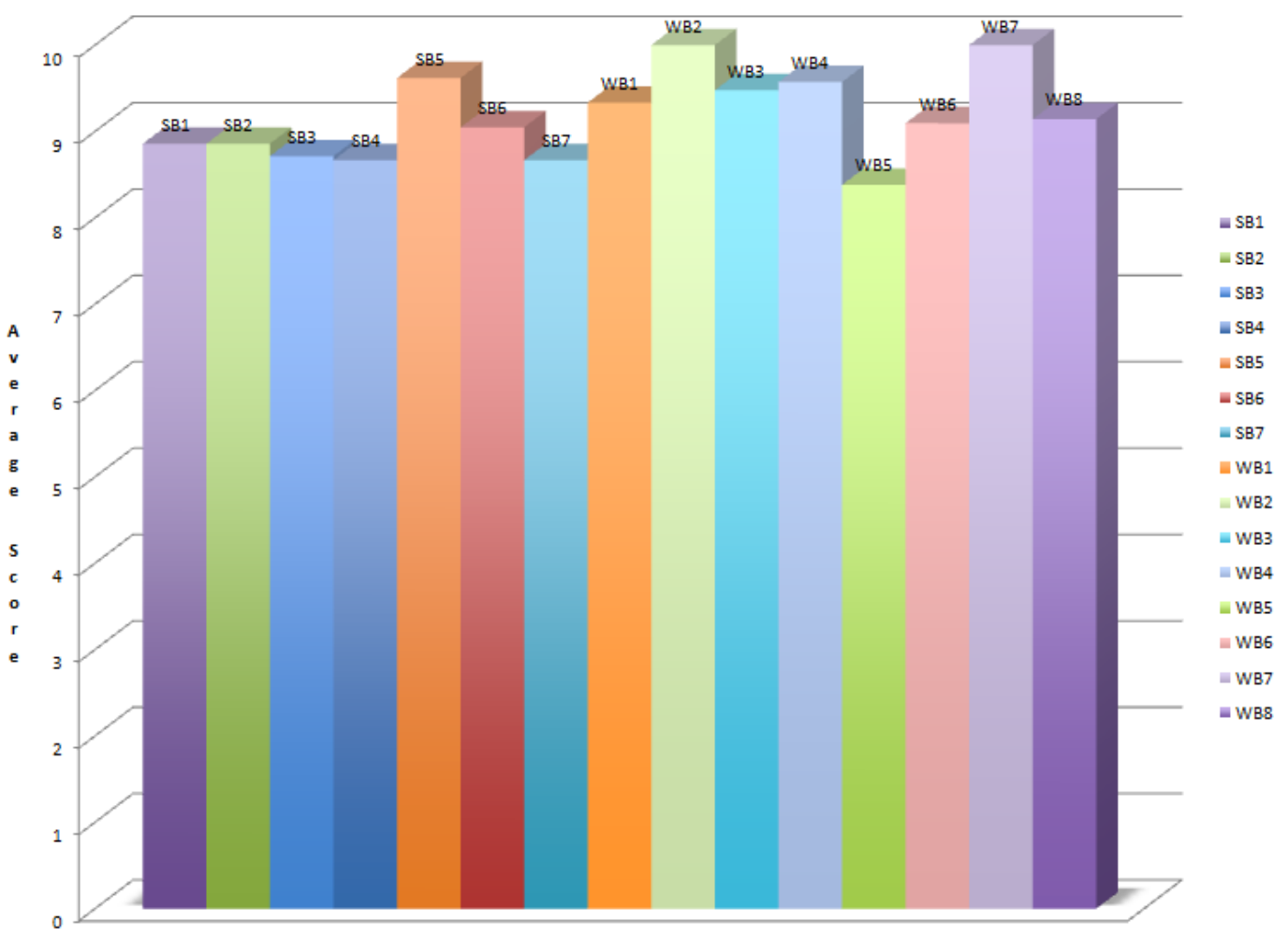

Figure 3.4: Marker Stain Test Rankings for all Primers and Stains, Excluding Green Highlighter. (Best: 10)

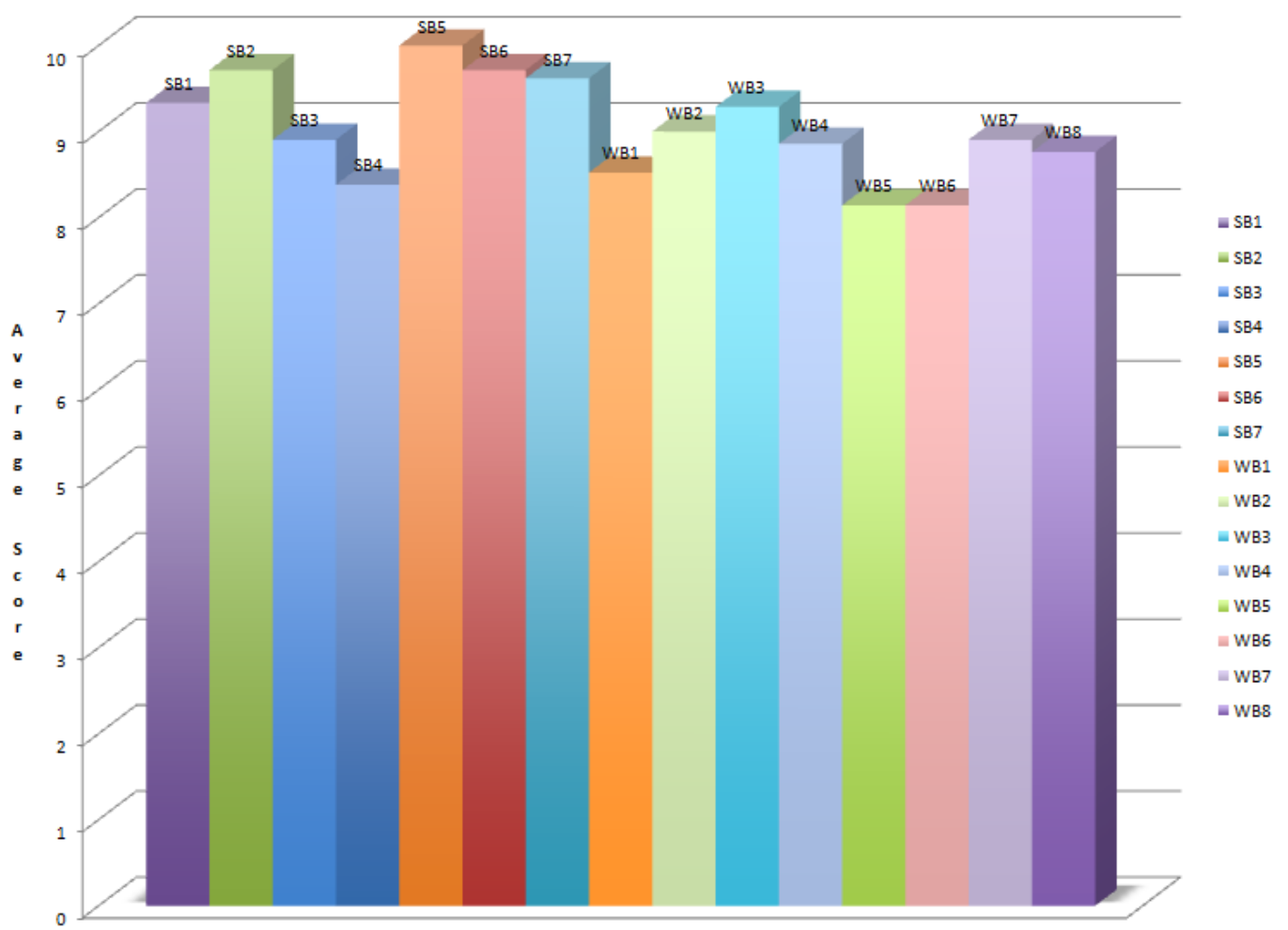

Figure 3.5: Marker Stain Test Rankings for all Primers and Stains, Excluding Red Sharpie. (Best: 10) 
Finally, the scores for both the red Sharpie and the green highlighter were omitted in order to remove all outliers (Figure 3.6, Table 3.9). From this data it can be seen that several of the primer, both solvent based and water based, had average rankings of 10 (best possible ranking), including SB2, SB5, SB6, SB7, WB2, WB3, WB4, and WB7.

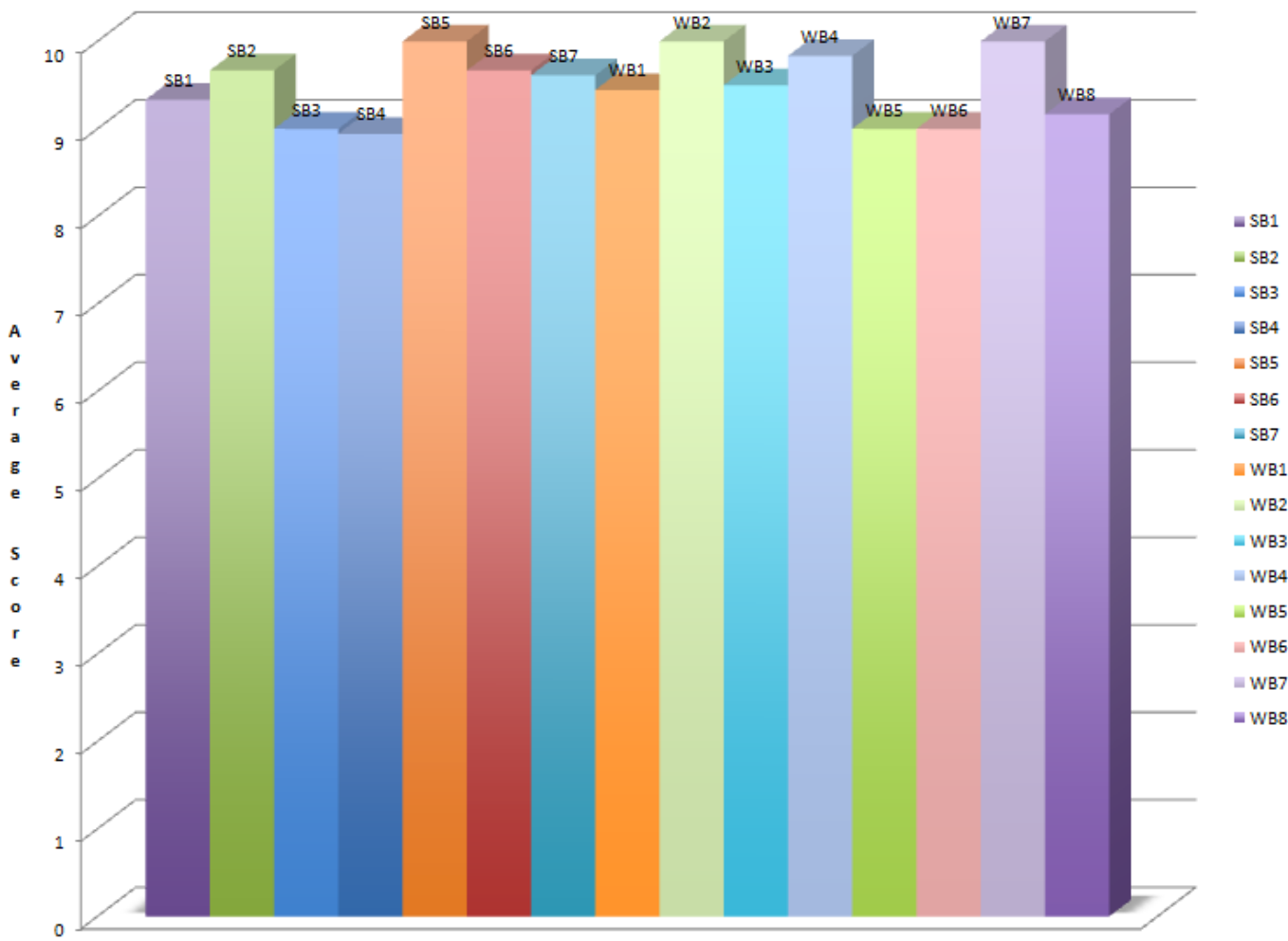

Figure 3.6: Marker Stain Test Rankings for all Primers and Stains, Excluding Green Highlighter and Red Sharpie. (Best: 10)

\subsubsection{Two Coat Marker Stain Testing}

A test was conducted using two coats of the water based primers. This test was completed in order to determine if two coats of water based primers can perform as well or better than one coat of the solvent based primers. Two coats of water based primer emit less VOCs than one coat of solvent based primer. The results of this test are shown in Table 3.10. Two solvent based primers were included in testing to ensure consistent results were obtained. From this table it can be seen that there was at least a one point increase in the average stain blocking capabilities of all water based primers with the use of a second coat, with the exception of the experimental primer which already had the best possible ranking. 


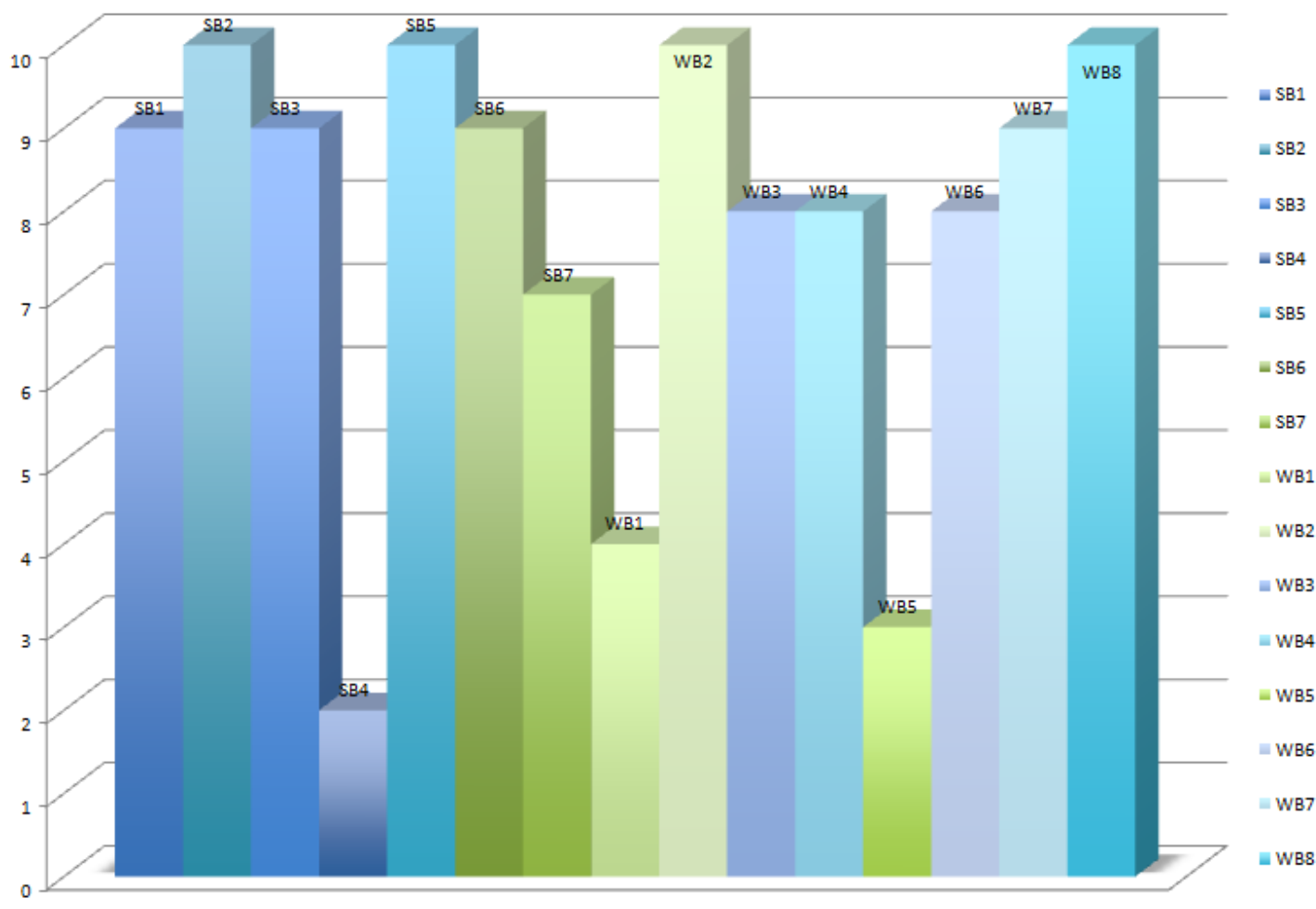

Table 3.10: Average Marker Stain Rankings for Two Coats of Water Based Primer Test. (Best: 10)

\begin{tabular}{|l|c|c|}
\hline Primer & One Coat & Two Coats (WB only) \\
\hline SB2 & 9 & 9 \\
\hline SB5 & 10 & 10 \\
\hline WB1 & 9 & 10 \\
\hline WB2 & 9 & 10 \\
\hline WB3 & 9 & 10 \\
\hline WB4 & 9 & 10 \\
\hline WB5 & 8 & 9 \\
\hline WB6 & 8 & 10 \\
\hline WB7 & 9 & 10 \\
\hline WB8 & 9 & 10 \\
\hline Experimental Primer & 10 & 10 \\
\hline
\end{tabular}

\subsubsection{Tannin Blocking Testing}

The ability of each primer to block tannin bleeding into the topcoat was measured on a scale of 1 to 10 , where 10 blocks $100 \%$ of the stain. The average of the two rankings for each primer coated with exterior topcoat (TC) was taken on both the cedar and redwood samples and the rankings can be seen in Figures 3.7 and 3.8, respectively. The values can also be seen in Table 3.11 .

Figure 3.7: Tannin Blocking Test Rankings for all Primers on Cedar. (Best: 10) 
Table 3.11: Tannin Stain Rankings for All Primers. (Best: 10)

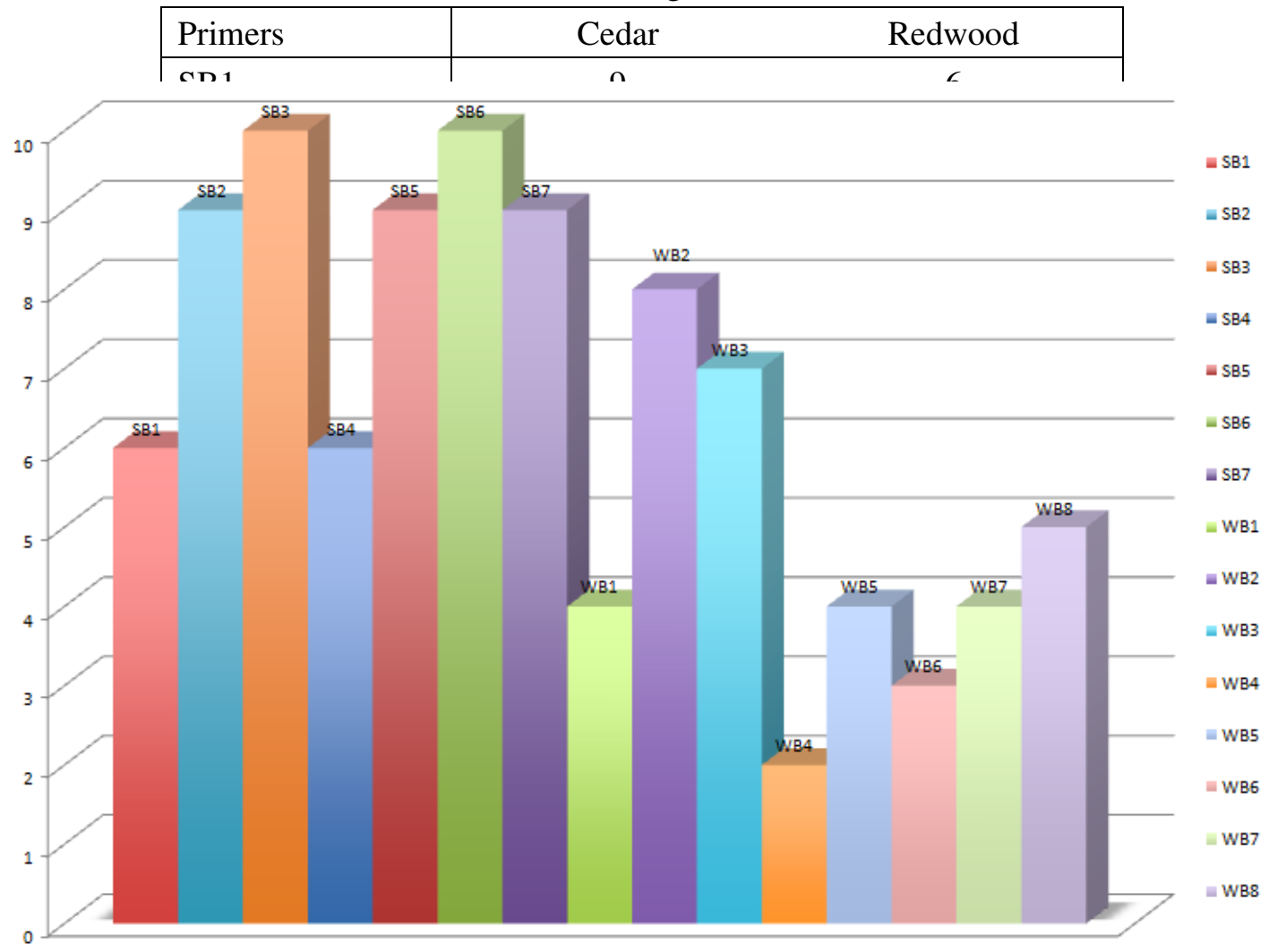

Figure 3.8: Tannin Blocking Test Rankings for all Primers on Redwood. (Best: 10)

A few statements can be made about the tannin blocking testing results. First, the ranking for the redwood samples are noticeably lower than the rankings for the cedar samples. Visual observation of these samples shows that the redwood samples are significantly darker in color than the cedar samples, which is most likely an indication of higher tannin content. Second, when looking at the cedar rankings in Figure 3.7, it can be seen that certain waterborne primers, namely WB2 and WB8, perform as well as the best solvent based primers. Finally, the redwood data shows a greater deal of variation in the performance of the primers, and solvent based primers SB3 and SB6 demonstrate the best stain blocking performance.

As previously mentioned, it is expected solvent based primers will have superior tannin blocking capabilities. Tannins are water soluble and will migrate through a water based primer 
into the water based topcoat, while it is not favorable for the tannins to migrate through a layer of hydrophobic solvent based primer.

It should be mentioned again that the wood boards used in testing were selected and sanded to provide uniform boards for all testing. Standard Dunn-Edwards exterior primer was applied to a small section of each board and ranked along with the other primers. As was expected, the rankings between the standard exterior primer sections were not consistent, due to inconsistencies within the wood selection. The results presented may be skewed as a result of this, and future testing may require a larger selection of wood samples and more repetition.

\subsubsection{Stain Characterization}

GC-MS and GC-FID results revealed the main components of the four stains tested. The results for the green and yellow highlighters show that they contain glycerin and triethanolamine, as seen from the FID of the green highlighter in Figure 3.9. Glycerin is soluble in water as a result of three hydrophilic groups and is also hygroscopic in nature. Triethanolamine is a base and is also water soluble. These characteristics of the two main components of the highlighters are ideal for carrying a staining agent, such as the ink in the highlighter, through a water based primer and into the water based topcoat. Ethylene glycol dimethyl ether was included in this sample as the internal standard, and can also be seen in Figure 3.9 as the peak marked "EGDE".

The results from the red and black Sharpies revealed small traces of several compounds, including: ethyl ether, 2-ethylhexanoic acid, 4-methyl-3-penten-2-one, and 4-hydroxy-4-methyl2-pentanone. The last component was the most abundant and is likely a contamination in the acetone used. None of the currently known components of the Sharpies provide information regarding why this stain migrated into the topcoat over solvent based primers. 


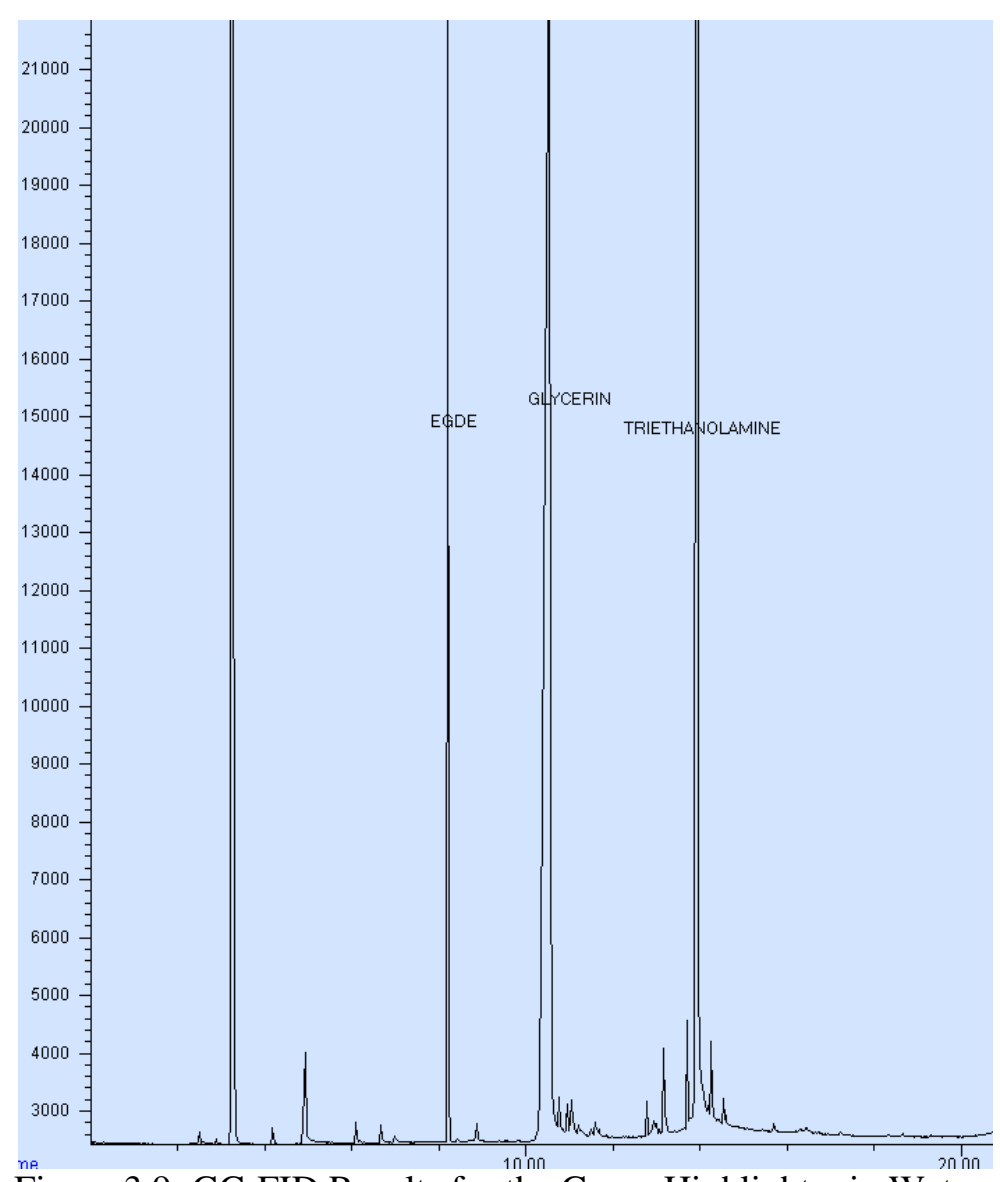

Figure 3.9: GC-FID Results for the Green Highlighter in Water.

\subsection{Experimental Primer Results}

\subsubsection{Primer Characterization}

Characterization data was provided by the manufacturer of the primer and can be seen in

Table 3.12 as adopted from the data sheet provided by Cytec.

Table 3.12: Primer Characterization Values for the Experimental Primer as Provided by Manufacturer.

\begin{tabular}{|ll|}
\hline Property & Value \\
\hline pH-Value & $5.0-6.5$ \\
Solids (wt. fraction) & 0.550 \\
PVC \% & 37.27 \\
VOC (g/L) & 98 \\
Density (lbs/gal) & 11.5 \\
\hline
\end{tabular}

Viscosity as a function of shear rate was measured four times for the experimental primer.

The results can be seen below in Figure 3.10. From these results it can be seen that the fast drying time of this primer affected the results. For this reason shorter continuous ramp tests were 
completed with durations of 2, 5, 10, and 20 minutes, seen in Figure 3.11. The shorter sample testing time provided improved results for viscosity as a function of shear rate, and confirmed that the results seen in Figure 3.10 were a result of the sample drying during testing.

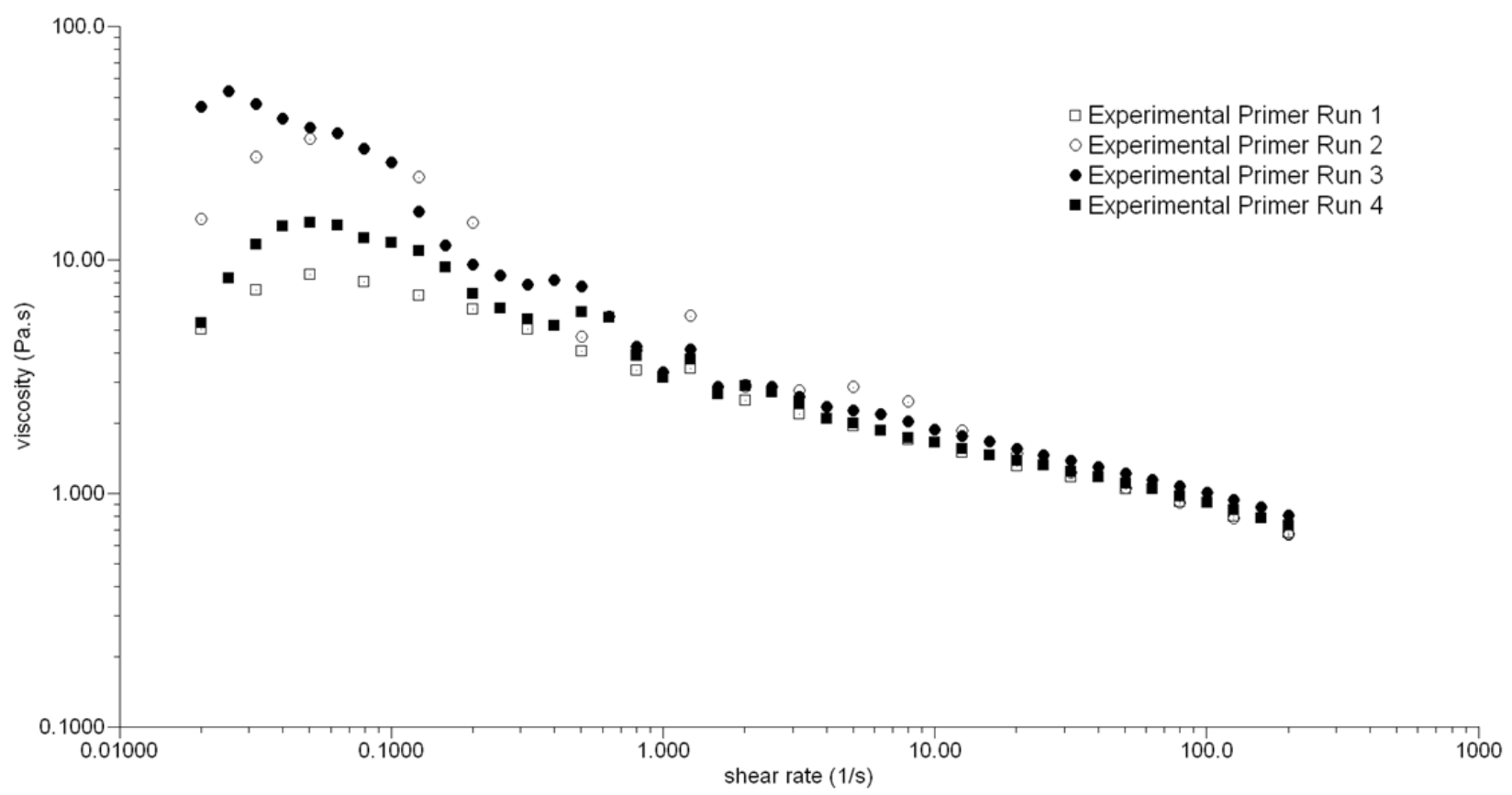

Figure 3.10: Rheology Results for the Experimental Primer. 


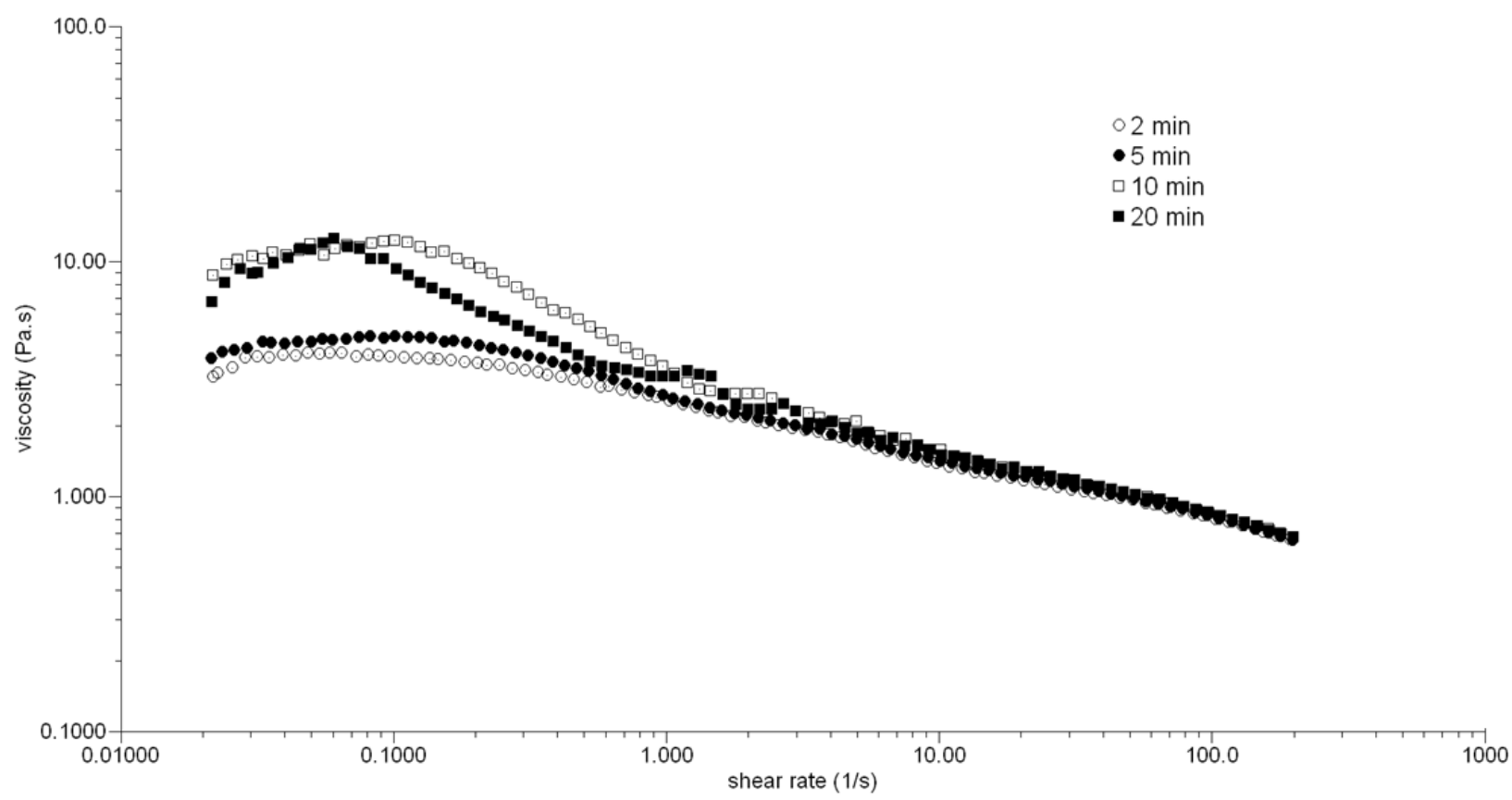

Figure 3.11: Continuous Ramp Rheology Results for the Experimental Primer.

\subsubsection{Marker Stain Blocking Testing}

The experimental primer marker stain blocking test results are presented in Figure 3.12 3.15 with a comparison to the best performing solvent based and water based stain blocking primers. The best performing primers selected for comparison in marker stain blocking were SB2, SB5, SB6, WB2, WB3, and WB7. As previously mentioned, the green highlighter and red Sharpie caused problems for several primers. Figures 3.13 - 3.15 show the experimental primer compared to the same six best performing primers without the green highlighter, without the red Sharpie, and without both the green highlighter and the red Sharpie, respectively.

From these results it can be seen that the experimental primer performs better than the other primers for total score. In the bar charts omitting the green highlighter and red Sharpie, it is not the top performing primer, however all results are within a small range. 


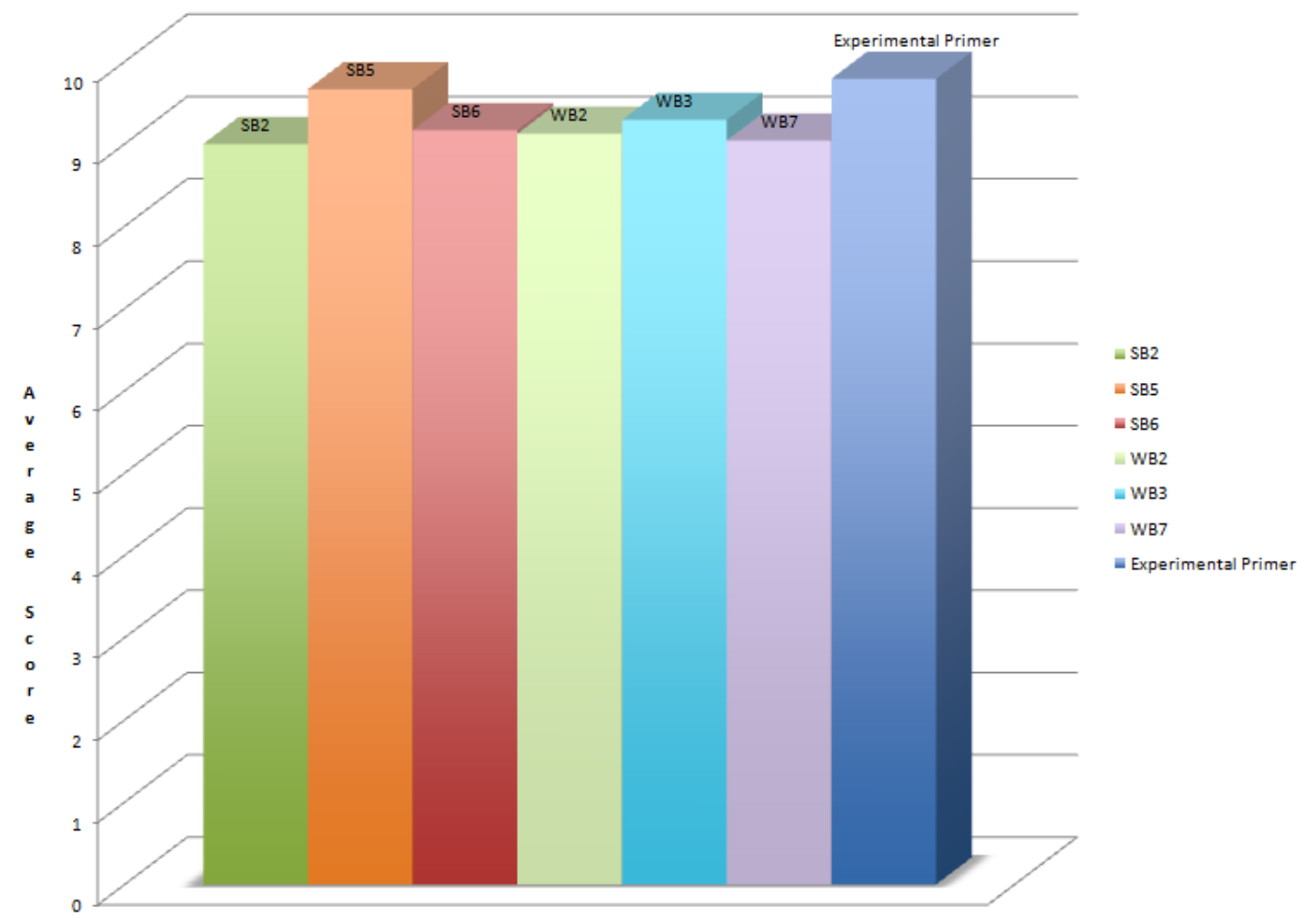

Figure 3.12: Marker Stain Test Rankings for the Experimental Primer and Top Performing Primers. (Best: 10)

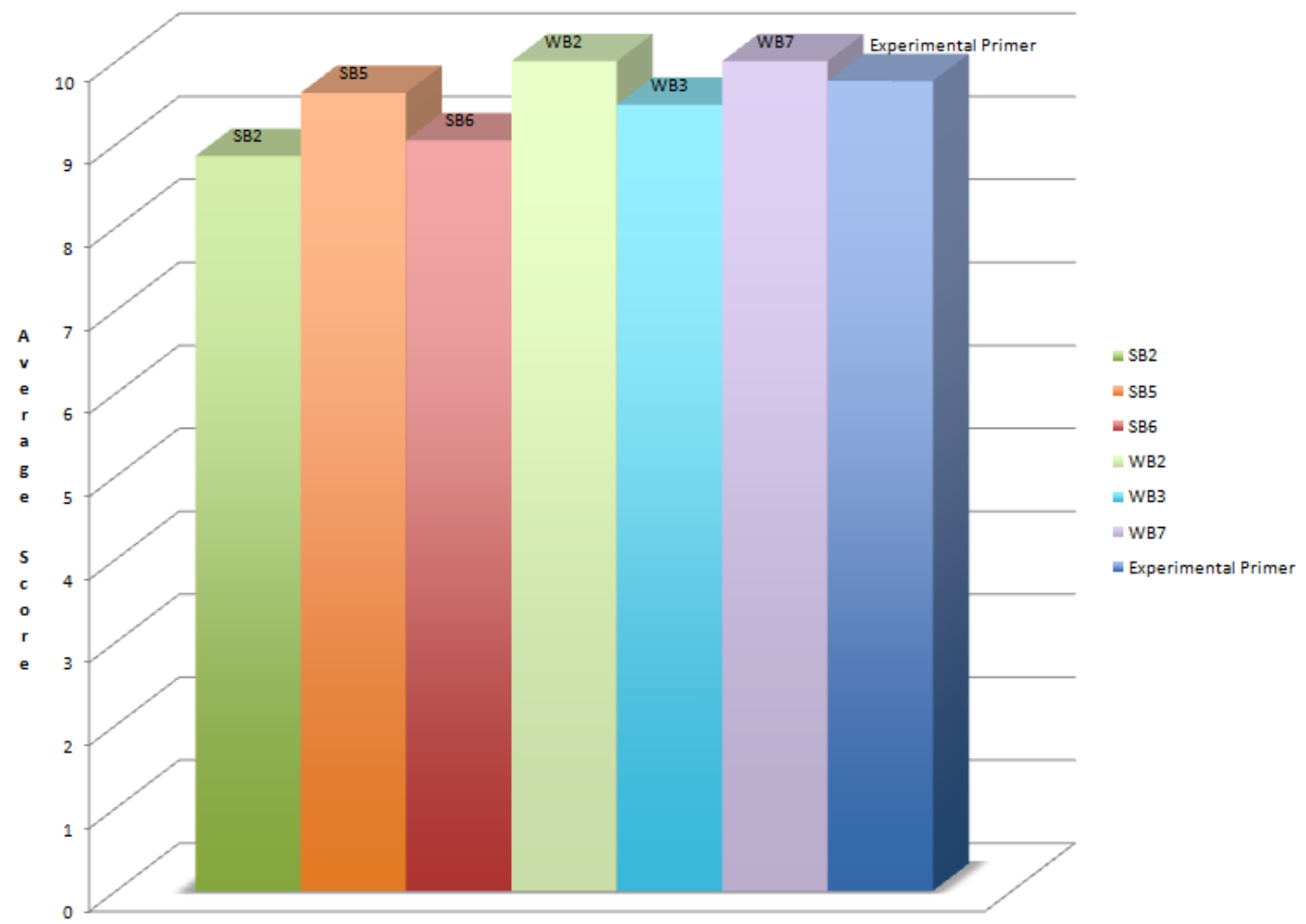

Figure 3.13: Marker Stain Test Rankings for the Experimental Primer and Top Performing Primers, Excluding Green Highlighter. (Best: 10) 


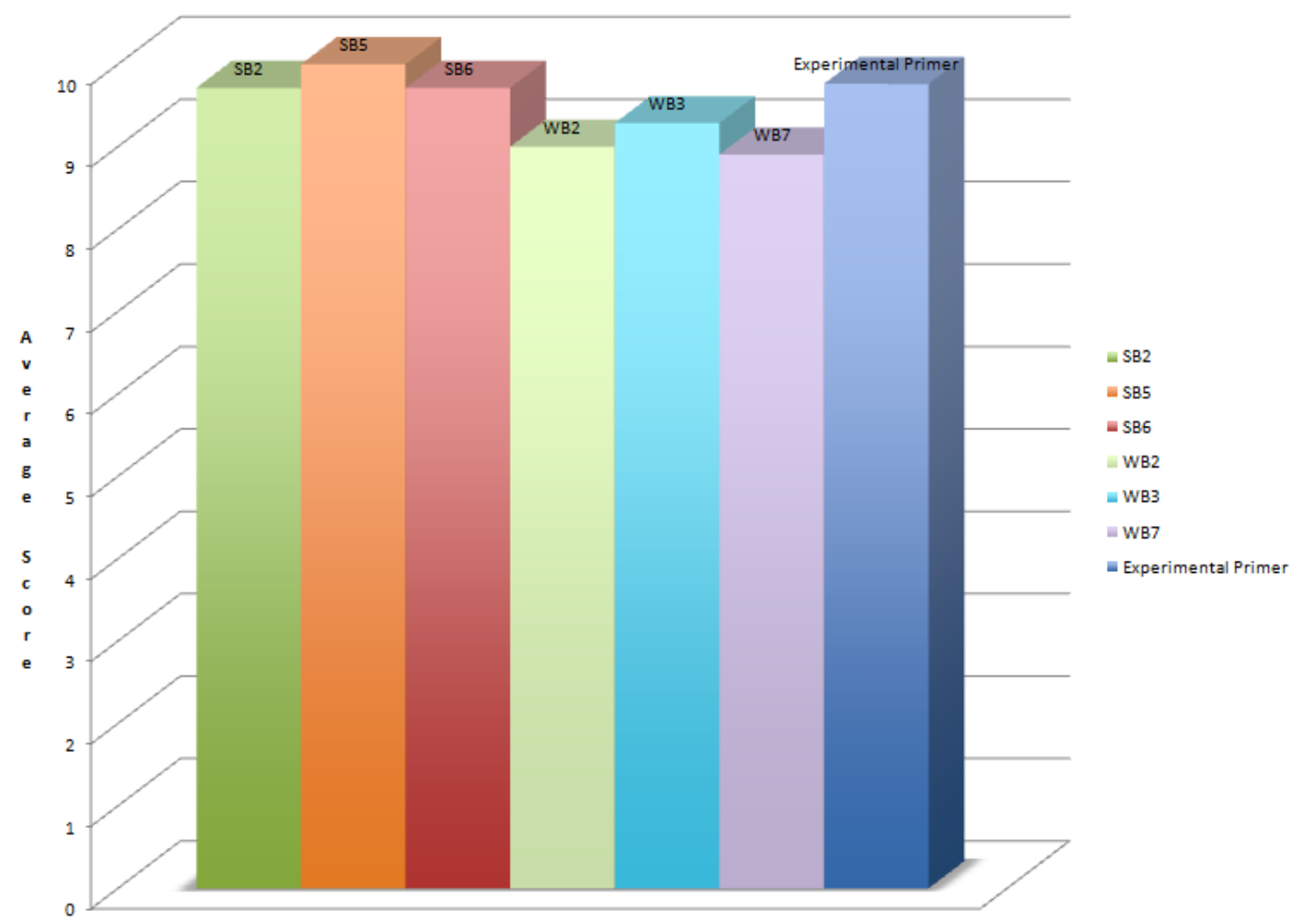

Figure 3.14: Marker Stain Test Rankings for the Experimental Primer and Top Performing Primers, Excluding Red Sharpie. (Best: 10)

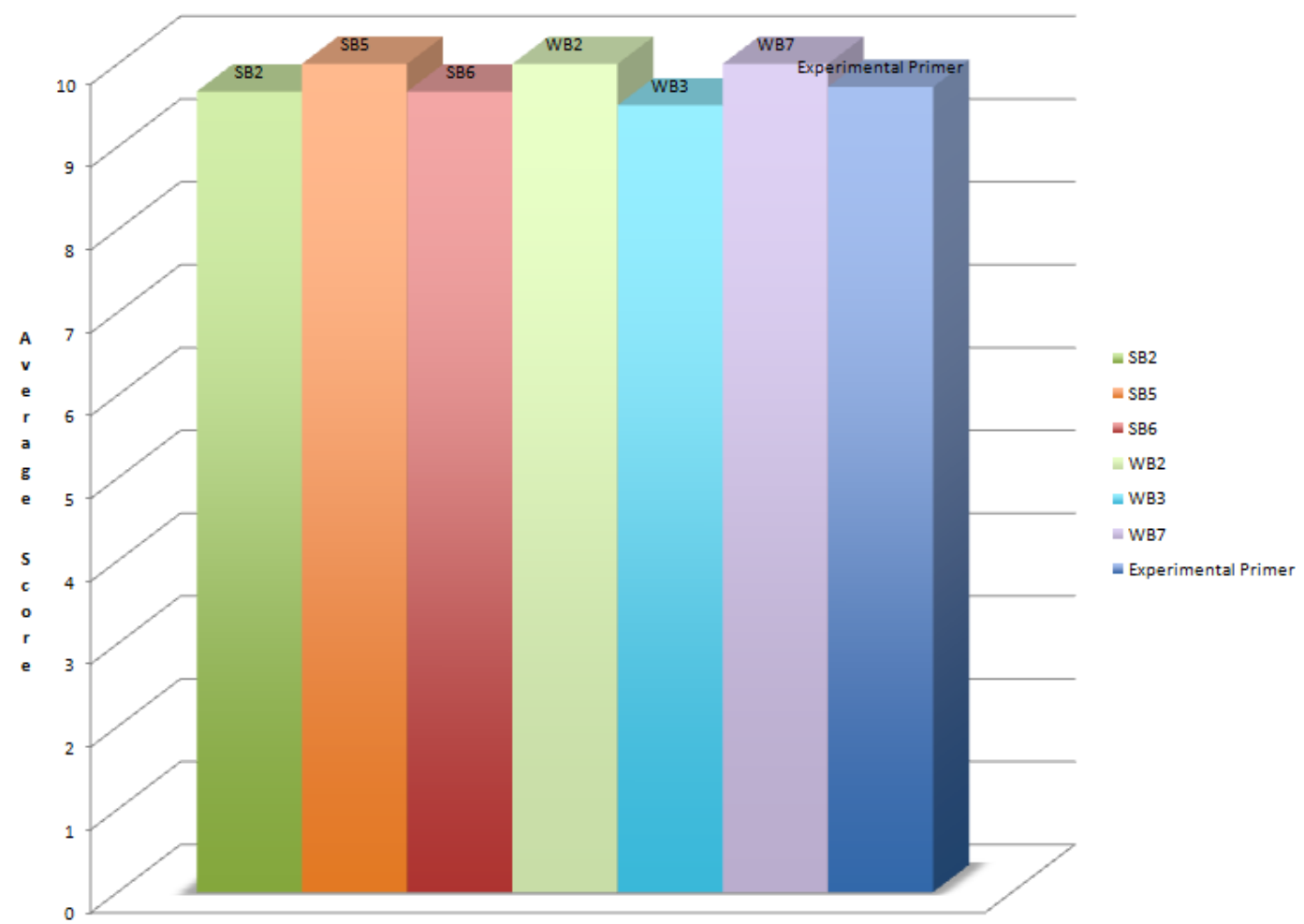

Figure 3.15: Marker Stain Test Rankings for the Experimental Primer and Top Performing Primers, Excluding Green Highlighter and Red Sharpie. (Best: 10) 


\subsubsection{Tannin Blocking Testing}

The experimental primer tannin blocking test results are presented in Figure 3.16 - 3.17 with a comparison to the best performing solvent based and water based stain blocking primers. The best performing primers selected for tannin blocking comparison are SB1, SB2, SB5, WB2, WB7, and WB8.

From these results it can be seen that on both types of wood there is a commercially available primer in both the solvent based and water based categories that performs better than the experimental primer. As previously mentioned, this may be a result in the inconsistencies in the wood samples and future testing should include more repetition.

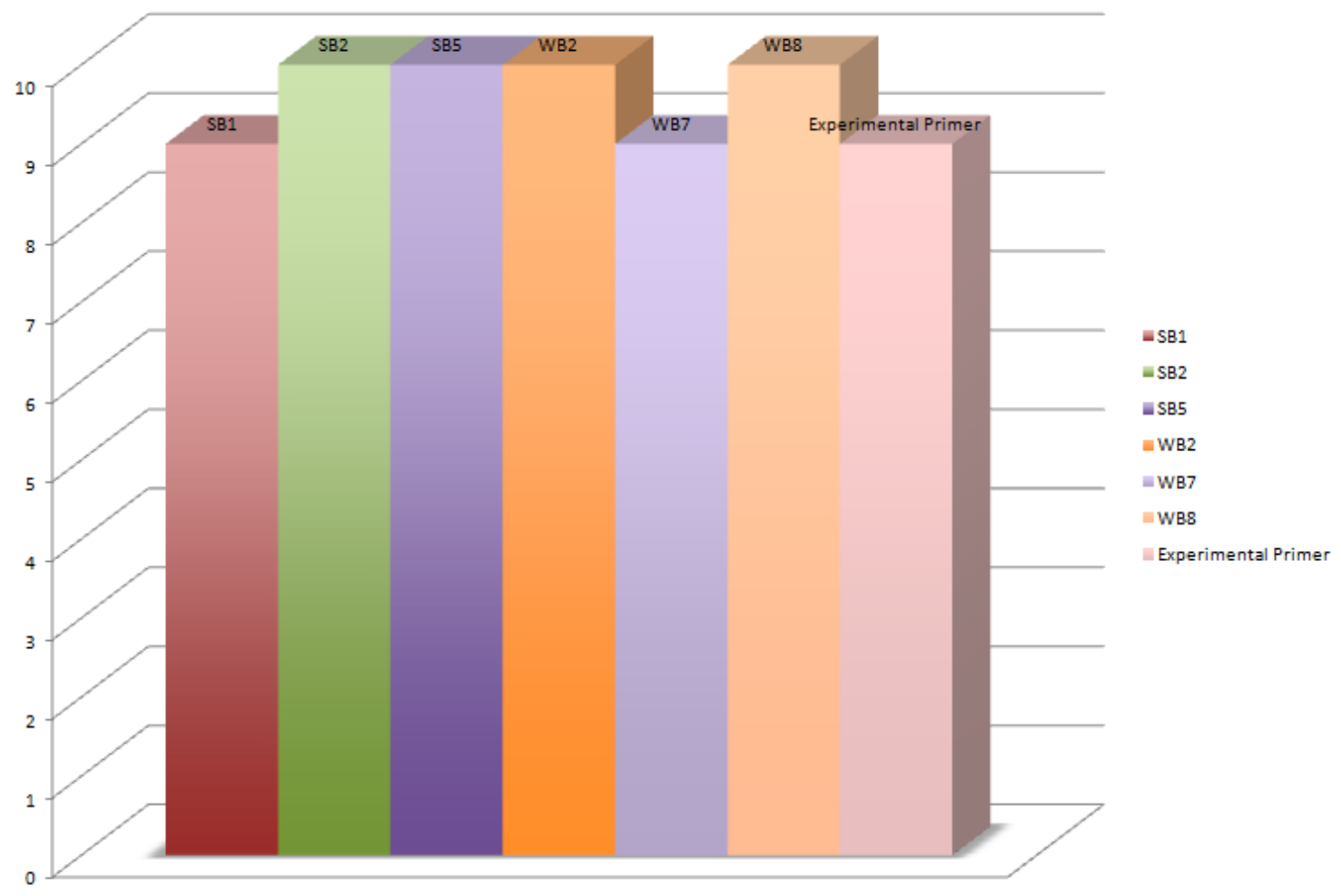

Figure 3.16: Cedar Tannin Blocking Results for the Experimental Primer and Top Performing Primers. (Best: 10) 


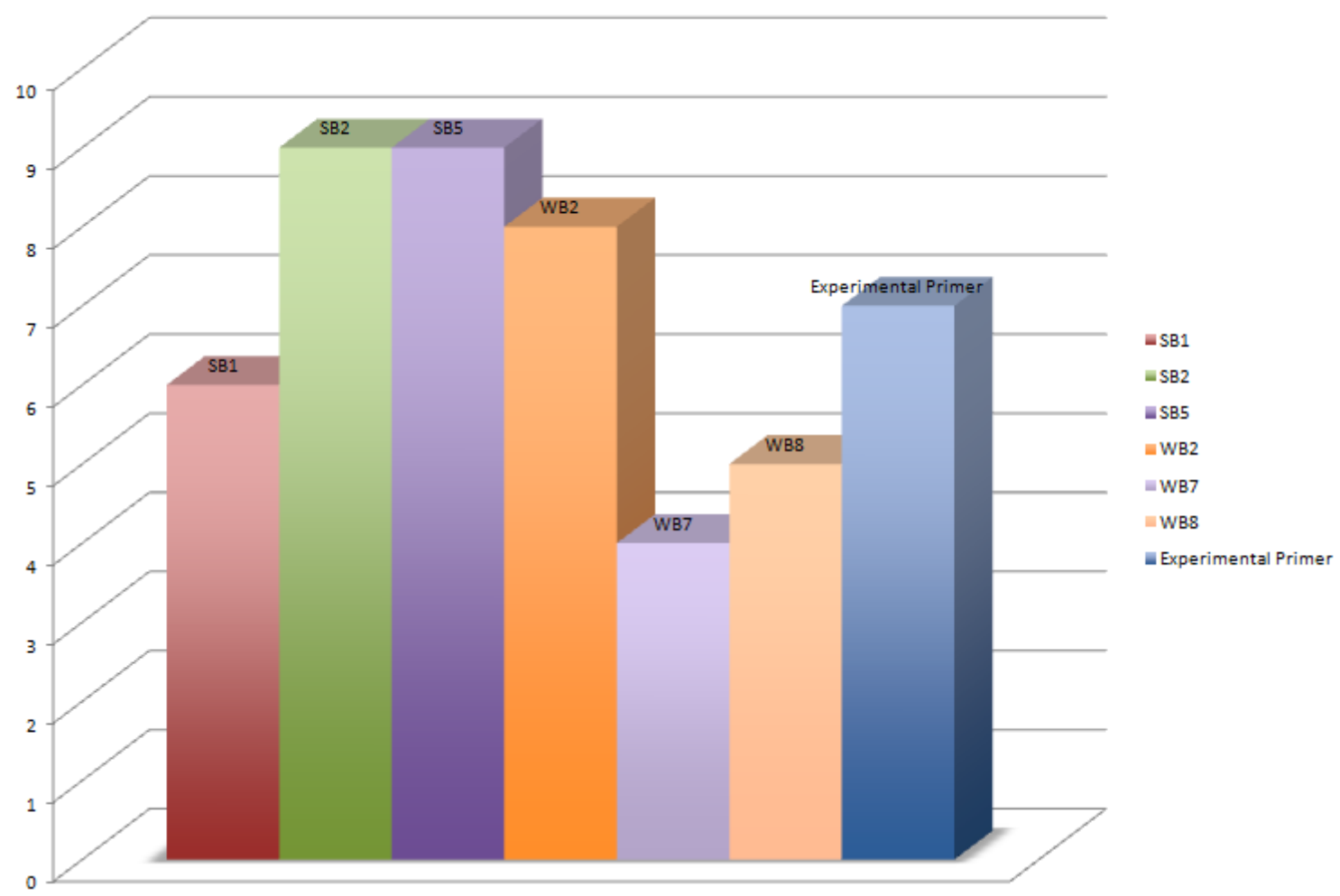

Figure 3.17: Redwood Tannin Blocking Results for the Experimental Primer and Top Performing Primers. (Best: 10) 


\section{Conclusions}

The stain blocking primers tested in this study were selected based on industry counsel. Preliminary testing was completed to solidify the test methods for the final study to be submitted to the California Air Resources Board for consideration when lowering the VOC limits for the SPSU category of paints, or stain blocking primers. A summary of the stain blocking testing for both marker stain blocking and tannin blocking results can be seen below in Table 4.1. In this table, a score of 10 is complete stain blocking where $100 \%$ of the stain is blocked.

Table 4.1: Summary of Stain Rankings for All Primers. (Best: 10)

\begin{tabular}{|l|ccc|}
\hline Primers & Marker Stains & Cedar & Redwood \\
\hline SB1 & 9 & 9 & 6 \\
SB2 & 9 & 10 & 9 \\
SB3 & 9 & 9 & 10 \\
SB4 & 8 & 2 & 6 \\
SB5 & 10 & 10 & 9 \\
SB6 & 9 & 9 & 10 \\
SB7 & 9 & 7 & 9 \\
WB1 & 9 & 4 & 4 \\
WB2 & 9 & 10 & 8 \\
WB3 & 9 & 8 & 7 \\
WB4 & 9 & 8 & 2 \\
WB5 & 8 & 3 & 4 \\
WB6 & 8 & 8 & 3 \\
WB7 & 9 & 9 & 4 \\
WB8 & 9 & 10 & 5 \\
\hline
\end{tabular}

From this table it can be seen that SB2, SB3, and SB5 have the highest stain blocking rankings in the solvent based category, and WB2 and WB8 have the highest stain blocking rankings in the water based category. It can also be seen that tannin blocking on redwood was the most difficult stain blocking test, as can be seen through the very low stain blocking scores for several of the primers. This test also shows a significant difference in stain blocking ability between categories of primers. 
From the testing completed to date, no concrete decision has been made establishing whether water based primers with a VOC content of $100 \mathrm{~g} / \mathrm{L}$ or less exhibit acceptable stain blocking performance when compared to solvent based primers for common problematic stains. Further stain blocking testing must be completed with a wider variety of stains to examine the stain blocking capabilities of solvent based primers and water based primers. 


\section{Future Work}

The work completed on this project has provided a foundation for the remainder of the project. Industry input was gathered regarding stain blocking primer selection and test methods, the selected primers were characterized, and select stain blocking testing was completed.

The remaining steps of this project were also outlined and include several more stain blocking tests. Drywall samples will be prepared at Cal Poly and tested with common household stains. Samples will be prepared by priming drywall samples with Dunn-Edwards Vinylastic Premium Wall Sealer, coating with Dunn-Edwards ENSO Interior Eggshell paint, applying appropriate stain, priming with appropriate SPSU primer, and coating again with Dunn-Edwards ENSO Interior Eggshell paint. Field substrates with smoke, water, and fire damage will also be obtained for stain blocking testing. The preparation of these samples will depend on the nature of the stain and the sample received. Future work may also include repetition of the tannin blocking test on cedar and redwood boards to try to reduce the effect of inconsistencies between wood samples on test results.

The completion of this work prior to January 2012 will lead to a conclusion regarding whether or not water based stain blocking primers are capable of acceptable performance. 


\section{References for Part A}

ASTM Standard D523, 2008, "Standard Test Method for Specular Gloss," ASTM International, West Conshohocken, PA, 2008, DOI: 10.1520/D0523-08.

ASTM Standard D1475, 1998 (2008), "Standard Test Method for Density of Liquid Coatings, Inks, and Related Products," ASTM International, West Conshohocken, PA, 2008, DOI: 10.1520/D1475-98R08.

ASTM Standard D2369, 2010, "Standard Test Method for Volatile Contents of Coatings," ASTM International, West Conshohocken, PA, 2010, DOI: 10.1520/D2369-10.

ASTM Standard D4062, 1999 (2003), "Standard Test Method for Leveling of Paints by DrawDown Method," ASTM International, West Conshohocken, PA, 2010, DOI: 10.1520/D4062-99R03.

ASTM Standard D4400, 1999 (2007), "Standard Test Method for Sag Resistance of Paints Using a Multinotch Applicator," ASTM International, West Conshohocken, PA, 2007, DOI: 10.1520/D4400-99R07.

ASTM Standard D6441, 2005 (2010), "Standard Test Methods for Measuring the Hiding Power of Powder Coatings," ASTM International, West Conshohocken, PA, 2007, DOI: 10.1520/D6441-05R10.

ASTM Standard D6886, 2003 (2009), "Standard Test Method for Speciation of the Volatile Organic Compounds (VOCs) in Low VOC Content Waterborne Air-Dry Coatings by Gas Chromatography," ASTM International, West Conshohocken, PA, 2007, DOI: 10.1520/D6886-03R09.

ASTM Standard D7514, 2009, "Standard Test Methods for Evaluating Ink Stainblocking of Architectural Paint Systems by Visual Assessment," ASTM International, West Conshohocken, PA, 2007, DOI: 10.1520/D7514-09.

Betremieux, I., Duque, B., "Stain Blocking by WB Systems: How Does it Work?," Cray Valley, Centre De Recherche De L'Oise, Parc Technologique, Alata, Bp., 2002.

Brandt-Rothermel, S., "Blocking Around the Clock," Asia Pacific Coatings Journal, 22-23, August 2010.

California Air Resources Board (CARB), 2011, "Laws and Regulations," www.arb.ca.gov/html/lawsregs.htm.

Challener, C., "The VOC Factor, Part 1: Resins and paints," JCT Coatings Tech, 2(12), 36-43, 2005.

Deng, H., Deshmukh, K., Sheppard, A., 2002, “Aqueous stain-blocking coating composition,” U.S. Patent Application Publication 6,485,786.

Environmental Protection Agency (EPA), 2010, “An Introduction to Indoor Air Quality: Volatile Organic Compounds (VOCs)," www.epa.gov/iaq/voc.html. 
Hodges, S., Novelli, W., Thorn, A., 2003, “Tannin stain inhibitor comprising and aluminate salt complexing agent," U.S. Patent Application Publication 6,533,856.

Jones, D., Censullo, A., Wills, M., "Direct VOC Analysis of Water-Based Coatings by Gas Chromatography and Solid-Phase Microextraction," Journal of Coatings Technology, 69(869), 33-41, 1997.

Jones, D., Censullo, A., Wills, M., "Speciation of the Volatile Organic Compounds (VOCs) in Solventborne Aerosol Coatings by Solid Phase Microextraction-Gas Chromatography," Journal of Coatings Technology, 75(936), 47-53, 2003.

Jones, D., Brickweg, L., Guillermo, A., Wills, M., "Comprehensive VOC Analysis Method for Architectural Coatings,” JCT Coatings Tech, 4(1), 48-55, 2007.

Kimerling, A. S., Bhatia, S. R., "Block Copolymers as Low-VOC Coatings for Wood: Characterization and tannin bleed resistance," Progress in Organic Coatings, 51(1), 1526, 2004.

Prestemon, D., "Paint Problems on Exterior Wood," Iowa State University Pm-363, January 1994.

Sullivan, C., Roberts, A., Shearon, S., 2010, "Coating compositions and methods of blocking tannin migration," U.S. Patent Application Publication 2010/0047598 A1.

True, H., "Graham Training Letter: Coating Wood Can be a Knotty Issue," Graham Paint Training, 1(3), 2007.

Tsang, M., "New Waterborne Cationic Resins for Wood Primers," Cytec Industries, Presented at: The Waterborne Symposium - Advances in Sustainable Coatings Technology, Feb. 1820, 2009.

Twene, Derrick, et. al., "Overcoming the stains: Wood contains many water-soluble chemicals, such as tannins, that bleed through water-based materials to stain paints. New resins can be used to make stain-blocking water-based primers that offer a zinc-free and low VOC alternative to solvent-based systems," From: Dec. 1, 2003

Wicks, Z. W., Jones, F. N., Pappas, S. P., Wicks, D. A., “Organic Coatings: Science and technology,” Third Edition, John Wiley \& Sons, Inc., Hobokenn, New Jersey, 2007. 


\section{PART B}

\section{Introduction}

All work discussed in Part B of this report was conducted with material supplied by CertainTeed company as part of a fee-for-service agreement between the Cal Poly Corporation and CertainTeed.

\subsection{Project Overview}

The main objective of the project was to determine the ideal conditions for improving the adhesion of a water-reducible coating onto polypropylene (PP) substrates provided by CertainTeed by varying the drying time and the substrate surface treatment. Currently, the manufacturing practice for drying polypropylene siding products coated with a water-reducible coating involves allowing the coating to remain drying at room temperature for 7 days after application and drying in a conveyor oven. It is anticipated that the results of this project will allow the 7 day hold time to be reduced.

Coating plastics present many challenges that are not common to other substrates such as metal, wood, drywall, etc. Low surface energy and low heat distortion temperature are two key challenges associated with coating plastics such as polypropylene. Low surface energy makes it difficult to wet the polypropylene surface with coatings, especially with water based coatings. The low heat distortion temperature of PP also limits the selection of coating types because coatings that require high heat for drying cannot be used. Also, the low polarity associated with low surface energy often results in poor adhesion between the dry coating and polypropylene substrate due to a lack of interaction between the surface of the substrate and the coating.

Topics such as surface tension, surface energy, and wetting, and effects of surface chemistry of a material on those parameters have been extensively reviewed (Awaja, 2009; Levine, 1964; Osterhold, 1998; Ryntz, 1994). Wetting can be measured in terms of the contact angle of a water droplet on the substrate. Good wetting is achieved when the contact angle is small, $0^{\circ}$ being defined as perfect wetting. The relative surface tensions of the coating and the 
polymer substrate govern the wetting of a coating on a substrate. The coating must have a surface tension equal to or lower than that of the substrate in order for the coating to wet the substrate.

Other factors such as the viscosity of the coating and the surface roughness of the substrate play a role in determining wetting of a substrate. Plastics have a range of surface tensions, but most are very low. Polypropylene, structure of which is given in Figure 7.1, in particular, has a low surface tension (30.1 mN/m) (Lawniczak, 1993).

Surface morphological variations represent another challenge with polypropylene (PP) as a substrate for coatings. These variations can be caused by, among other factors, tacticity of the polymer (i.e., isotactic, syndiotactic, and atactic). For example, isotactic PP can be highly crystalline. High surface crystallinity on the surface layer adversely affects diffusion of molecules from a coating into the PP matrix. The average chain length and the molecular weight distribution of the PP polymer are also important factors. The surface layer is commonly referred to as the Weak Boundary Layer (WBL), and its morphology and composition are often different from the bulk matrix (Ryntz, 1994).

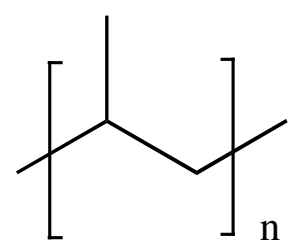

Figure 7.1: Structure of Polypropylene.

Most plastic substrates in commercial products, including PP used in CertainTeed's siding products, are compounded with other ingredients (i.e. similar to sheet molding compounds). This presents yet another challenge. On one hand, it creates further variations in the WBL depending on the process conditions used for making the product. In addition, processing aids and other additives can remain on the surface of the substrate. These are low surface energy additives that help reduce interactions between the molded part and the mold. They can cause major problems downstream in the process, adding to the wetting and adhesion problems of the substrate. 


\subsection{Adhesion to Polypropylene}

Despite the many challenges reviewed above, many commercial products based on PP are manufactured and sold. A majority of those products are in automotive applications such as bumpers and fascia (Ryntz, 2005). For many decades, industry and academia have done extensive research on adhesion and its mechanism (Carrino, 2002; Ryntz, 2005; Sathyanarayana, 1995). In recent years, adhesion research has become focused on polymers due to their many appealing bulk, mechanical, and surface properties, relatively low costs, and design flexibility. The chemical groups at or near the surface (i.e. those that influence short range forces) control adhesion between polymers and coatings. Adhesion is the interatomic and intermolecular interaction at the interface of two surfaces. Development of adhesion with a coating is influenced by a wide range of factors that influence the interfacial interactions. A thorough understanding of adhesion requires a multidisciplinary approach that takes into account chemistry, physics, diffusion, rheology, stress analysis, fracture analysis, etc. These aspects, as they relate to adhesion to plastics, have been reviewed (Awaja, 2009; Cognard, 2006). The recent review by Awaja et al. contains a great deal of information that relates specifically to polypropylene. PP has low surface energy and does not have polar functional groups on the surface. Both of these factors result in poor adhesion properties. Increasing surface tension and polarity is essential for achieving good adhesion of coatings to PP. In addition, increasing the ability of inter-diffusion of molecules at the interface is important, and this is a form of mechanical adhesion. Evidence for the inter-diffusion at the interface that leads to adhesion improvements in plastics has been reported (Ryntz, 2005).

\subsection{Chemical Modification of Polypropylene}

In this approach, the PP surface is subjected to the surface to chemical treatments with acids and oxidizers. The added polarity that results would increase the interaction of molecular forces between substrate and coating, which would in turn increase the adhesion between the two. Another approach, use of a solvent wipe, provides the added benefit of cleaning the substrate of 
any organic contaminants which can reduce the adhesion. Use of solvents such as trichloroethane is no longer acceptable. Physiochemical ways to promote adhesion is with plasma and flame treatments that will be discussed later.

\subsection{Chlorinated Polyolefins (CPOs)}

In recent years, the use of chlorinated polyolefins (CPOs) as adhesion promoters has become a viable option (Bugajski, 1998; Lawniczak, 1993 \& 2005; Wang, 2001; Ryntz, 2005). Introduction of CPOs to the market by Eastman Chemical Company in the early 1990's led to these developments (Fry, 1990). Today, several grades of commercial CPO's are available as aqueous dispersions (e.g. CP-310W supplied by Eastman Chemical Co.). Their solvent based counterparts are also available. Relative adhesion performance on PP, thermoplastic olefins (TPOs), and other plastics and information on how to formulate the adhesion promoters, is also available from suppliers. Typically these adhesion promoters are spray applied at about 0.3 mil (8 micron) dry thickness (Lawniczak, 1993 \& 2005). Molecular weight of the CPOs are relatively low - between approximately 9,000 - 50,000. Studies have shown that the CPO layer significantly improves adhesion of waterborne basecoat/acrylic clear coats; but, adhesion of the CPO layer with 2-component polyurethane coatings is poor (Ryntz, 2005). The CPO layer has been shown to increase the surface tension of the plastic substrate due to the presence of chlorine on the surface. The presence of chlorine has been demonstrated through the use of ESCA (XPS) spectroscopy (Ryntz, 2005).

Another development (Sonnenschein, 2008) has led to a new coating that does not require any surface pretreatments to achieve good adhesion to low surface energy substrates.

Sonnenschein and coworkers formulated a poly(acrylate/siloxane) hybrid adhesive, which results from the independent polymerization of silicone oligomers and acrylic monomers. The polymerization of the acrylic phase and adhesion promotion to plastics is catalyzed by decomplexation and oxidation of trialkylbornae-amine or -aminosilane complexes. Their results, along with many others, showed good adhesion to plastic substrates at temperatures from -40 to 
$150^{\circ} \mathrm{C}$. Another study (Hintze-Bruning, 2000) has shown the viability of non-halogenated aqueous coatings as adhesion promoters for PP. This was accomplished with the use of graft copolymers prepared by grafting acrylic acid to a PP backbone. The resultant copolymer is amphiphilic. PP segments have compatibility with the substrate, leaving a layer of acrylic acid rich surface to interact with a coating material.

Other researchers also found that halogen free aqueous adhesion promoters made from copolymers of acrylics and isotactic polypropylene adhered very well to multiple forms of copolymer propylene substrates (Hintze-Bruning, 2000). Hintze-Bruning and coworkers (2000) used 3 different substrates. Two of them were blends of PP with ethylene-propylene rubber (EPR): one was a soft blend with more EPR. The third substrate was PP copolymerized with ethylene. They tested two adhesion promoters: one was a thermomechanically degraded PP with isotactic PP and 5 mol\% ethylene comonomer. The second was degraded isotactc PP with 7 wt\% maleic anhydride. They found that adhesion with all three adhesion promoters was excellent for the maleated PP, while the adhesion with the ethylene containing PP was dependent on the substrates. The wetting angle of the different forms of copolymer adhesion promoters used played no part in the slight differences in adhesion. The ethylene containing adhesion promoter only adhered well to the softest substrate, which had the higher amount of EPR. Degradation products having a low molecular weight are formed during the graft process of the polypropylene that contained the copolymerized ethylene. These products cannot penetrate the more rigid substrates. They form a weak boundary layer on the surface, thus thwarting mechanical interlocking of the species having a sufficient high molecular weight with the substrate's polymers (HintzeBrunning, 2000). Applied on the softest substrate, the oligomeric degradation products penetrate into the surface-near EPR phase and/or they coalesce with the material that has been exuded from this substrate (Hintze-Brunning, 2000). Consequently, a weak boundary does not form and the interface requires a high force to peel off the coating. 


\subsection{Corona and Plasma Treatments}

Plasma and flame treatments are effective and allow for surface modification of the substrate without affecting the bulk properties (Carrino, 2002). A flame treatment is essentially a very fast and controlled intensive oxidation of the very thin surface layer of a polymer surface by flame. Plasma is an ionized gas containing both charged and neutral particles, such as electrons, ions, atoms, molecules, and radicals (Carrino, 2002). Inert gas plasmas (such as Ar) are used to help crosslink polymer surfaces. Reactive plasma treatments (such as $\mathrm{N}_{2}, \mathrm{NH}_{3}, \mathrm{O}_{2}, \mathrm{CF}_{4}$, and $\mathrm{SF}_{6}$ ) can be used to introduce functional groups (Carrino, 2002). In general, such treatments alter surfaces in one or more of the following ways:

(i) by removing the weak boundary layer (WBL)

(ii) by changing the surface topography

(iii) by changing the chemical nature of the surface

(iv) by modifying the physical structure (Carrino, 2004).

Green and others (Green, 2002) found that surface pretreatments are especially effective on polyolefins such as polypropylene, which is the polymer being investigated in this study. It was found that corona discharge, flame, fluorination, vacuum plasma, and air plasma were all highly effective in increasing adhesion. The listed pretreatments added functional groups to the surface or caused molecular modification at different depths of the surface. Functional groups reported to aid adhesion at the surface of polymers such as $\mathrm{PP}$ include $\mathrm{C}=\mathrm{O}$, in particular, but also $\mathrm{CO} \sim$, $\mathrm{COO} \sim, \sim \mathrm{OH}$ and $\sim \mathrm{OOH}$ (Awaja, 2009). The pretreatments also can modify the surface topography of the polypropylene, roughening the surface as to create more point for molecular "hooking." The flame treatment is ideal for roughening the surface.

The mechanisms that are responsible for improving adhesion by these methods have been studied intensively for years, but there has not been one definitive explanation. The most widely accepted theories include:

(i) mechanical interlocking, or "hooking" 
(ii) molecules from the adhesive being attracted to a spot on the surface of the substrate and reacting with it

(iii) diffusion

(iv) electrostatic attraction caused by electron transfer at the surface.

A comprehensive comparison of 13 industrial pretreatments of PP has been published (Green, 2002).

Although flame and plasma treatments are well suited for introducing functional groups to achieve better adhesion, an aging affect must be taken into account for treated substrates. Aging can lead to chalking, crack formation, discoloring, and most importantly, loss of adhesion. Uptake of environmental contaminants, re-orientation of surface groups, and further chemical reactions at the surface with time (Awaja, 2009) can revert the increase in adhesion gained by the surface treatment. Some studies (Awaja, 2009) have suggested that this is due to the newly formed polar molecules reorienting themselves into the bulk material. Another theory suggests that the polar chemical groups diffuse into the polymer matrix, a side effect being surface degradation through the rapid interaction of the polymer with radicals or ions. It has also been suggested that the bulk material plays a role, but further research is needed to examine the polymer sub-surface layers and explain their effect on surface properties.

\subsection{Coatings for polypropylene}

Although there are few commercial suppliers of coatings for polypropylene (such as Kalcor Coatings Company), literature on coating compositions applicable to polypropylene is very limited. Available patents (Bugajski, 1998; Wang, 2001) and other literature (Lawniczak, 1993 \& 2005) relate mostly to the adhesion promoter coatings based on chlorinated polyolefins CPOs. Research has shown that waterborne coating systems that perform well on polypropylene are treated with CPOs, but no corona or plasma treatment. It is also the current trend to move away from solvent based systems, since VOC regulations continue to become stricter. Incorporation of adhesion promoters additives to the coating is certainly a viable option. 
Although no open literature could be found on this topic, an extended review of such additives for coatings has been published (Sathyanarayana, 1995). 


\section{Materials and Methods}

\subsection{Coating Characterization}

A stainless steel pycnometer was used to determine the coating density in pounds per gallon, according to the procedure outlined in ASTM D1475-98. The percent of solids by weight was determined according to ASTM D2369-07. To determine the percent solids by weight, an aluminum pan was weighed and approximately $0.5 \mathrm{~g}$ of paint was added and weighed, and $3 \mathrm{~mL}$ of deionized water was added to each pan. All samples were then placed in an oven at $110^{\circ} \mathrm{C}$ for exactly 1 hour. The weight of the paint and the pan was then recorded after heating and the percent solids by weight was determined.

The volatile organic compound (VOC) levels were determined according to ASTM D6886-03. HPLC grade methanol was used as the solvent for sample preparation. An Agilent GC/MS/FID was used.

Viscosity versus shear rate data were obtained at shear rates from $0.02 \mathrm{~s}^{-1}$ to $200 \mathrm{~s}^{-1}$ with 10 points per decade at $25^{\circ} \mathrm{C}$. A continuous ramp method was also used with times of $2,5,10$, and 20 minutes. All measurements were taken with a TA Instruments AR 2000 Rheometer using a cone-and-plate geometry.

\subsection{Oven Temperature Profiling}

A Despatch LFD Series Oven was used for sample drying throughout this study. Timed drying was done throughout the study and it is important to have accurate knowledge of the time each sample was dried. Because of this, oven temperature profiling was done to determine the amount of heat lost with the opening and closing of the door when samples are placed inside.

A Vernier Stainless Steel Temperature Probe was used with Vernier Logger Lite software for time versus temperature data collection. The Despatch LFD Series oven was used at $60{ }^{\circ} \mathrm{C}$ and $70^{\circ} \mathrm{C}$. Blank glass plates were used to simulate samples. 
The oven and probe were allowed to reach a given temperature before testing. The oven door was opened, the glass plate was inserted, and the oven door was closed. When the door closed, temperature data collection as a function of time began.

The probe was placed in four different locations on the top shelf of the oven: in the center of the shelf with the glass plate to one side, against the back of the shelf, at the front of shelf, and again in the center of the shelf with the glass plate behind the probe against the back wall.

\subsection{Determination of Solvent Retention with Thermogravimetric Analysis}

Thermogravimetric analysis (TGA) was used to compare the amount of retained solvent for different drying times and different coating film thicknesses. A TA Instruments Q 500 TGA was used with aluminum pans and heated at a rate of $20^{\circ} \mathrm{C}$ per minute from ambient temperature to $590^{\circ} \mathrm{C}$.

\subsubsection{Room Temperature Drying}

Initial solvent retention tests were conducted using draw-downs made on glass plates at a wet film thickness of 3 mil. A series of samples were dried for 1-11 days at room temperature; another sample was dried for 24 hours at $70{ }^{\circ} \mathrm{C}$ in a Despatch LFD Series Oven. All samples were then tested using the TGA procedure described above.

\subsubsection{Simulation of Factory Drying}

An additional test using the Despatch LFD Series Oven was conducted to simulate the factory drying conditions employed at CertainTeed. Draw-downs on glass plates with a wet film thickness of 3 mil were made, allowed to air dry for two minutes, and then placed into the $60{ }^{\circ} \mathrm{C}$ or $70^{\circ} \mathrm{C}$ oven. Different sets of samples were allowed to dry in the oven for 3 or 5 minutes. Three replicates of each drying time were done for each temperature. Only one sample was in the oven at a time. Samples were tested using the TGA procedure described above after 30 minutes and again after 24 hours. 


\subsubsection{Effect of Film Thickness on Drying}

To determine the effect of film thickness on solvent retention, draw-downs were made on glass plates with a wet film thickness of 1.5, 2, or 3 mil. Each sample was allowed to air dry for two minutes and then dried at $70{ }^{\circ} \mathrm{C}$ for 3 or 5 minutes in a Despatch LFD Series Oven. Duplicates were made for each sample. Samples were tested using the TGA procedure described above after 30 minutes and again after 24 hours.

8.3.4. Extended Room Temperature Drying of Samples Dried Under Factory Simulated Conditions

A final set of films were made to complete the solvent retention measurements. Drawdowns on glass plates with a wet film thickness of 3 mil were made, allowed to air dry for two minutes, and then placed into a Despatch LFD Series Oven at $70{ }^{\circ} \mathrm{C}$ for 3 minutes. Samples were tested using the TGA procedure described above after 30 minutes, 1 day, 2 days, 3 days, 6 days, and 7 days. From this data, the weight percent lost at select temperatures $\left(50{ }^{\circ} \mathrm{C}, 100{ }^{\circ} \mathrm{C}, 150^{\circ} \mathrm{C}\right.$, and $200^{\circ} \mathrm{C}$ ) was determined for each day.

\subsection{Pendulum Hardness Testing}

Pendulum hardness testing was used to compare the effect of retained solvents on the hardness of the film. The samples described in section 8.3.1 with varying film thicknesses and drying times were used in this study. A Byk Gardner pendulum hardness tester was used in the Konig setting, which measures the time taken for the pendulum amplitude to decrease from $6^{\circ}$ to $3^{\circ}$. Six data points were obtained for each sample after 30 minutes and again after 24 hours.

\subsection{Dry Film Thickness Measurements}

Dry film thickness was determined for the films used in pendulum hardness testing using an optical microscope with 100x magnification. The differences in focus travel between the glass plate surface and the top of the film were determined in 5 different locations of the film and glass plate. The magnification differences were calibrated using a standard glass slide with a known thickness of $1016 \mu \mathrm{m}$. 


\subsection{Adhesion Testing}

Adhesion testing was conducted using polypropylene panels supplied by CertainTEED. Each panel was corona treated using a UVSP Dyne Laboratories Corona Treatr no. N001-020 for $0,5,15$, or 30 seconds. Treated panels had 7 to 8 consecutive treatment areas, identified by black pen marks. Immediately following Corona treatment, the panels were coated. For each length of Corona treatment, four panels were made. Two panels were allowed to dry at room temperature for 24 hours, and two panels were dried for 5 minutes at $70^{\circ} \mathrm{C}$ in a Despatch LFD Series oven prior to drying at room temperature for 24 hours.

Dried panels were tested for differences in adhesion according to ASTM D3359. A BykoCut Universal tool was used with the cross-cut tool attachment. Scotch Tape 375 was used throughout the test. The adhesion scale specified by ASTM D3359 ranks adhesion based on visual assessment, and ranks the samples on a scale from $0 \mathrm{~B}$ to $5 \mathrm{~B}$, with $0 \mathrm{~B}$ representing no adhesion and 5B representing complete adhesion. 


\section{Results and Discussion}

\subsection{Coating Characterization}

The water-reducible coating for polypropylene sample provided by CertainTeed was characterized in order to compare with other samples that may be used in future work related to this project. Table 9.1 shows the results for density, percent solid by weight, and VOC measurements. The density is shown in both weight per gallon and grams per liter units. The VOC results show that there is solvent present within the coating. The MSDS provided by CertainTeed for this coating lists dipropylene glycol monobutyl ether as a solvent. This solvent has a boiling point of $230^{\circ} \mathrm{C}$.

Table 9.1: Characterization Results for CertainTeed Water Reducible Coating.

\begin{tabular}{|c|c|c|c|c|c|c|}
\hline & WPG & density $(\mathrm{g} / \mathrm{L})$ & $\begin{array}{l}\text { solids wt. } \\
\text { fraction }\end{array}$ & \multicolumn{3}{|c|}{ VOC (ASTM D6886; g/L) } \\
\hline Coating A & 9.1 & 1090 & 0.365 & $\begin{array}{l}\text { run } 1 \\
\text { run } 2\end{array}$ & $\begin{array}{c}\text { coating } \\
\text { VOC } \\
270 \\
250\end{array}$ & $\begin{array}{c}\text { material } \\
\text { VOC } \\
110 \\
100\end{array}$ \\
\hline Coating B & 9.2 & 1110 & 0.366 & & & \\
\hline
\end{tabular}

Figures 9.1 and 9.2 show viscosity as a function of shear rate results. The results in Figure 9.1 show considerable scatter and repeated attempts to generate clean results failed. Upon examination of the sample following testing, dried paint was seen around the edges of the coneand-plate fixture. It takes approximately 40 minutes for this test to be completed. To prevent drying, rheology testing was completed in the continuous ramp mode, scanning the shear rate range in shorter lengths of time $(2,5,10$, and 20 minutes). The results of this experiment are shown in Figure 9.2. 


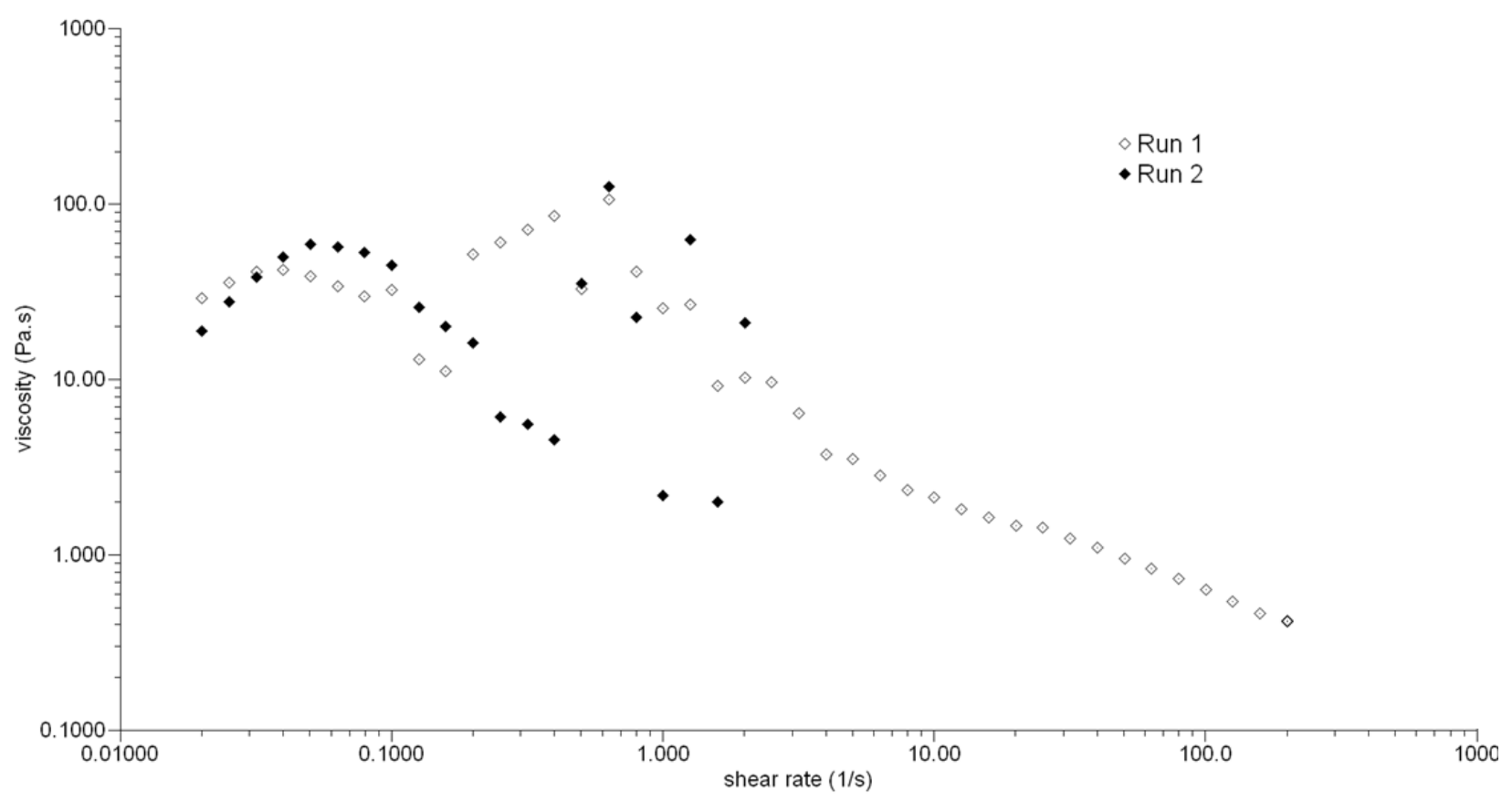

Figure 9.1: Rheology Results for Water-Reducible Coating Supplied by CertainTeed.

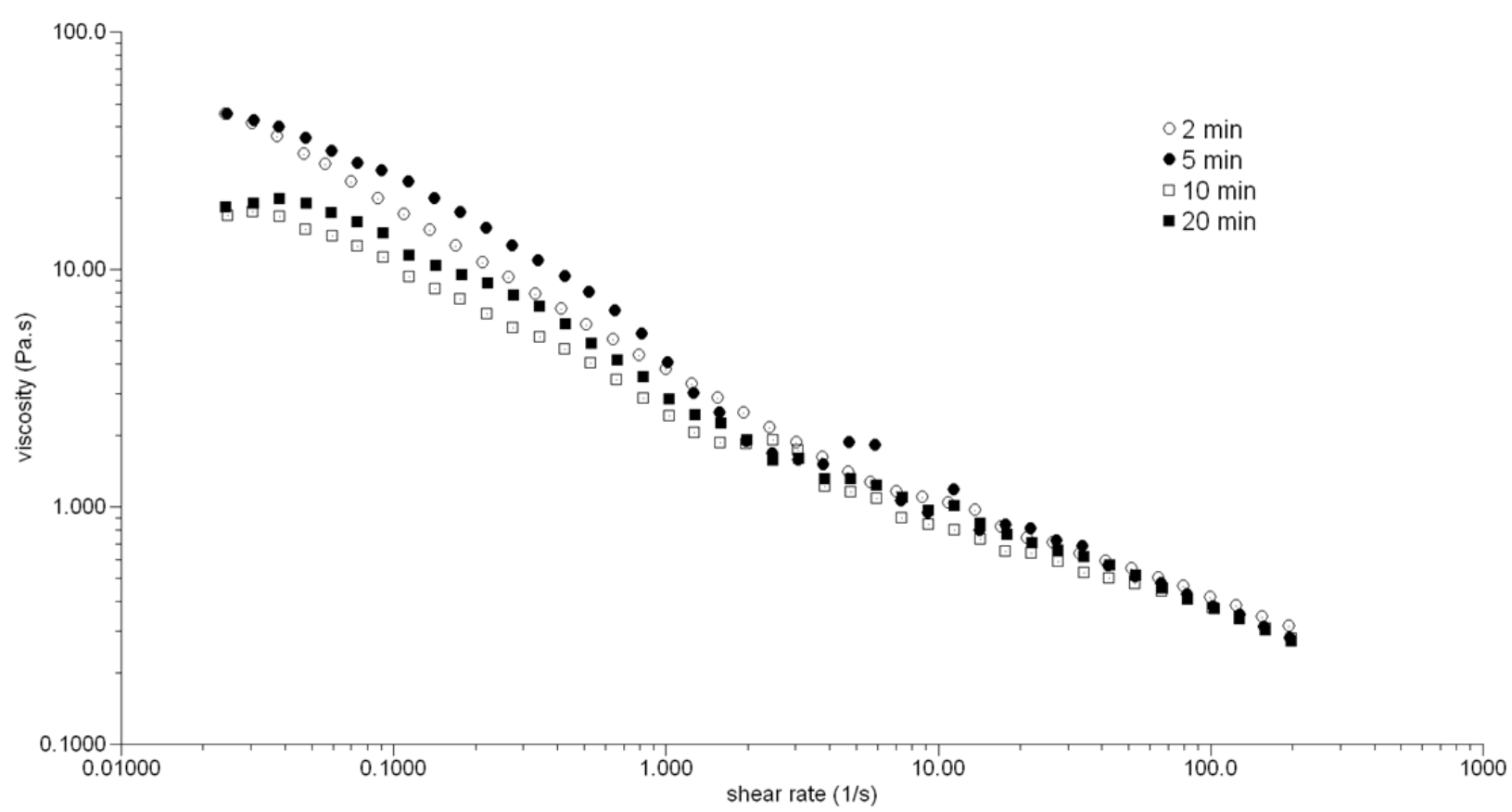

Figure 9.2: Continuous Ramp Rheology Results for Water-Reducible Coating Supplied by CertainTeed. 


\subsection{Oven Temperature Profiling}

Figures 9.3 and 9.4 show the temperature versus time results for $60{ }^{\circ} \mathrm{C}$ and $70{ }^{\circ} \mathrm{C}$ experiments, respectively. In these plots, the red line represents the measurements where the probe was in the center of the shelf with the glass plate to one side, the blue line shows data for the probe against the back shelf, the green line shows data for the probe at the front of the shelf, and the orange line shows data from the center of the shelf with the glass plate behind the probe. Table 9.2 shows the minimum and maximum temperatures as well as the average temperature. The colors listed within the table correspond to the data presented in the graphs.

From these results it can be seen that the temperature change that occurs while inserting

the sample into the oven is small, $\pm 2{ }^{\circ} \mathrm{C}$, and generally occurs to a lesser extent at the back of the oven. The temperature came to equilibrium after approximately 30 seconds in all measurements, with the smallest change occurring when the sample was farthest from the oven door. As a result of this data, it was decided that placing the sample against the back wall of the oven is the best way to provide a consistent drying temperature for future samples. 


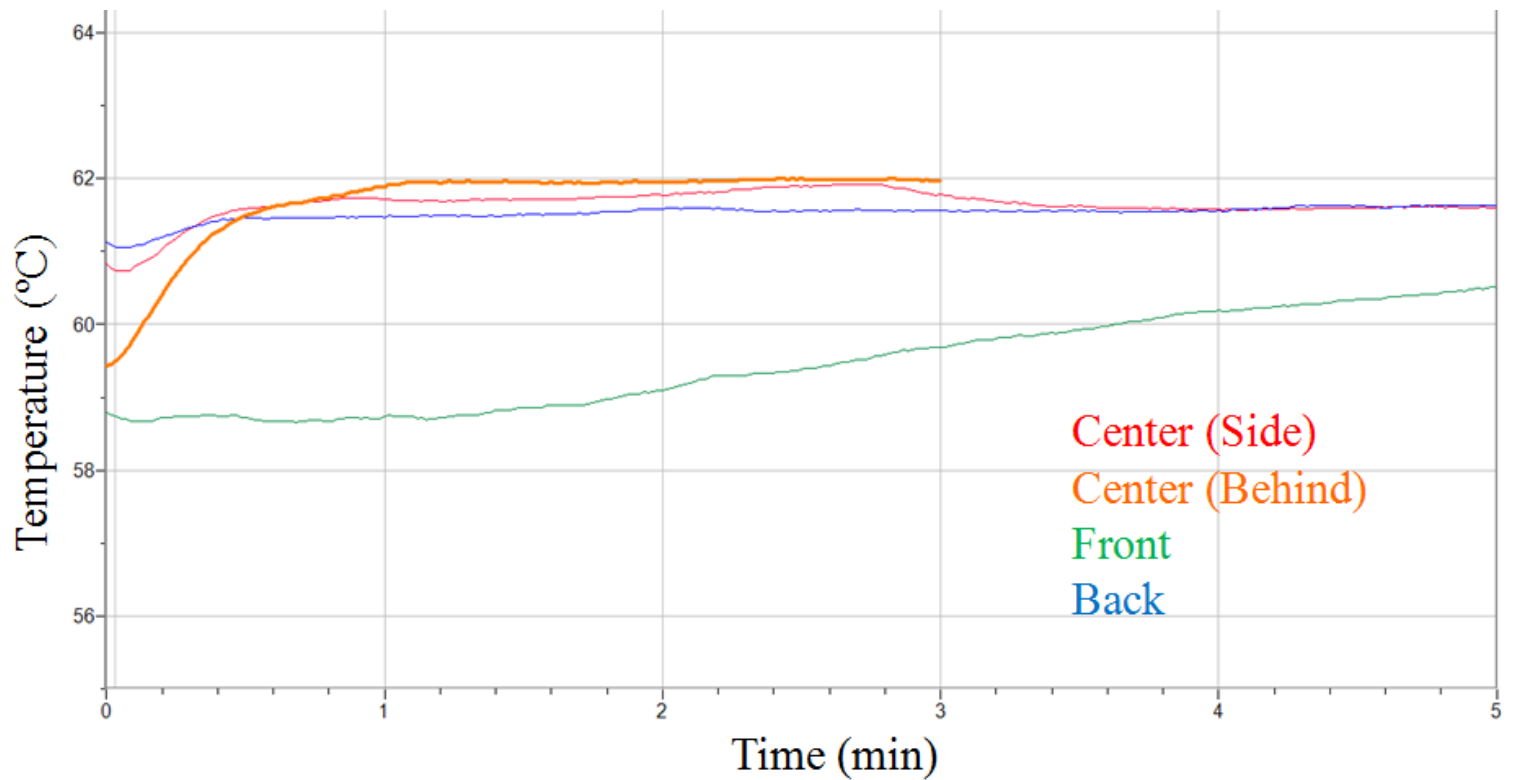

Figure 9.3: Oven Temperature Profiling Results at $60^{\circ} \mathrm{C}$.

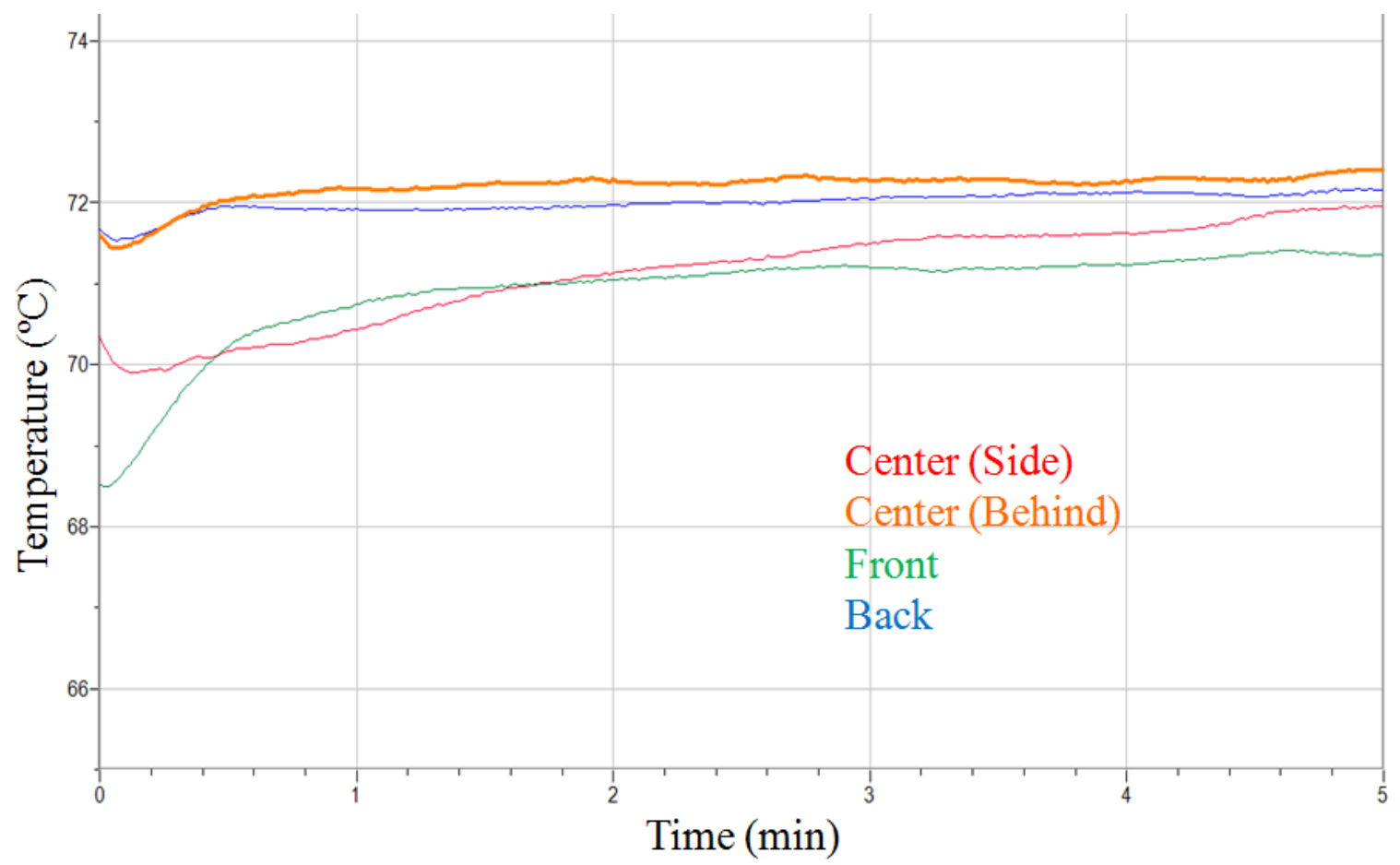

Figure 9.4: Oven Temperature Profiling Results at $70^{\circ} \mathrm{C}$. 
Table 9.2: Minimum, Maximum, and Average Temperature Values from Oven Temperature Profiling Experiments.

\begin{tabular}{|l|l|l|l|l|}
\hline & & $\min \left({ }^{\circ} \mathrm{C}\right)$ & $\max \left({ }^{\circ} \mathrm{C}\right)$ & average $\left({ }^{\circ} \mathrm{C}\right)$ \\
\hline \multirow{3}{*}{$60^{\circ} \mathrm{C}$} & center-side (red) & 60.73 & 61.93 & 61.65 \\
& back (blue) & 61.05 & 61.64 & 61.52 \\
& front (green) & 58.66 & 60.51 & 59.45 \\
& center-behind (orange) & 59.43 & 62.01 & 61.69 \\
\hline \multirow{3}{*}{$70^{\circ} \mathrm{C}$} & center-side (red) & 69.90 & 71.96 & 71.14 \\
& back (blue) & 71.53 & 72.17 & 72.00 \\
& front (green) & 68.50 & 71.41 & 70.91 \\
& center-behind (orange) & 71.45 & 72.41 & 72.20 \\
\hline
\end{tabular}

\subsection{Thermogravimetric Analysis Results}

All TGA data presented in this section includes a sample dried for 24 hours at $70{ }^{\circ} \mathrm{C}$.

Previous work completed at Cal Poly has shown that this is a completely dried sample with no remaining solvent.

\subsubsection{Room Temperature Drying and Simulation of Factory Drying}

Figure 9.5 shows a TGA scan comparison of the coating applied on glass plates at a 3 mil wet film thickness and dried for various lengths of time at room temperature and at $70{ }^{\circ} \mathrm{C}$. Generally the weight percent loss before $300{ }^{\circ} \mathrm{C}$ was greatest for samples with the shortest length of drying time. It is reasonable to assume that weight loss up to $100{ }^{\circ} \mathrm{C}$ is due to water, and weight loss up to $250^{\circ} \mathrm{C}$ is due to solvent. All weight lost after this point is assumed to be degradation of the polymer in the coating. The remaining $30 \%$ of the weight of the coating is assumed to be inorganic material. From this data it can be said that the amount of retained solvent decreases over time. It can also be seen that room temperature drying for 11 days is comparable to the completely dried sample (24 hours at $\left.70{ }^{\circ} \mathrm{C}\right)$.

Figures 9.6 and 9.7 show the TGA results of the samples dried for 3 and 5 minutes at $60{ }^{\circ} \mathrm{C}$ and $70{ }^{\circ} \mathrm{C}$, respectively, after 30 minutes and after 24 hours. These plots follow weight percent loss trends similar to those described above. From this data it can be seen that the samples tested 30 minutes after being taken out of the oven contain more solvent than the sample that was dried for 24 hours at room temperature. 


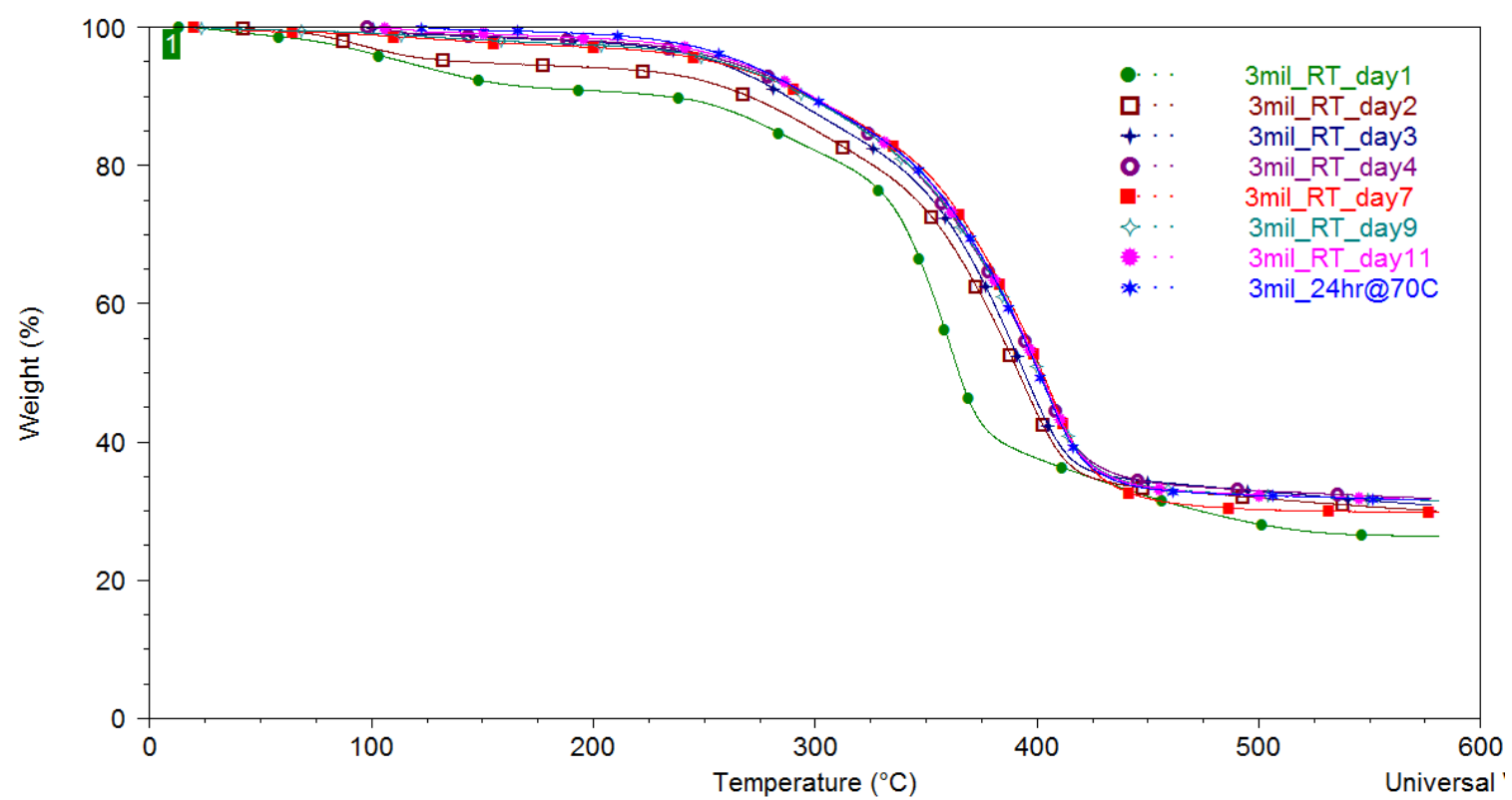

Figure 9.5: TGA Results for 3 mil Film at Different Room Temperature Drying Times.

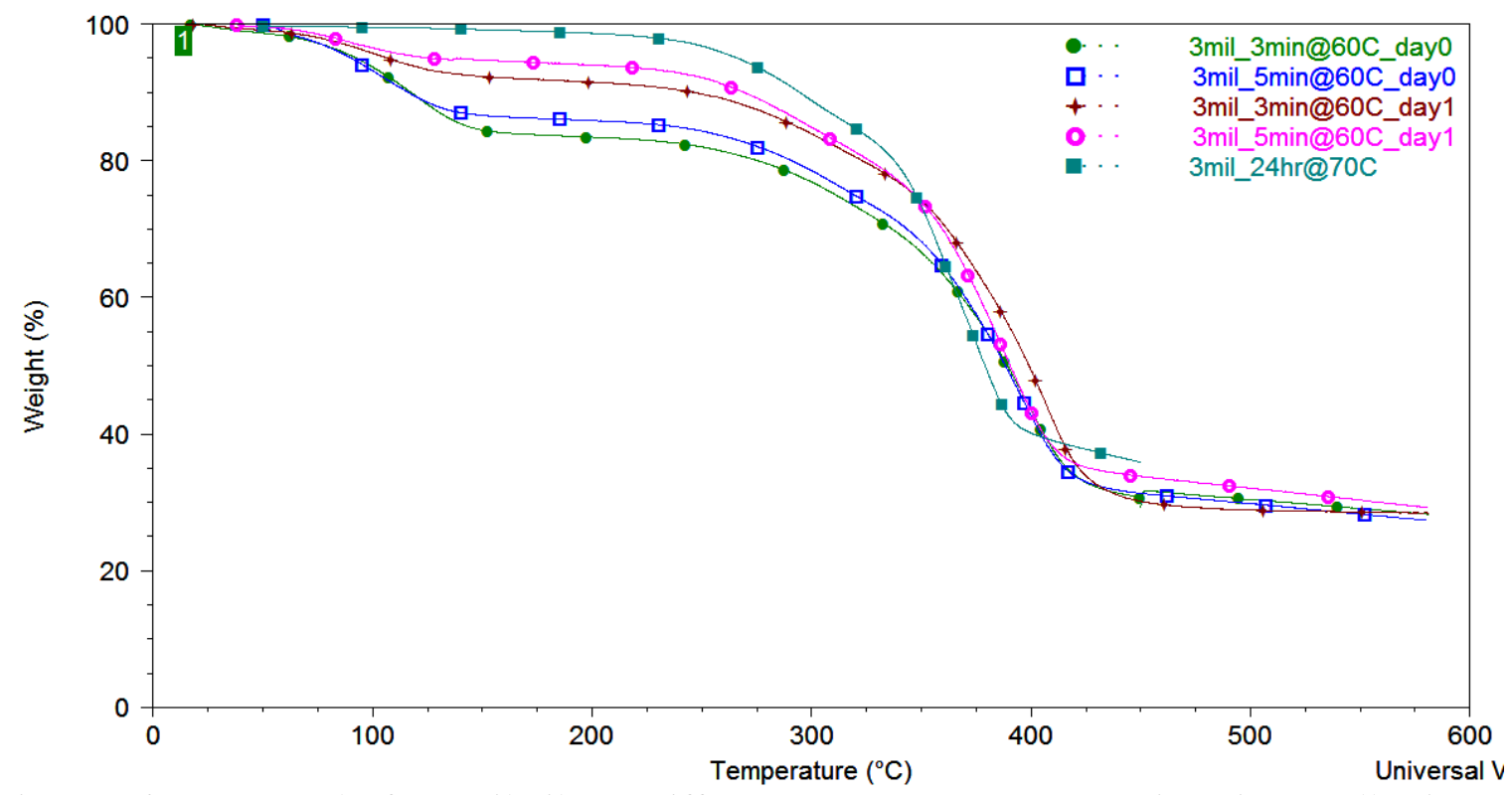

Figure 9.6: TGA Results for 3 mil Film at Different Room Temperature Drying Times Following Oven Drying at $60^{\circ} \mathrm{C}$ for 3 or 5 Minutes. 


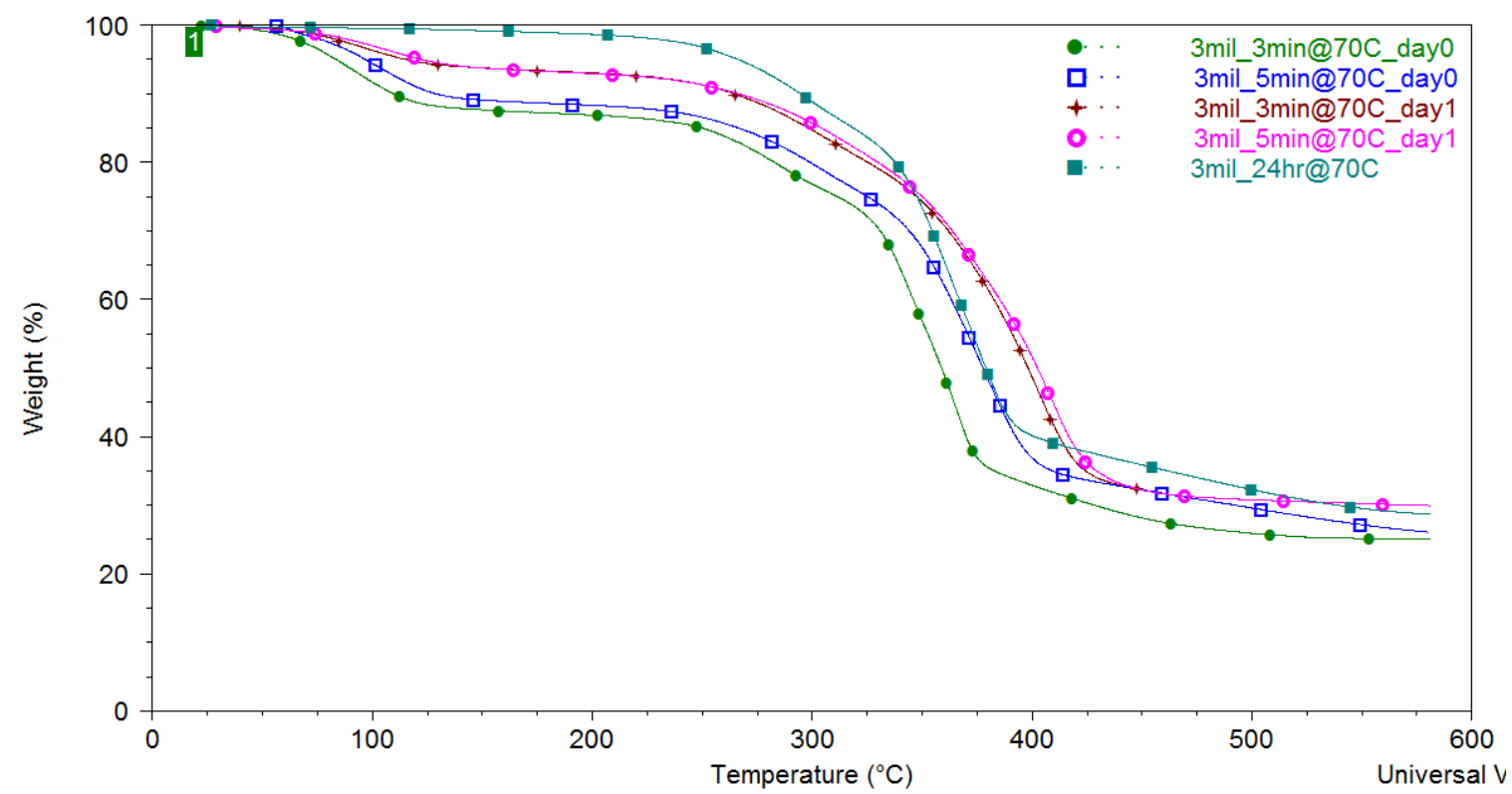

Figure 9.7: TGA Results for 3 mil Film at Different Room Temperature Drying Times Following Oven Drying at $70{ }^{\circ} \mathrm{C}$ for 3 or 5 Minutes.

\subsubsection{Effect of Film Thickness on Drying}

Figures 9.8 and 9.9 show TGA scans of the coating film samples with varying thicknesses, 30 minutes and 24 hours after the samples were removed from the oven. Again, the samples show weight loss at $100{ }^{\circ} \mathrm{C}$ and approximately $230{ }^{\circ} \mathrm{C}$ where water and solvent are lost, respectively. From these data sets it can be seen that, with the same drying time, the weight percent lost below $300{ }^{\circ} \mathrm{C}$ increases with increasing film thickness.

9.3.3. Extended Room Temperature Drying of Samples Dried Under Factory Simulated Conditions

Figure 9.10 shows the results of a drying time study for three 3 mil draw-downs of the coating. The samples were oven dried in an Despatch LFD Series Oven for 3 minutes at $70{ }^{\circ} \mathrm{C}$ and TGA was run after 30 minutes, 1 day, 2 days, 3 days, 6 days, and 7 days. Table 9.3 shows the weight percent lost at select temperatures for each day. The weight loss followed the same trend as the other TGA plots, with water removed from the samples at $100{ }^{\circ} \mathrm{C}$ and solvent removed from the samples at approximately $230^{\circ} \mathrm{C}$. From this data it can be seen that after approximately three days of room temperature drying the sample has reached complete drying. 


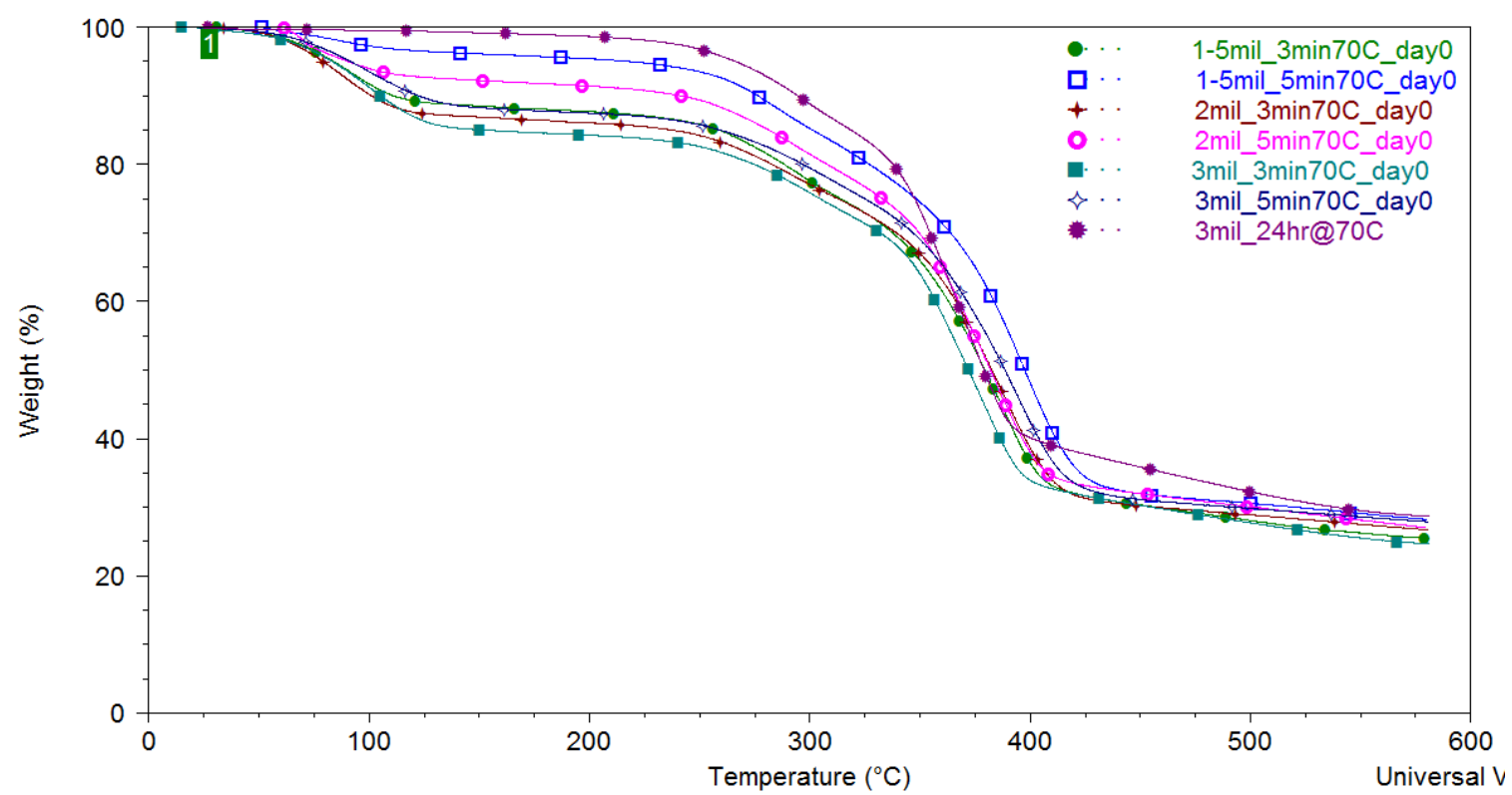

Figure 9.8: TGA Results for Films Having Varying Thickness, 30 Minutes After Oven Drying at $70{ }^{\circ} \mathrm{C}$ for 3 or 5 Minutes.

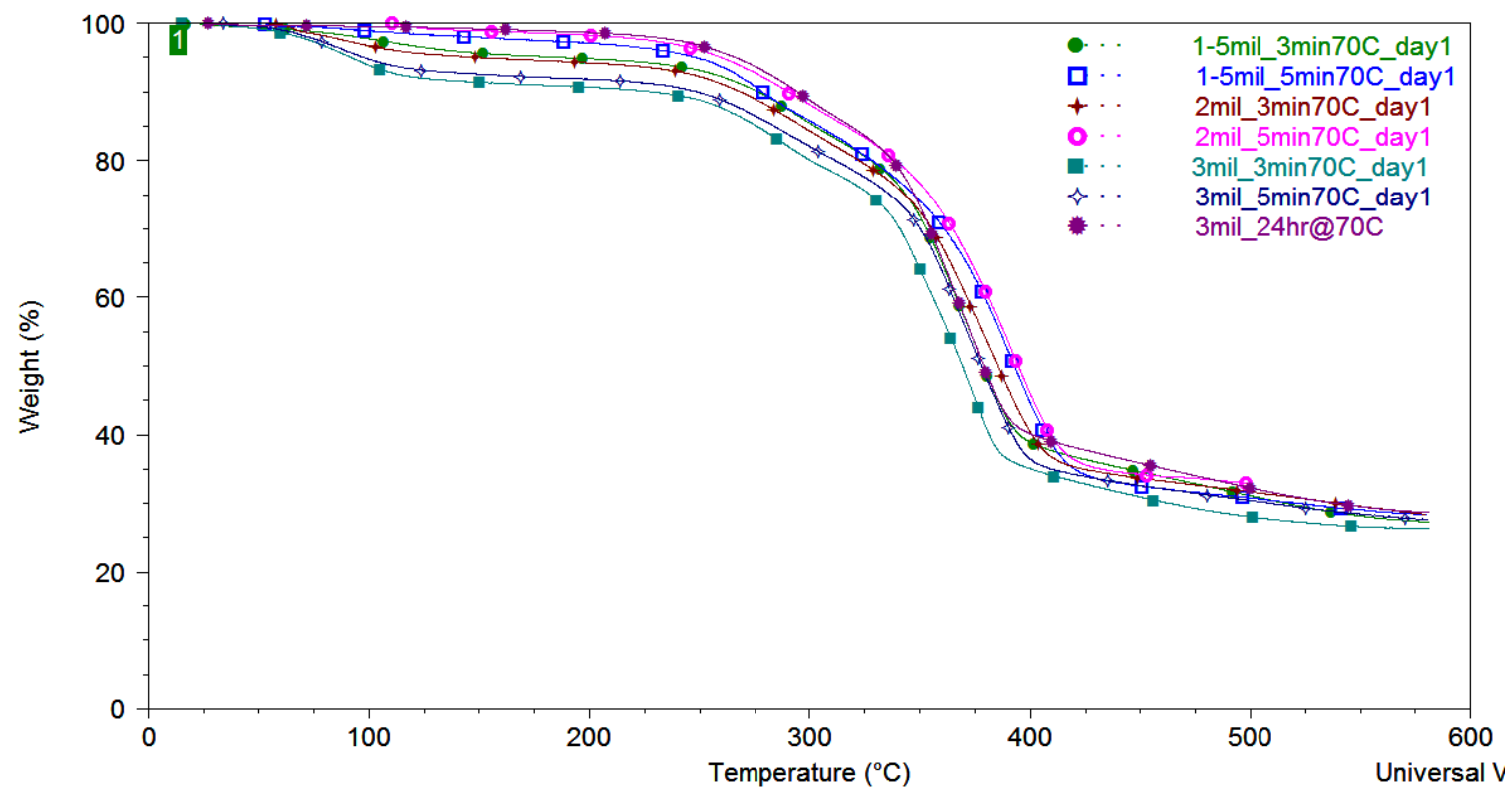

Figure 9.9: TGA Results for Films Having Varying Thickness, 24 Hours After Oven Drying at $70{ }^{\circ} \mathrm{C}$ for 3 or 5 Minutes. 


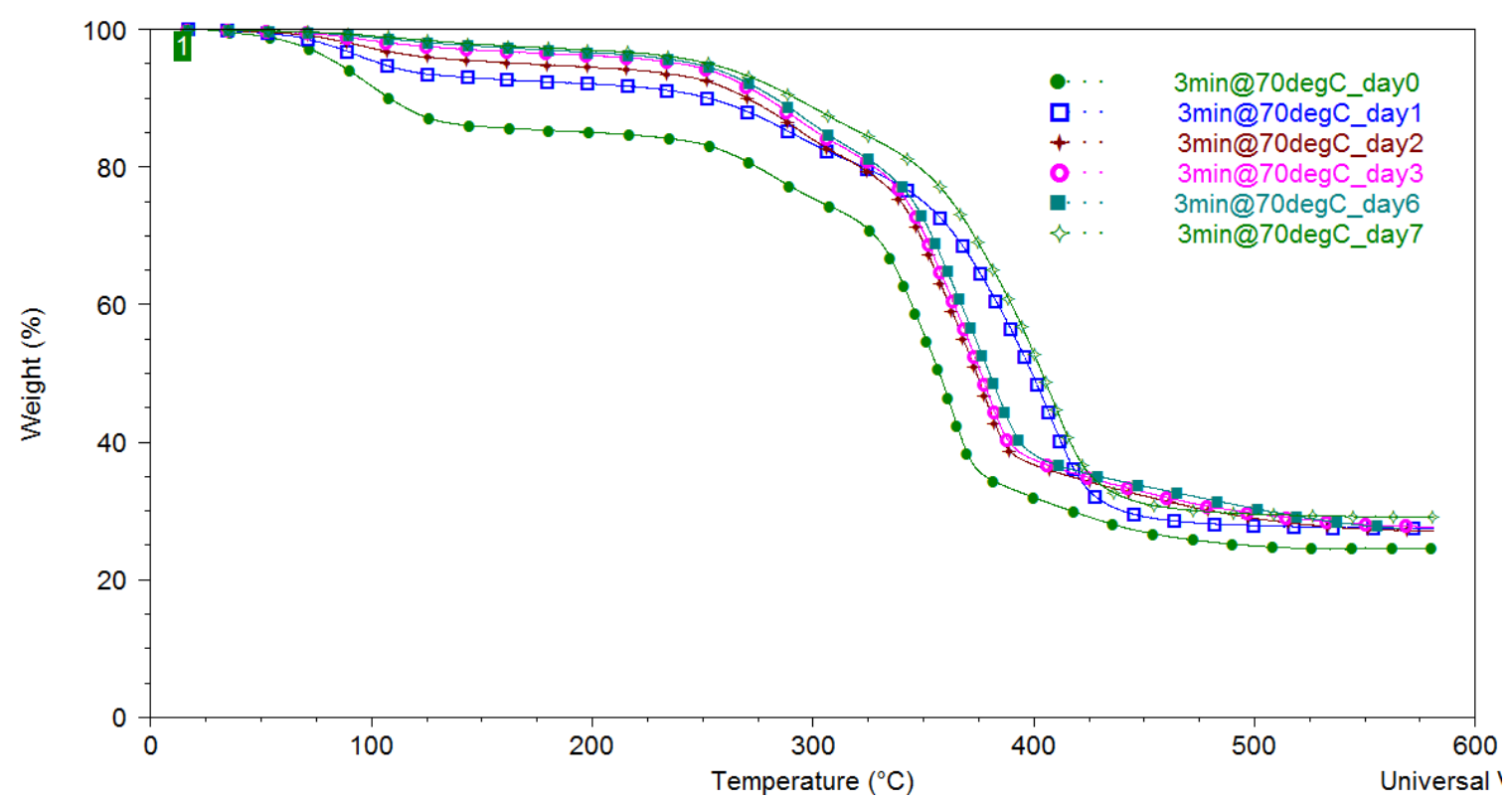

Figure 9.10: TGA Results for 3 mil Film at Different Room Temperature Drying Times Following Oven Drying at $70{ }^{\circ} \mathrm{C}$ for 3 Minutes.

Table 9.3: Sample Weight Loss Percent at Select Temperatures, Based on Results in Figure 9.10.

\begin{tabular}{|c|cccc|}
\hline & $50^{\circ} \mathrm{C}$ & $100^{\circ} \mathrm{C}$ & $150^{\circ} \mathrm{C}$ & $200{ }^{\circ} \mathrm{C}$ \\
\hline day 0 & 0.92 & 8.2 & 14 & 15 \\
day 1 & 0.47 & 4.5 & 7.1 & 7.9 \\
day 2 & 0.33 & 2.7 & 4.6 & 5.5 \\
day 3 & 0.22 & 1.6 & 3.0 & 3.8 \\
day 6 & 0.24 & 1.1 & 2.5 & 3.3 \\
day 7 & 0.19 & 0.91 & 2.2 & 3.0 \\
\hline
\end{tabular}

\subsection{Pendulum Hardness Testing Results}

Table 9.4 contains the results obtained from the pendulum hardness testing. In this table the six data points are shown for each sample after 30 minutes and after 24 hours, along with the calculated average hardness and the standard deviation. In this test a higher number represents a harder sample.

From this data it can be seen that there is a noticeable difference between the 3 and 5 minute drying times 30 minutes after being out of the oven for each film thickness, but this difference is not seen after the samples have been out of the oven for 24 hours. This data also shows that the 1.5 mil wet thickness film shows the greatest amount of inconsistency in both sets 
of measurements. Thickness variation as a percent of thickness is high in thin films and could have affected the hardness testing results.

Generally this data agrees with the TGA results. It is expected that thin films will have less retained solvent and be harder than thicker films. This was also seen in the weight percent loss in the TGA results (Figures 9.8 - 9.9). 
Table 9.4: Pendulum Hardness Testing Results for A. 30 Minutes After Drying, and B. 24 Hours After Drying of CertainTeed Water Reducible Coating.

\begin{tabular}{|c|c|c|c|c|}
\hline A. $30 \mathrm{~min}$ & & & Average & $\begin{array}{c}\text { Standard } \\
\text { Deviation }\end{array}$ \\
\hline \multirow{4}{*}{$1.5 \mathrm{mil}$} & \multirow{2}{*}{$3 \min @ 70^{\circ} \mathrm{C}$} & Sample 1 & 58.8 & 6.55 \\
\hline & & Sample 2 & 46.5 & 1.87 \\
\hline & \multirow{2}{*}{$5 \min @ 70^{\circ} \mathrm{C}$} & Sample 1 & 60.2 & 5.12 \\
\hline & & Sample 2 & 57.8 & 5.19 \\
\hline \multirow{4}{*}{$2 \mathrm{mil}$} & \multirow{2}{*}{$3 \min @ 70^{\circ} \mathrm{C}$} & Sample 1 & 32.2 & 0.75 \\
\hline & & Sample 2 & 28.3 & 0.82 \\
\hline & \multirow{2}{*}{$5 \min @ 70^{\circ} \mathrm{C}$} & Sample 1 & 36.3 & 0.52 \\
\hline & & Sample 2 & 33.7 & 0.52 \\
\hline \multirow{4}{*}{3 mil } & \multirow{2}{*}{$3 \min @ 70^{\circ} \mathrm{C}$} & Sample 1 & 26.5 & 0.84 \\
\hline & & Sample 2 & 40.7 & 3.56 \\
\hline & \multirow{2}{*}{$5 \min @ 70^{\circ} \mathrm{C}$} & Sample 1 & 34.7 & 1.51 \\
\hline & & Sample 2 & 31.8 & 3.37 \\
\hline
\end{tabular}

\begin{tabular}{|c|c|c|c|c|}
\hline B. $24 \mathrm{hr}$ & & & Average & $\begin{array}{c}\text { Standard } \\
\text { Deviation }\end{array}$ \\
\hline \multirow{4}{*}{$1.5 \mathrm{mil}$} & \multirow{2}{*}{$3 \min @ 70^{\circ} \mathrm{C}$} & Sample 1 & 59.8 & 7.49 \\
\hline & & Sample 2 & 45.5 & 1.22 \\
\hline & \multirow{2}{*}{$5 \min @ 70^{\circ} \mathrm{C}$} & Sample 1 & 55.7 & 7.87 \\
\hline & & Sample 2 & 53.5 & 5.17 \\
\hline \multirow{4}{*}{2 mil } & \multirow{2}{*}{$3 \min @ 70^{\circ} \mathrm{C}$} & Sample 1 & 44.5 & 1.52 \\
\hline & & Sample 2 & 46.5 & 1.05 \\
\hline & \multirow{2}{*}{$5 \min @ 70^{\circ} \mathrm{C}$} & Sample 1 & 44.8 & 1.72 \\
\hline & & Sample 2 & 44.2 & 0.41 \\
\hline \multirow{4}{*}{$3 \mathrm{mil}$} & \multirow{2}{*}{$3 \min @ 70^{\circ} \mathrm{C}$} & Sample 1 & 41.5 & 1.38 \\
\hline & & Sample 2 & 46.5 & 2.74 \\
\hline & \multirow{2}{*}{$5 \min @ 70^{\circ} \mathrm{C}$} & Sample 1 & 43.2 & 1.33 \\
\hline & & Sample 2 & 44.7 & 1.03 \\
\hline
\end{tabular}

\subsection{Dry Film Thickness Measurements}

Table 9.5 shows the results of the dry film thickness determination. The samples used were the samples used in both the film thickness variation TGA testing and the pendulum hardness testing. The glass slide used had a thickness of $1016 \mu \mathrm{m}$. From this information it was determined that each unit of focus corresponded to $1.6 \mu \mathrm{m}$. Film thickness was calculated using 
this information and is shown in the table, along with the average film thickness for each sample and the standard deviation.

Table 9.5: Dry Film Thickness Determination Using Optical Microscope.

\begin{tabular}{|c|c|c|c|c|c|}
\hline & & & $\begin{array}{l}\text { Average } \\
\text { Reading }\end{array}$ & $\begin{array}{c}\text { Average } \\
\text { Thickness }(\mu \mathrm{m})\end{array}$ & $\begin{array}{l}\text { Standard } \\
\text { Deviation }\end{array}$ \\
\hline & & Sample 1 & 17.4 & 27.53 & 4.98 \\
\hline $1.5 \mathrm{mil}$ & $3 \min @ 70^{\circ}$ & Sample 2 & 17.6 & 27.84 & 11.89 \\
\hline$(38.1 \mu \mathrm{m})$ & $5 \mathrm{~min} \Omega 70^{\circ} \mathrm{C}$ & Sample 1 & 15 & 23.73 & 3.32 \\
\hline & J & Sample 2 & 24 & 37.97 & 5.87 \\
\hline & $2 \min \Omega 70^{\circ} \mathrm{C}$ & Sample 1 & 31.2 & 49.36 & 4.38 \\
\hline 2 mil & s mm @ @ & Sample 2 & 38.2 & 60.43 & 16.21 \\
\hline$(50.8 \mu \mathrm{m})$ & $5 \min @ 70^{\circ} \mathrm{C}$ & Sample 1 & 49.6 & 78.47 & 34.14 \\
\hline & J ImIn! & Sample 2 & 53.4 & 84.48 & 10.64 \\
\hline & $3 \min \Omega 70^{\circ} \mathrm{C}$ & Sample 1 & 34 & 53.79 & 22.10 \\
\hline 3 mil & उ & Sample 2 & 29.4 & 46.51 & 10.33 \\
\hline$(76.2 \mu \mathrm{m})$ & $5 \mathrm{~min} @ 70^{\circ} \mathrm{C}$ & Sample 1 & 31.6 & 49.99 & 5.22 \\
\hline & mm @ & Sample 2 & 46 & 72.77 & 19.22 \\
\hline $\begin{array}{l}\text { glass slide } \\
\text { measured) }\end{array}$ & $016 \mu \mathrm{m}$ thick, & & 642.2 & 1016 & 15.77 \\
\hline
\end{tabular}

\subsection{Adhesion Testing}

Corona treatment successfully increased the surface tension of polypropylene to a maximum of 40 dynes/cm after treatment for 120 seconds, as seen in Table 9.6. The surface tension was measured using AccuDyne Test dyne solutions supplied by Diversified Enterprises. The dyne solutions ranged from 30-42 dynes/cm (in intervals of 2 dynes $/ \mathrm{cm}$ ) and were used to compare the surface energy before and after treatment.

Table 9.6: Effect of Corona Treatment Time on Surface Tension. 


\begin{tabular}{|c|c|}
\hline Time (Seconds) & Surface Tension (dynes/cm) \\
\hline 0 & $<30$ \\
5 & 36 \\
10 & 37 \\
15 & 38 \\
20 & 38 \\
25 & 38 \\
30 & 38 \\
40 & 38 \\
60 & 38 \\
120 & 40 \\
\hline
\end{tabular}

Adhesion testing revealed that the increase in surface energy from less than 30 dynes/cm to approximately 38 dynes/cm greatly affects the adhesion of the paint to the polypropylene substrate. The samples with no Corona treatment prior to painting showed poor adhesion, with the paint lifting from the surface anywhere the tape came in contact with the paint. Samples treated for 15 seconds showed better results than the samples treated for 5 seconds, and the samples treated for 30 seconds gave the best adhesion results. The rankings for each sample based on ASTM D3359 can be seen in Table 9.7.

Table 9.7: Adhesion Test Results (ASTM D3359) of CertainTeed Water Reducible Coating to Polypropylene.

\begin{tabular}{|c|c|c|}
\hline Treatment (seconds) & 24 @ RT & $5 \min @ 70^{\circ} \mathrm{C}$ \\
\hline 0 & 0B & $0 \mathrm{~B}$ \\
\hline 5 & 0B & $0 \mathrm{~B}$ \\
\hline 15 & 1B & $2 \mathrm{~B}$ \\
\hline 30 & 4B & $3 \mathrm{~B}$ \\
\hline
\end{tabular}

Ranking values range from $0 \mathrm{~B}$ to $5 \mathrm{~B}$, with $0 \mathrm{~B}$ having greater than $65 \%$ of the test area paint removed, 1B having $35 \%$ to $65 \%$ of the test area paint removed, $2 \mathrm{~B}$ having $15 \%$ to $35 \%$ of the test area paint removed, $3 \mathrm{~B}$ having $5 \%$ to $15 \%$ of the test area paint removed, $4 \mathrm{~B}$ having a maximum of 5\% of the test are paint removed, and 5B having none of the test area paint removed. The ranking presented in this table are average rankings between samples with the same treatment time and drying conditions. The data is presented in this manner because all samples with the same treatment time and drying conditions resulted in the same ranking. 
It should be noted that although the untreated samples and the samples treated for 5 seconds resulted in the same ASTM ranking of $0 \mathrm{~B}$, the samples with 5 seconds of Corona treatment showed improved adhesion, with the paint lifting off only from sections cut by the cross-cut test blade. 


\section{Conclusions}

The experimental work conducted provided a characterization of the CertainTeed waterreducible paint for use on polypropylene substrates. The focus was of this work was to provide more information about the characteristics and drying conditions for this coating. As indicated in the introduction, CertainTeed holds panels that were coated and conveyor oven dried for 7 days,

which is not desirable in the manufacturing process. Results of this work indicate that the holding time can be cut down from 7 days to 3 days. This was recommended to CertainTeed and they are in the process of pilot testing this manufacturing process.

This study also showed that increasing the surface tension of polypropylene using corona treatment from 30 dynes/cm to 38 dynes/cm greatly affects the adhesion of the coating to the substrate. Adhesion was increased from no adhesion $(0 \mathrm{~B})$ of the coating to the substrate to acceptable adhesion (3B and 4B). 


\section{References for Part B}

Awaja, F., Gilbert, M., Kelly, G., Fox, B., and Pigram, P. "Adhesion of Polymers”, Progress in Polymer Science 34, 948-968 (2009)

Bugajski, J., Kooy, R., Moeller, R. J., and Jackson, M. L., “One-Coat, waterborne coating system for untreated polypropylene-based substrates”, US Patent No. 5777022 (1998)

Carrino, L., Moroni, G., and Polini, W., "Cold Plasma Treatment of Polypropylene Surface: A Study on Wettability and Adhesion", Journal of Materials Processing Technology, 121, 373-382 (2002)

Carrino, L., Polini, W., and Sorrentino, L., "Ageing Time of Wettability on Polypropylene Surfaces Processed by Cold Plasma”, Journal of Materials Processing Technology, 153$154,519-525$ (2004)

Cognard, J., "Some Recent Progress in Adhesion Technology and Science", C. R. Chimie, 9, 1324 (2006)

Fry, S. E., Magouyark, D. W., Blankenship, A. J., Greene, P. J., and Johnson, L. K., "Modified Chlorinated Polyolefins", US Patent No. 4,954,573 (1990)

Green, M. D., Guild, F. J., and Adams, R.D., "Characterization and comparison of industrially pre-treated homopolymer polypropylene HF 135M", Int. J. Adhes. Adhes. 22 (1) 81-90 (2002)

Hintze-Bruning, H. and Borgholte, H., "Coating of untreated polyproylene with halogen free aqueous materials", Progress in Organic Coatings, 40, 49-54 (2000)

Lawniczak, J. E., Greene, P. J., Evens, R., and Sass, C., "Water-Reducible Adhesion Promoters for Coatings on Polypropylene-Based Substrates", Journal of Coatings Technology, 65(827), 21 (1993)

Lawniczak, J. E., Williams, K. A., and Germinario, L. T., "Characterization of Adhesion Performance of Topcoats and Adhesion Promoters on TPO Substrates", Journal of Coatings Technology: Research, 2(5), 399 (2005)

Levine, M., Ilkka, G., and Weiss, P., "Relation of the Critical Surface Tension of Polymers to Adhesion”, Polymer Letters, 2, 915 (1964)

Osterhold, M. and Armbruster, K., "Correlation between Surface Tension and Physical Paint Properties", Progress in Organic Coatings, 33, 197-201 (1998)

Ryntz, R. A., "Attaining Durable Painted Plastic Components", Journal of Coatings Technology: Research, 2(5), 351 (2005)

Ryntz, R. A., "Painting of Plastics”, FSCT Monograph, June (1994) 
Sathyanarayana, M. N. and Yaseen, M., "Role of Promoters in Improving Adhesion of Organic Coatings to a Substrate", Progress in Organic Coatings, 26, 275-313 (1995)

Sonnenschein, M. F., Webb, S. P., and Wendt, B. L., "Poly(acrylate/siloxane) hybrid adhesives for polymers with low surface energy", International Journal of Adhesion and Adhesives, 28(3), 126-134 (2008)

Wang, I-H., "One-Pack Waterborne Adhesion Coatings for Thermoplastic Olefins", US Patent No. 6,297,312 B1 (2001) 


\section{APPENDIX A}

CIELAB Values for Preliminary Marker Stain Testing

\begin{tabular}{|c|c|c|c|c|c|c|c|}
\hline & \multicolumn{2}{|c|}{$\mathrm{L}$} & \multicolumn{2}{|c|}{$\mathrm{a}$} & \multicolumn{2}{|c|}{$\mathrm{b}$} & \multirow[t]{2}{*}{$\mathrm{E}$} \\
\hline & avg & $\mathrm{sd}$ & avg & sd & avg & $\mathrm{sd}$ & \\
\hline Red Permanent Marker & 50.22 & 2.49 & 55.97 & 2.76 & 32.29 & 3.74 & 81.839 \\
\hline \multicolumn{8}{|l|}{ Primer Only } \\
\hline KILZ 2 Latex & 91.21 & 0.26 & 3.86 & 0.41 & -0.15 & 0.15 & 91.289 \\
\hline KILZ Orig & 67.48 & 2.39 & 37.71 & 1.48 & 7.06 & 1.25 & 77.622 \\
\hline Zin BIN & 68.03 & 0.78 & 42.14 & 0.77 & 0.39 & 0.37 & 80.030 \\
\hline Behr Latex & 62.71 & 53.21 & 7.16 & 0.29 & -0.03 & 0.33 & 63.119 \\
\hline Zin HH CS & 68.98 & 1.88 & 35.53 & 1.36 & 3.78 & 0.23 & 77.680 \\
\hline Zin WB CS & 91.95 & 0.22 & 8.78 & 0.24 & -0.06 & 0.16 & 92.372 \\
\hline KM Ext OB & 68.82 & 1.02 & 41.85 & 0.87 & 3.27 & 0.14 & 80.608 \\
\hline \multicolumn{8}{|l|}{ Primer \& Topcoat } \\
\hline KILZ 2 Latex & 95.61 & 0.01 & 1.23 & 0.08 & 0.89 & 0.07 & 95.622 \\
\hline KILZ Orig & 94.75 & 0.19 & 2.55 & 0.42 & 0.29 & 0.13 & 94.780 \\
\hline Zin BIN & 93.93 & 0.30 & 10.33 & 1.44 & -0.86 & 0.23 & 94.500 \\
\hline Behr Latex & 96.17 & 0.04 & 1.07 & 0.28 & 1.17 & 0.14 & 96.183 \\
\hline Zin HH CS & 94.66 & 0.35 & 2.02 & 0.18 & 0.38 & 0.08 & 94.682 \\
\hline Zin WB CS & 95.20 & 0.04 & 4.97 & 0.68 & 0.88 & 0.01 & 95.329 \\
\hline KM Ext OB & 94.19 & 0.03 & 4.31 & 0.65 & 0.00 & 0.08 & 94.289 \\
\hline
\end{tabular}

\begin{tabular}{|c|c|c|c|c|c|c|c|}
\hline & \multicolumn{2}{|c|}{$\mathrm{L}$} & \multicolumn{2}{|c|}{$\mathrm{a}$} & \multicolumn{2}{|c|}{$\mathrm{b}$} & \multirow[t]{2}{*}{$\mathrm{E}$} \\
\hline & avg & $\mathrm{sd}$ & avg & $\mathrm{sd}$ & avg & $\mathrm{sd}$ & \\
\hline Black Permanent Marker & 32.55 & 6.94 & 4.66 & 1.87 & 0.33 & 2.83 & 32.885 \\
\hline \multicolumn{8}{|l|}{ Primer Only } \\
\hline KILZ 2 Latex & 88.08 & 1.26 & -1.05 & 0.12 & -3.99 & 1.15 & 88.180 \\
\hline KILZ Orig & 86.16 & 1.64 & -0.63 & 0.33 & 1.67 & 0.31 & 86.182 \\
\hline Zin BIN & 82.52 & 12.28 & -0.83 & 0.29 & -2.98 & 5.62 & 82.576 \\
\hline Behr Latex & 92.18 & 1.26 & -0.89 & 0.07 & -2.02 & 1.38 & 92.206 \\
\hline Zin HH CS & 82.46 & 1.80 & 0.56 & 0.05 & 1.52 & 0.06 & 82.476 \\
\hline Zin WB CS & 90.03 & 0.06 & -1.36 & 0.40 & -2.44 & 0.40 & 90.070 \\
\hline KM Ext OB & 89.41 & 0.31 & -1.19 & 0.07 & 1.05 & 0.29 & 89.424 \\
\hline \multicolumn{8}{|l|}{ Primer \& Topcoat } \\
\hline KILZ 2 Latex & 95.35 & 0.14 & -0.85 & 0.01 & 0.24 & 0.26 & 95.354 \\
\hline KILZ Orig & 95.47 & 0.21 & -0.85 & 0.01 & 0.67 & 0.01 & 95.476 \\
\hline Zin BIN & 94.56 & 0.37 & -1.04 & 0.06 & -0.40 & 0.27 & 94.567 \\
\hline Behr Latex & 96.17 & 0.36 & -0.80 & 0.04 & 0.96 & 0.35 & 96.178 \\
\hline Zin HH CS & 95.18 & 0.07 & -0.81 & 0.05 & 0.32 & 0.09 & 95.179 \\
\hline Zin WB CS & 95.20 & 0.06 & -1.02 & 0.08 & 0.49 & 0.13 & 95.207 \\
\hline KM Ext OB & 95.64 & 0.17 & -0.86 & 0.01 & 0.74 & 0.10 & 95.647 \\
\hline
\end{tabular}




\begin{tabular}{|lccccccc|}
\hline & \multicolumn{2}{c}{ L } & \multicolumn{2}{c}{$\mathrm{a}$} & \multicolumn{2}{c|}{$\mathrm{b}$} & $\mathrm{E}$ \\
\hline & $\mathrm{avg}$ & $\mathrm{sd}$ & $\mathrm{avg}$ & $\mathrm{sd}$ & $\mathrm{avg}$ & $\mathrm{sd}$ & \\
\hline Blue Pen & 51.64 & 3.40 & 2.53 & 1.28 & -35.86 & 2.56 & 62.917 \\
& & & & & & & \\
Primer Only & & & & & & & \\
KILZ 2 Latex & 83.53 & 1.07 & -9.05 & 0.85 & -9.87 & 0.68 & 84.600 \\
KILZ Orig & 90.06 & 0.07 & -1.82 & 0.03 & 1.37 & 0.22 & 90.085 \\
Zin BIN & 75.15 & 1.18 & 2.75 & 0.21 & -18.17 & 1.11 & 77.361 \\
Behr Latex & 84.94 & 1.64 & -10.51 & 0.32 & -10.99 & 1.29 & 86.294 \\
Zin HH CS & 90.45 & 0.17 & -1.58 & 0.04 & 1.60 & 0.25 & 90.475 \\
Zin WB CS & 83.18 & 0.35 & -7.95 & 0.11 & -10.66 & 0.40 & 84.233 \\
KM Ext OB & 91.66 & 0.58 & -1.35 & 0.07 & 0.87 & 0.48 & 91.677 \\
& & & & & & & \\
Primer \& Topcoat & & & & & & & \\
KILZ 2 Latex & 93.16 & 0.49 & -4.93 & 0.95 & -2.15 & 0.97 & 93.315 \\
KILZ Orig & 95.67 & 0.34 & -0.93 & 0.03 & 0.80 & 0.04 & 95.678 \\
Zin BIN & 93.64 & 0.06 & -1.57 & 0.16 & -2.12 & 0.05 & 93.672 \\
Behr Latex & 94.62 & 0.13 & -2.82 & 0.18 & -1.06 & 0.16 & 94.668 \\
Zin HH CS & 95.87 & 0.35 & -0.90 & 0.04 & 1.14 & 0.25 & 95.881 \\
Zin WB CS & 86.89 & 0.15 & -10.08 & 0.18 & -9.33 & 0.45 & 87.963 \\
KM Ext OB & 95.48 & 0.64 & -0.89 & 0.06 & 1.00 & 0.22 & 95.489 \\
\hline
\end{tabular}

\begin{tabular}{|lccccccc|}
\hline & \multicolumn{2}{c}{ L } & \multicolumn{2}{c}{ a } & \multicolumn{2}{c|}{ b } & E \\
\hline & avg & sd & avg & sd & avg & sd & \\
\hline Yellow Highlighter & 87.69 & 1.16 & -3.69 & 1.69 & 73.27 & 9.70 & 114.33 \\
Primer Only & & & & & & & \\
KILZ 2 Latex & 92.17 & 0.14 & -1.78 & 0.13 & 12.62 & 0.97 & 93.05 \\
Behr Latex & 95.10 & 0.31 & -1.84 & 0.27 & 14.41 & 2.56 & 96.20 \\
Zin WB CS & 93.96 & 0.49 & -2.19 & 0.22 & 20.54 & 3.77 & 96.21 \\
& & & & & & & \\
Primer \& Topcoat & & & & & & & \\
KILZ 2 Latex & 94.76 & 0.42 & -1.95 & 0.08 & 9.40 & 1.36 & 95.24 \\
Behr Latex & 96.17 & 0.18 & -0.69 & 0.01 & 6.16 & 0.57 & 96.37 \\
Zin WB CS & 95.17 & 0.06 & -1.79 & 0.11 & 13.22 & 1.65 & 96.09 \\
\hline
\end{tabular}

\begin{tabular}{|lccccccc|}
\hline & \multicolumn{2}{c}{ L } & \multicolumn{2}{c}{ a } & \multicolumn{3}{c|}{ b } \\
\hline & avg & sd & avg & sd & avg & sd & \\
\hline Green Highlighter & 85.81 & 1.40 & -43.71 & 3.06 & 76.51 & 2.60 & 123.00 \\
Primer Only & & & & & & & \\
KILZ 2 Latex & 90.42 & 0.03 & -8.71 & 0.33 & 1.41 & 0.47 & 90.85 \\
Behr Latex & 92.92 & 0.31 & -10.94 & 0.69 & 4.65 & 0.42 & 93.68 \\
Zin WB CS & 90.56 & 0.67 & -14.91 & 1.19 & 8.28 & 1.16 & 92.15 \\
& & & & & & & \\
Primer \& Topcoat & & & & & & & \\
KILZ 2 Latex & 92.60 & 0.93 & -6.25 & 0.74 & 0.36 & 0.04 & 92.81 \\
Behr Latex & 95.00 & 0.71 & -4.44 & 1.16 & 1.48 & 0.08 & 95.12 \\
Zin WB CS & 93.10 & 0.15 & -8.92 & 0.11 & 2.24 & 0.07 & 93.55 \\
\hline
\end{tabular}




\section{APPENDIX B}

Rheology Results for All Primers in Final Testing
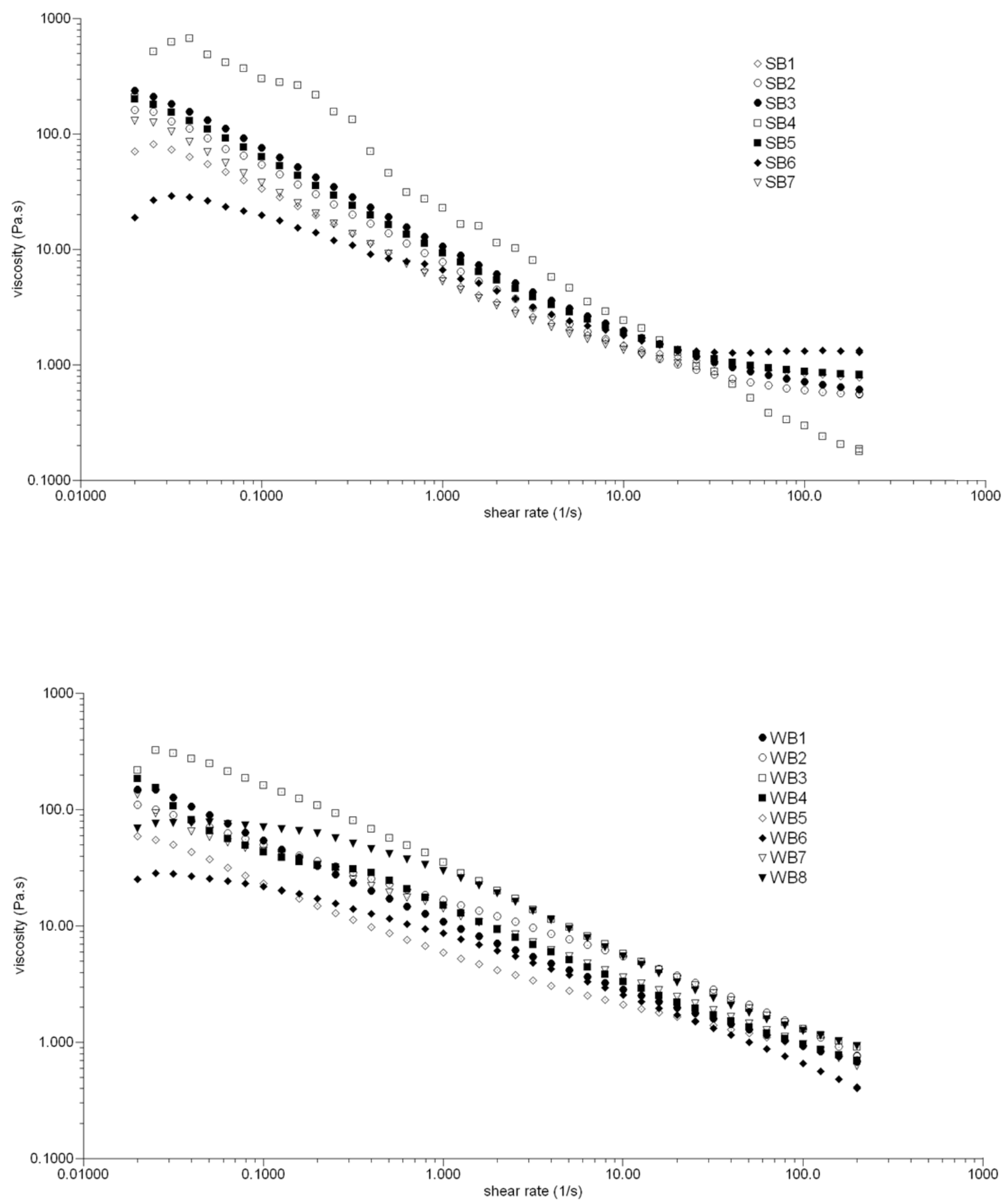


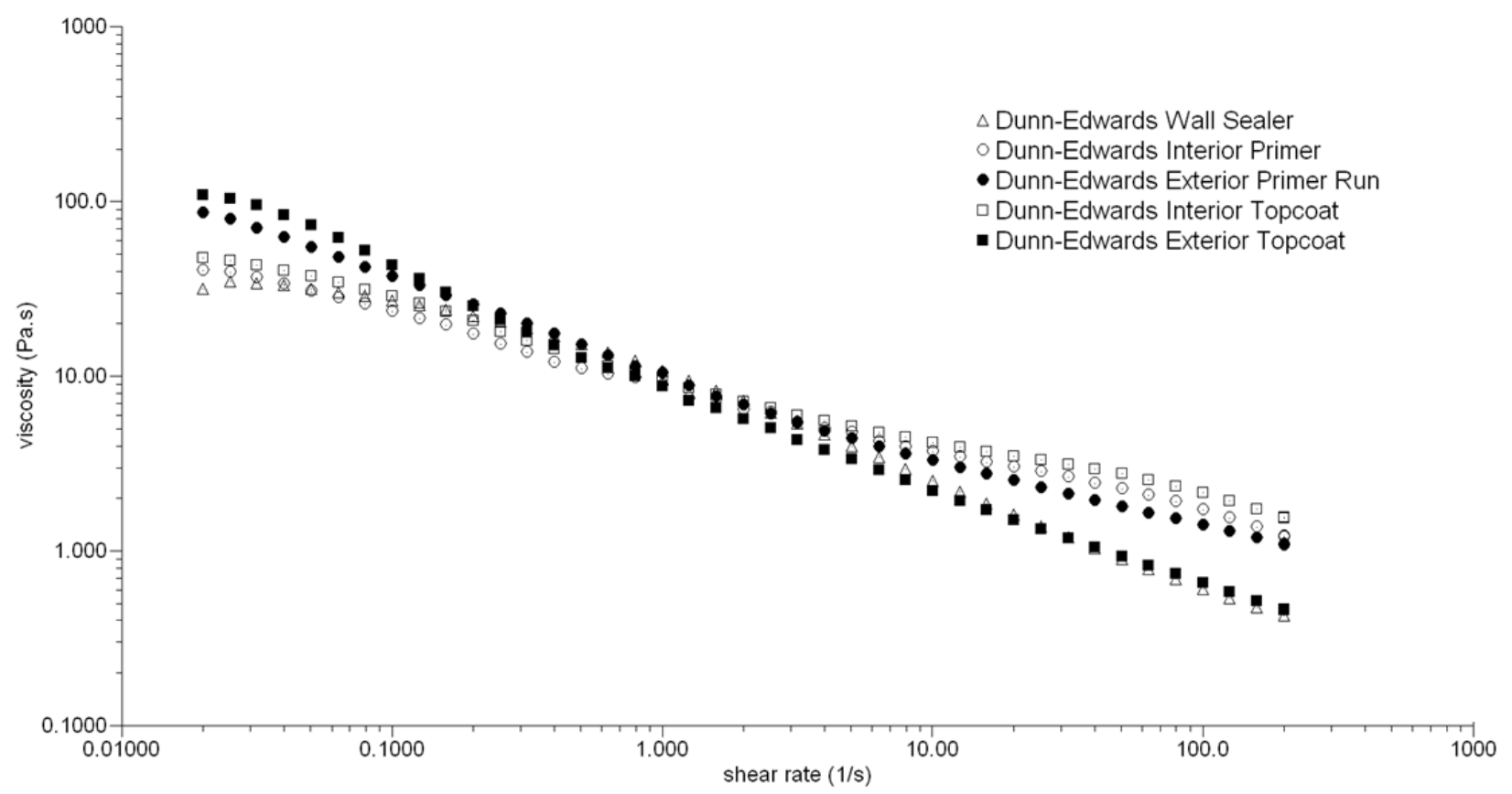

